AUTARQUIA ASSOCIADA À UNIVERSIDADE DE SÃO PAULO

\title{
AVALIAÇÃO DE ALGUNS FATORES INTERFERENTES NA ESTABILIDADE RADIOQUÍMICA DE ALGUNS RADIOFÁRMACOS MARCADOS COM 99m TC
}

Cássia Yumi Furukawa

Dissertação apresentada como parte dos requisitos para obtenção do Grau de Mestre em Ciências na Área de Tecnologia Nuclear - Aplicações

Orientadora:

Profa. Dra. Margareth Mie Nakamura Matsuda 
INSTITUTO DE PESQUISAS ENERGÉTICAS E NUCLEARES

Autarquia associada à Universidade de São Paulo

\title{
AVALIAÇÃO DE ALGUNS FATORES INTERFERENTES NA ESTABILIDADE RADIOQUÍMICA DE ALGUNS RADIOFÁRMACOS MARCADOS COM 99m Tc
}

\author{
Cássia Yumi Furukawa
}

Dissertação apresentada como parte dos requisitos para obtenção do Grau de Mestre em Ciências na Área de Tecnologia Nuclear - Aplicações

Orientadora:

Profa. Dra. Margareth Mie Nakamura Matsuda

Versão Corrigida

Versão Original disponível no IPEN

São Paulo

2016 


\section{DEDICATÓRIA}

Á minha mãe, Katsue Hashizume, por todo seu carinho e compreensão, ensinando a nunca desistir dos meus sonhos e ajudando a enfrentar os mais difíceis caminhos. Mãe, muito obrigada por tudo que a senhora fez e faz por mim.

Ao meu pai, Iwao Furukawa, por sempre acreditar no meu potencial, por sempre estar ao meu lado, por cada sacrifício feito para poder dar asas aos meus sonhos. Pai, muito obrigada!

A Deus, Nossa Senhora Aparecida, a Santo Expedito e São Miguel Arcanjo, por me acompanhar cada passo, ajudando a superar cada obstáculo e sempre iluminando o meu caminho. 


\section{AGRADECIMENTOS}

Aos meus pais, por tudo. Sem eles não teria chegado até aqui.

Ás minhas grandes amigas-irmãs Renata Ferreira Costa e Natália Kaori Minami, por estarem sempre ao meu lado em todos os momentos.

À Dra. Margareth Mie Nakamura Matsuda em aceitar ser a minha orientadora, e por todo carinho e compreensão.

À "familia" que me acolheu com todo carinho e amor no controle de qualidade do Centro de Radiofarmácia, em especial Bico, Jurandir, Mário, Natan, Freire, Patrícia, Vivian e Marcelo.

Aos companheiros adquiridos nessa jornada Luciana Valéria Ferrari Machado Porto e Rafael Silva Puga, não é por acaso que Deus trouxe vocês.

A Comissão Nacional de Energia Nuclear (CNEN) e CNPQ pela concessão da bolsa de mestrado.

Ao Instituto de Pesquisas Energéticas e Nucleares juntamente com o Centro de Radiofarmácia pela infraestrutura proporcionada para o desenvolvimento deste trabalho. 
"Faça apenas o que amas e serás feliz. Aquele que faz o que ama, está benditamente condenado ao sucesso, que chegará quando for a hora, porque o que deve ser será e chegará naturalmente. Não faças coisas alguma por obrigação nem por compromisso, apenas por amor". Facundo Cabral. 


\title{
AVALIAÇÃO DE ALGUNS FATORES INTERFERENTES NA ESTABILIDADE RADIOQUÍMICA DE ALGUNS RADIOFÁRMACOS MARCADOS COM 99m TC
}

\author{
Cássia Yumi Furukawa
}

\begin{abstract}
RESUMO
Os radiofármacos são fármacos que possuem em sua composição um radionuclídeo e são utilizados para diagnóstico e tratamento de diversas doenças na medicina nuclear. O principal objetivo desse trabalho foi avaliar o efeito da temperatura e umidade na estabilidade de alguns reagentes liofilizados ALBUMINA-TEC, CIS-TEC, DEX-500-TEC, DEX-70-TEC, DISI-TEC, DMSA-TEC, DTPA-TEC, FITA-TEC, PUL-TEC, MIBI-TEC, MDP-TEC, PIRO-TEC, e TIN-TEC. Foi utilizada uma câmara climática para expor amostras destes produtos a uma temperatura de $40{ }^{\circ} \mathrm{C}$ e $75 \%$ de umidade relativa por 48 horas, para simular uma condição de transporte. Foram avaliadas duas situações: após um determinado tempo de armazenamento em temperatura de $2-8{ }^{\circ} \mathrm{C}$, amostras de $\mathrm{RL}$ foram expostas por 48 horas em $40{ }^{\circ} \mathrm{C}$ e $75 \%$ UR e em seguida foram analisadas enquanto outras amostras foram colocadas por 48 horas em $40{ }^{\circ} \mathrm{C}$ e $75 \%$ UR, mantidas em temperatura de $2-8{ }^{\circ} \mathrm{C}$ até a validade do radiofármaco e analisadas quanto à pureza radioquímica e biodistribuição.

Os radiofármacos ALBUMINA-TEC, DEX-70-TEC, DEX-500-TEC, DISITEC, DMSA-TEC, DTPA-TEC, PIRO-TEC, MDP-TEC, MIBI-TEC e MDP-TEC apresentaram resultados de \% $\mathrm{PRq}$ e biodistribuição que atenderam às especificações, enquanto que CIS-TEC, PUL-TEC e TIN-TEC apresentaram alguns valores de \% PRq menor que o especificado. TIN-TEC apresentou \% PRq de $84 \%$ em um de três lotes, enquanto PUL-TEC apresentou \% PRq de $88 \%$ em um de quatro lotes analisados; CIS-TEC é um RL que ainda precisa melhor analisado pois os resultados fora do especificado no controle radioquímico e
\end{abstract}


biológico foram obtidos com um produto fora da validade especificada. Estes resultados indicaram que a pureza radioquímica pode ser afetada pela condição de estudo, o que não foi confirmado pelo controle biológico.

Palavras-chave: radiofármaco, pureza radioquímica, estabilidade de transporte. 


\title{
EVALUATION OF SOME INTERFERING FACTORS ON THE RADIOCHEMICAL STABILITY OF SOME RADIOPHARMACEUTICALS LABELED TECHNETIUM- $99 m$
}

\section{Cássia Yumi Furukawa}

\begin{abstract}
Radiopharmaceuticals are pharmaceuticals that have in their composition a radionuclide and are used for diagnosis and treatment of various diseases in nuclear medicine. The main objective of this study was to evaluate the effect of temperature and humidity on the stability of some lyophilized reagents: ALBUMINA-TEC, CIS-TEC, DEX-500-TEC, DEX-70-TEC, DISI-TEC, DMSA-TEC, DTPA-TEC, FITA-TEC, PUL-TEC, MIBI-TEC, MDP-TEC, PIRO-TEC and TINTEC. A climatic chamber was used for exposing some samples of these products to a temperature of $40{ }^{\circ} \mathrm{C}$ and $75 \% \mathrm{RH}$ for 48 hours to simulate a transport condition. Two situations were evaluated: after a certain storage time at $2-8{ }^{\circ} \mathrm{C}$, LR samples were exposed for 48 hours at $40{ }^{\circ} \mathrm{C}$ and $75 \% \mathrm{RH}$ and analyzed while other samples were placed for 48 hours at $40{ }^{\circ} \mathrm{C}$ and $75 \% \mathrm{RH}$, kept at $2-8{ }^{\circ} \mathrm{C}$ until the expiration time of each radiopharmaceutical and analyzed for radiochemical purity and biodistribution. ALBUMINA-TEC, DEX-70-TEC, DEX500-TEC, DISI-TEC, DMSA-TEC, DTPA-TEC, PIRO-TEC, MDP-TEC, MIBI-TEC and MDP-TEC presented results of \% RCP and biodistribution that met the specifications while CIS-TEC PUL-TEC and TIN-TEC presented some \% RCP lower than specified. TIN-TEC presented \% RCP of $84 \%$ in one of three lots while PUL-TEC presented \% RCP of $88 \%$ in a one of four batches analyzed; CIS-TEC is a LR that further need to be analyzed because probable the out of specification results of radiochemical and biological controls were obtained with a product outside of the validity date. These results indicated that radiochemical purity, can be affected by study condition, which has not been confirmed by biological control.
\end{abstract}

Keywords: radiopharmaceutical, radiochemical purity, transport stability. 


\section{SUMÁRIO}

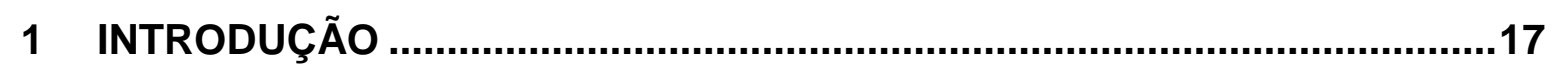

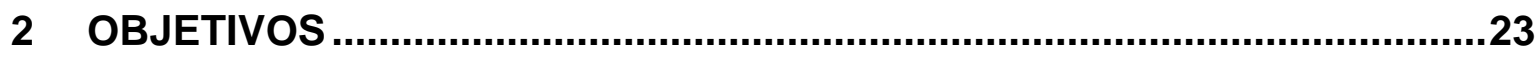

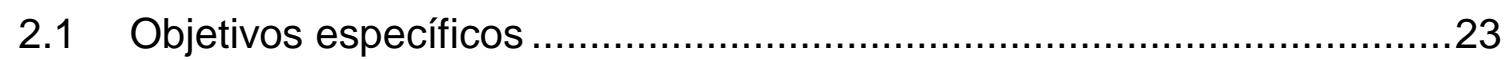

3 REVISÃO DA LITERATURA

3.1 A história da produção de radiofármacos no IPEN ................................26

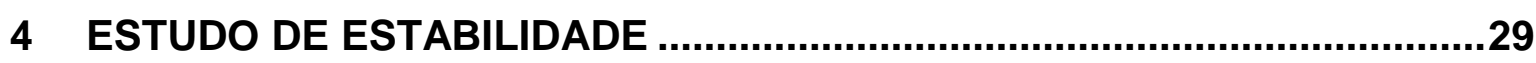

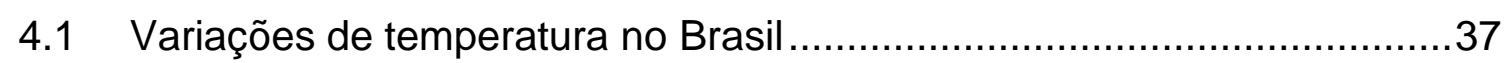

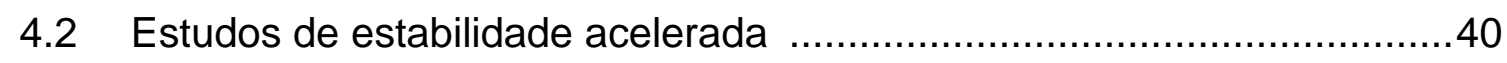

4.3 Estudos de estabilidade de longa duração .............................................40

4.4 Estudos de estabilidade de acompanhamento ......................................40

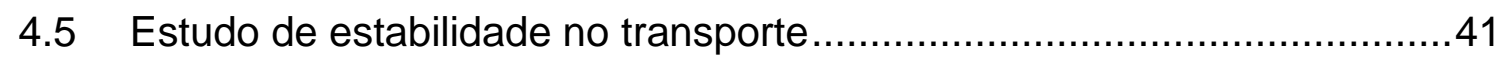

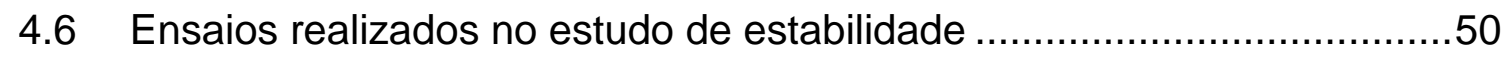

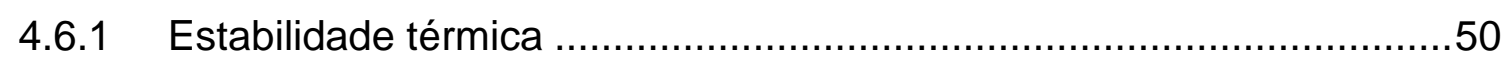

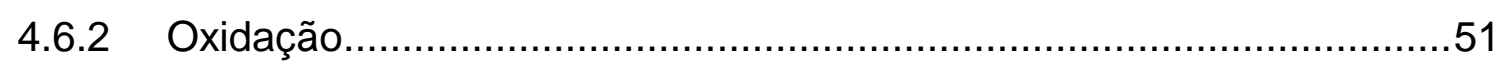

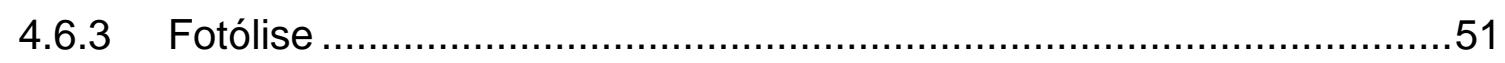

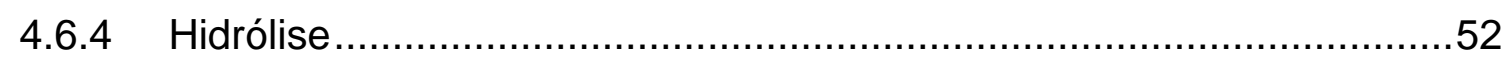

4.6 Estabilidade de radiofármacos............................................................. 52

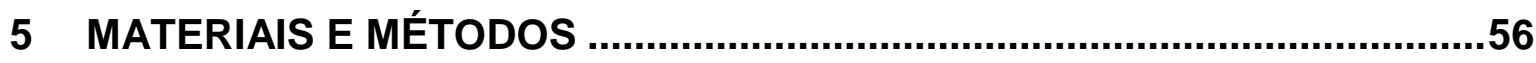

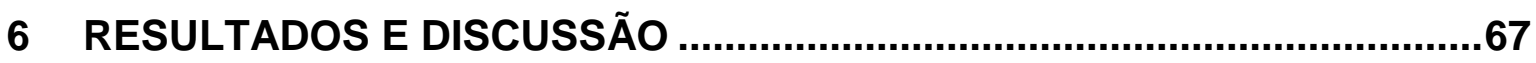

6.1 Monitoramento da temperatura no interior de embalagem utilizada ........67

6.2 Avaliação da pureza radioquímica e da biodistribuição em rl mantidos por 48 horas em temperatura de $40^{\circ} \mathrm{C}$ e $75 \%$ UR....................................................

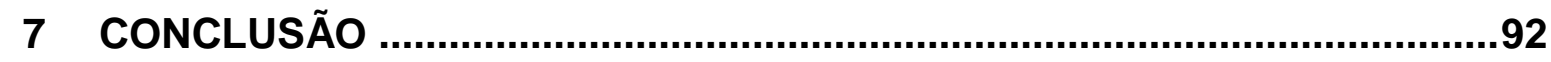

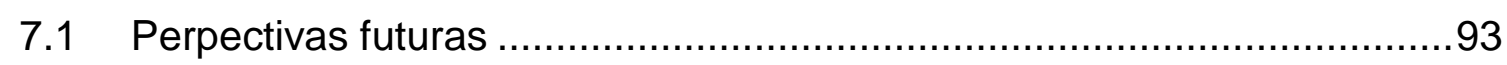




\section{LISTA DE TABELA}

Tabela 1. Alguns reagentes liofilizados e suas aplicações. .20

Tabela 2. Parâmetros dos fármacos a serem avaliados durante o período de estabilidade. .30

Tabela 3. Exemplos do efeito da temperatura em medicamentos .33

Tabela 4. Divisão do globo para estabelecimento das condições nos estudos de estabilidade.

Tabela 5. Condições de temperatura e umidade para realização dos estudos de estabilidade no Brasil. 36

Tabela 6. Classificação dos estudos de estabilidade conforme etapa do processo de lançamento do fármaco 39

Tabela 7. Proposta de ciclo de excursão térmica

Tabela 8. Exemplo de condições de transporte e armazenamento para teste rápido para malária

Tabela 9. Levantamento das temperaturas média e máxima em trajetos de São Paulo até as principais capitais do Brasil no período de 1961-1990 47

Tabela 10. Tipos e dimensões de suportes cromatográficos. .56

Tabela 11. Composição de alguns $R L$ produzidos no $C R$, IPEN e utilizados neste trabalho $4^{\prime}$

Tabela 12. Condições de tempo, temperatura e umidade aplicados aos $R L$ em câmara climática. .60

Tabela 14. Limites de \% PRq e a condição de armazenamento para os $R L$ 62

Tabela 15. Limites de aceitação para a biodistribuição nos órgãos (\%DI) para cada um dos RL marcados com 99m Tc e as respectivas referências .64

Tabela 16. Validade dos reagentes liofilizados. .65

Tabela 17. Condição de experimentos para avaliar a estabilidade dos $R L$, após exposição a $40{ }^{\circ} \mathrm{C}$ de temperatura e $75 \%$ umidade, por 48 horas.

Tabela 18. Período após a fabricação em que os $R L$ foram analisados. .65

Tabela 19. Período após a fabricação em que os $\mathrm{RL}$ foram analisados continuação. 
Tabela 20. Perfil de temperatura da blindagem do FDG com tampa....................70

Tabela 21. Perfil de temperatura da blindagem do FDG sem tampa...................70

Tabela 22. Resultados de pureza radioquímica e biodistribuição da ALBUMINATEC após exposição à temperatura de $40{ }^{\circ} \mathrm{C}$ e $75 \%$ UR, e resultados obtidos imediatamente após a produção de $R L$ mantidos em temperatura de $2-8^{\circ} \mathrm{C}$.....74

Tabela 23. Resultados de pureza radioquímica do RL DEX-70-TEC após exposição à temperatura de $40^{\circ} \mathrm{C}$ e $75 \%$ UR, e resultados obtidos imediatamente após a produção de $\mathrm{RL}$ mantidos em temperatura de $2-8{ }^{\circ} \mathrm{C}$............................77

Tabela 24. Resultados de pureza radioquímica do RL DEX-500-TEC após exposição àtemperatura de $40{ }^{\circ} \mathrm{C}$ e $75 \%$ UR, e resultados obtidos imediatamente após a produção de $\mathrm{RL}$ mantidos em temperatura de 2 - $8{ }^{\circ} \mathrm{C}$.............................77

Tabela 25. Resultados de pureza radioquímica e biodistribuição do DISI-TEC da após exposição à temperatura de $40{ }^{\circ} \mathrm{C}$ e $75 \%$ UR, e resultados obtidos imediatamente após a produção de $R L$ mantidos em temperatura de $2-8^{\circ} \mathrm{C}$.....79

Tabela 26. Resultados de pureza radioquímica e biodistribuição do DMSA-TEC da após exposição à temperatura de $40{ }^{\circ} \mathrm{C}$ e $75 \%$ UR, e resultados obtidos imediatamente após a produção de $\mathrm{RL}$ mantidos em temperatura de $2-8^{\circ} \mathrm{C}$......80 Tabela 27. Resultados de pureza radioquímica e biodistribuição do DTPA-TEC da após exposição à temperatura de $40{ }^{\circ} \mathrm{C}$ e $75 \%$ UR, e resultados obtidos imediatamente após a produção de $\mathrm{RL}$ mantidos em temperatura de $2-8^{\circ} \mathrm{C} . . . .82$ Tabela 28. Os resultados de pureza radioquímica e biodistribuição do MDP-TEC após exposição à temperatura de $40{ }^{\circ} \mathrm{C}$ e $75 \%$ UR, e resultados obtidos imediatamente após a produção de $R L$ mantidos em temperatura de $2-8^{\circ} \mathrm{C}$......83 Tabela 29. Resultados de pureza radioquímica e biodistribuição do MIBI-TEC da após exposição à temperatura de $40{ }^{\circ} \mathrm{C}$ e $75 \%$ UR, e resultados obtidos imediatamente após a produção de $\mathrm{RL}$ mantidos em temperatura de $2-8^{\circ} \mathrm{C} . . . .85$ Tabela 30. Resultados de pureza radioquímica e biodistribuição do PIRO-TEC após exposição à temperatura de $40{ }^{\circ} \mathrm{C}$ e $75 \%$ UR, e resultados obtidos imediatamente após a produção de $\mathrm{RL}$ mantidos em temperatura de $2-8^{\circ} \mathrm{C}$.....88 Tabela 31. Resultados de pureza radioquímica e biodistribuição do PUL-TEC da após exposição à temperatura de $40{ }^{\circ} \mathrm{C}$ e $75 \%$ UR, e resultados obtidos imediatamente após a produção de $\mathrm{RL}$ mantidos em temperatura de $2-8^{\circ} \mathrm{C} \ldots . . .88$ 
Tabela 32. Resultados de pureza radioquímica e biodistribuição do TIN-TEC após exposição à temperatura de $40^{\circ} \mathrm{C}$ e $75 \%$ UR, e resultados obtidos imediatamente após a produção de $\mathrm{RL}$ mantidos em temperatura de $2-8^{\circ} \mathrm{C}$.............................. 89 


\section{LISTA DE FIGURAS}

Figura 1. Decaimento do gerador ${ }^{99} \mathrm{Mo} / 99 \mathrm{~m}$ Tc 18

Figura 2. Esquema simplificado de a) um gerador de ${ }^{99} \mathrm{Mo} / 99 \mathrm{~m}$ Tc e de b) reações que ocorrem na obtenção de radiofármacos com pertecnetato de sódio $(99 \mathrm{~m}$

Figura 3. A) Kit com cinco reagentes liofilizados - MIBI-TEC B) Kit contendo os reagentes liofilizados e o kit com a solução tampão na embalagem acrílica - CISTEC C) Kit na embalagem de plástico polionda. 20

Figura 4. Tipos de radiação

Figura 5. Influência da temperatura sobre a velocidade de degradação do produto Influência da temperatura sobre a velocidade de degradação do produto 32

Figura 6. Variação de temperatura no Brasil em 2004: A) Média; B) Máxima e C) Mínima .38

Figura 7. Dispositivo para monitoramento de temperatura. .57

Figura 8. Câmara climática .58

Figura 9. Reservatório/circulador/purificador de água acoplada à câmara climática. Contém filtros de purificação e luz UV. .58

Figura 10. Representação da disposição de frascos de $R L$ no interior da câmara de climática (não foi utilizada iluminação durante o período de exposição dos frascos). 59

Figura 11. Esquema geral das condições de marcação de $R L$ com eluato de ${ }^{99 \mathrm{~m}} \mathrm{TcO}_{4}^{-}$

Figura 12. Embalagem secundária para envio de radiofármacos utilizados em exames PET, mostrando a posição em que fica o frasco de embalagem primária, e onde foi colocado o sensor de temperatura.

Figura 13. a) Perfil de variação de temperatura no interior da embalagem de chumbo b) Embalagem FDG sem tampa submetidos à temperatura de $40^{\circ} \mathrm{C} \mathrm{e}$ $75 \%$ UR por 48 horas em câmara climática. 
Figura 14. a) Perfil de variação de temperatura no interior da embalagem de chumbo. b) com tampa, quando submetidos à temperatura de $40{ }^{\circ} \mathrm{C}$ e $75 \%$ UR por 48 horas em câmara climática. 69

Figura 15. Embalagem para envio do CIS-TEC e ECD-TEC, mostrando a disposição interna da caixa de isopor contendo uma unidade de gelo reciclável e um kit de RL. Fazem parte do kit de RL a caixa de papelão, duas embalagens acrílicas e cinco frascos de RL em cada embalagem. .71 Figura 16. Perfil de variação de temperatura na embalagem para transporte de alguns $\mathrm{RL}$, quando submetidos à temperatura de $40{ }^{\circ} \mathrm{C}$ e $75 \%$ UR por 48 horas em câmara climática. .72 


\title{
LISTA DE ABREVIATURAS E/ OU SIGLAS
}

\author{
${ }^{99 \mathrm{~m}} \mathrm{Tc} \quad$ Tecnécio meta estável \\ ${ }^{99 \mathrm{~m}} \mathrm{TcO}_{2} \quad$ Tecnécio coloidal \\ ${ }^{99 m} \mathrm{TCO}_{4-} \quad$ Pertecnetato livre \\ ANVISA Agência Nacional de Vigilância Sanitária \\ BPF Boas Práticas de Fabricação \\ CCD Cromatografia em Camada Delgada \\ CIS-TEC Etilenodicisteína \\ CNEN Comissão Nacional de Energia Nuclear \\ CP Cromatografia em Papel \\ CR Centro de Radiofarmácia
}

DISI-TEC Ácido 2,6 diisopropiliminodiacético

DMSA-TEC Ácido 2,3-dimercaptosuccínico

DTPA-TEC Ácido dietilenotriamino pentacético

ECD-TEC Etilenodicisteinato de dietila

FA Farmacopeia Americana

FDA Food and Drug Administration

FE Farmacopeia Europeia

HPTLC High Performance Thin Layer Chromatography

$\mathrm{ICH}$ The International Conference on Harmonisation

IPEN Instituto de Pesquisas Energeticas e Nucleares

ITLC Instant Thin Layer Chromatography 


$\begin{array}{ll}\text { mCi } & \text { MiliCurie } \\ \text { MDP-TEC } & \text { Metileno 1,1-ácido bifosfônico } \\ \text { MIBI-TEC } & \text { hexaquis-2-metoxi-isobutil-isonitrila } \\ \text { PET } & \text { Tomografia por Emissão de Pósitrons } \\ \text { PIRO-TEC } & \text { Pirofosfato de sódio } \\ \text { PRq } & \text { Pureza Radioquimica } \\ \text { PUL-TEC } & \text { Albumina humana } \\ \text { QI } & \text { Qualificação de instalações } \\ \text { QO } & \text { Qualificação operacional } \\ \text { RDC } & \text { Resolução da Diretoria Colegiada } \\ \text { Rf } & \text { Fator de retardamento } \\ \text { RL } & \text { Reagente Liofilizado } \\ \text { SAH-TEC } & \text { Soro Albumina Humano } \\ \text { Sn } & \text { Estanho } \\ \text { TLC } & \text { Thin Layer Chromatography } \\ \text { UR } & \text { Umidade Relativa } \\ \text { USP } & \text { Farmacopeia dos Estados Unidos } \\ \text { W1MM } & \text { Whatman1MM } \\ \text { W3MM } & \text { Whatman 3M }\end{array}$




\section{INTRODUÇÃO}

Os radiofármacos são compostos, que têm na sua composição um radionuclídeo e são utilizados em Medicina Nuclear para diagnóstico ou terapia de várias doenças. Para aplicações em diagnóstico na Medicina Nuclear, utilizam-se radiofármacos que apresentam na sua constituição radionuclídeos emissores de radiação gama $(\gamma)$ ou emissores de pósitrons $(\beta+)$, já que o decaimento destes radionuclídeos dá origem à radiação eletromagnética penetrante, que consegue atravessar os tecidos e pode ser detectada externamente. Existem dois métodos tomográficos para aquisição de imagens em Medicina Nuclear: o SPECT (Tomografia Computorizada de Emissão de Fóton Único), que utiliza radionuclídeos emissores y $\left({ }^{99 \mathrm{~m}} \mathrm{Tc},{ }^{123} \mathrm{l},{ }^{67} \mathrm{Ga},{ }^{201} \mathrm{TI}\right)$ e o PET (Tomografia por Emissão de Pósitrons), que usa radionuclídeos emissores de pósitrons $\left({ }^{11} \mathrm{C},{ }^{12} \mathrm{~N}\right.$, ${ }^{15} \mathrm{O},{ }^{18} \mathrm{~F}$ ) (AGÊNCIA INTERNACIONAL DE ENERGIA ATÔMICA, 1999).

A ANVISA, na RDC 64, de 2009, apresentou uma classificação para os radiofármacos em quatro categorias, muito similar à descrita pela Organização Mundial de Saúde (AGÊNCIA NACIONAL DE VIGILÂNCIA SANITÁRIA, 2009) (WORLD HEALTH ORGANIZATION, 2004)

$\checkmark \quad$ Produtos radioativos prontos para uso;

$\checkmark \quad$ Geradores de radionuclídeos;

$\checkmark \quad$ Componentes não radioativos (reagentes liofilizados - RL) para preparação de compostos marcados com elementos radioativos (geralmente o eluato de um gerador de radionuclídeo) (WORLD HEALTH ORGANIZATION, 2004).

Os chamados componentes não radioativos para marcação com um componente radioativo são comumente chamados de kits de $\mathrm{RL}$ (a embalagem com cinco frascos é conhecida por kit) e são amplamente utilizados nas radiofarmácias hospitalares, devido ao maior prazo de validade que outro. 
radiofármacos, pois podem ser comercializados e armazenados antes da complexação ou marcação com o eluato de gerador de ${ }^{99} \mathrm{Mo} / 99 \mathrm{~m}$ Tc (AGÊNCIA INTERNACIONAL DE ENERGIA ATÔMICA, 1999; Saha, 2010).

Mais de $80 \%$ dos radiofármacos usados em medicina nuclear são compostos marcados com 99m Tc e seu vasto uso clínico decorre de algumas características físicas favoráveis do 99m Tc, meia-vida física de 6 horas, fótons monocromáticos de $140 \mathrm{keV}$ produzindo imagem com boa resolução espacial e baixa porcentagem de emissão de elétrons evitando dose de radiação significativa ao paciente. Além disso, 99m Tc está disponível facilmente, estéril a partir dos geradores de ${ }^{99} \mathrm{Mo} /{ }^{99 \mathrm{~m}}$ Tc. O gerador de tecnécio é um sistema composto por uma coluna cromatográfica empacotada com óxido de alumínio $\left(\mathrm{Al}_{2} \mathrm{O}_{3}\right)$, onde é depositado o molibdato $\left({ }^{99} \mathrm{MoO}_{4}{ }^{2-}\right)$, o qual decai a ${ }^{99 \mathrm{~m}} \mathrm{TcO}_{4}{ }^{-}$(Figura 1a). A preparação se inicia pela adição de uma solução estéril de ${ }^{99 m} \mathrm{TcO}_{4}{ }^{-}$a um frasco de $\mathrm{RL}$. $\mathrm{O}^{99 \mathrm{~m}} \mathrm{TcO}_{4}{ }^{-}$é reduzido do estado de oxidação VII para menor valência, pela ação de Sn(II) presentes nos frascos dos reagentes liofilizados (Figura 1b). (Saha, 2010).

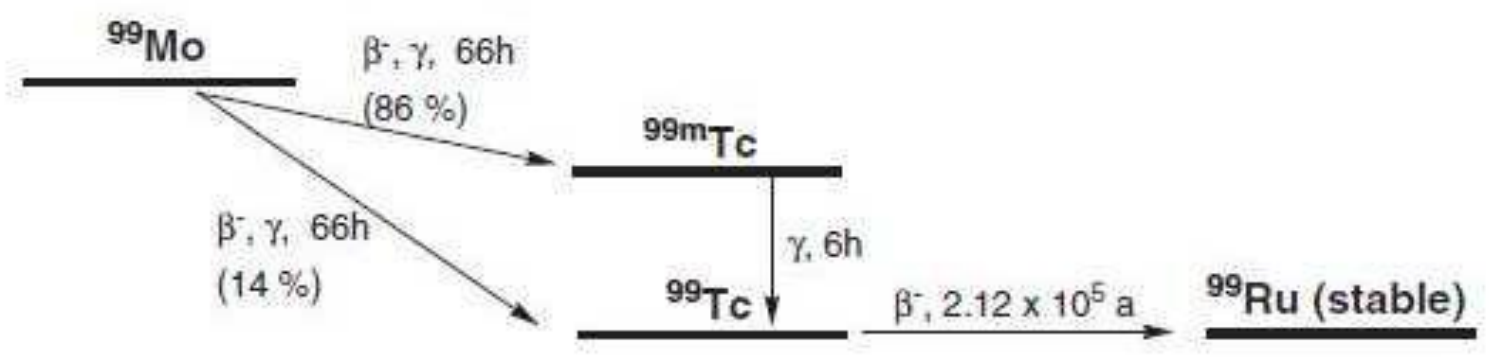

Figura 1. Decaimento do gerador ${ }^{99} \mathrm{Mo} / 99 \mathrm{~m}$ Tc (Abram apud Ribeiro, 2006, p. 2). 
a)

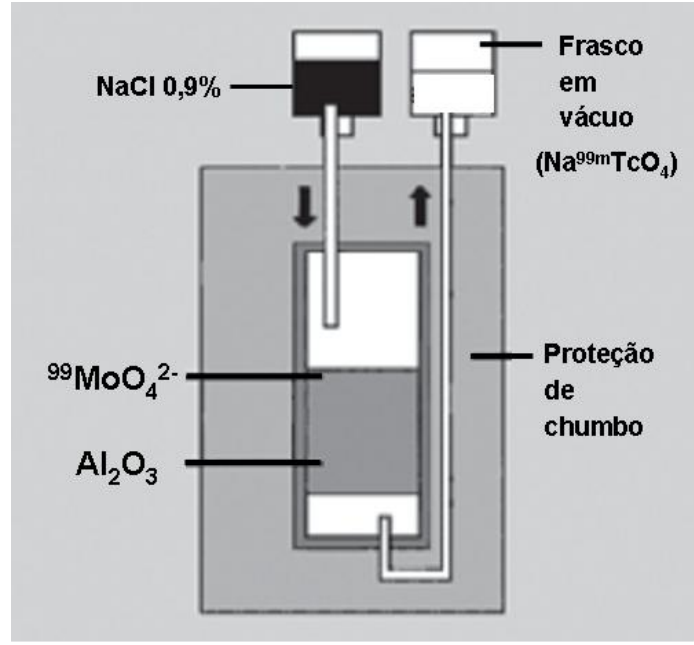

b)

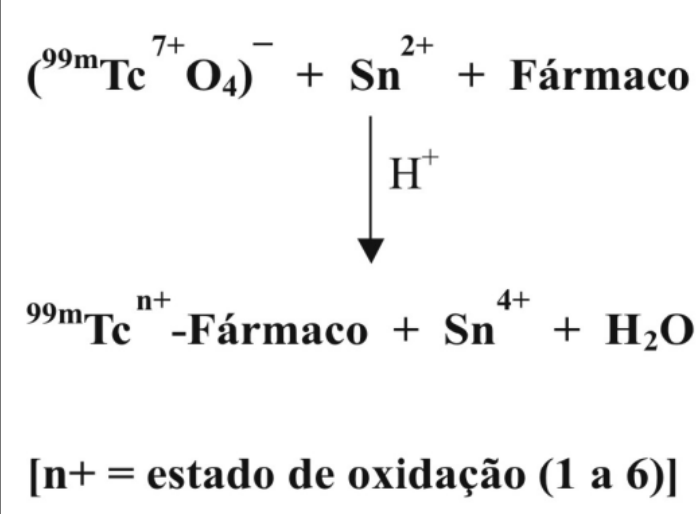

Figura 2. Esquema simplificado de a) um gerador de ${ }^{99} \mathrm{Mo} / 99 \mathrm{~m}$ Tc e de b) reações que ocorrem na obtenção de radiofármacos com pertecnetato de sódio (99m Tc) (Oliveira et al, 2006; Marques, Okamoto, \& Buchpiguel, 2001).

As reações de marcação de um eluato de gerador com o fármaco podem não ser tão eficientes em consequência da qualidade do eluato ou mesmo de procedimentos inadequados utilizados nas marcações. Por exemplo, existem clínicas que realizam a reconstituição dos $\mathrm{RL} \operatorname{com~NaCl} 0,9 \%$ e congelam até o momento do uso, e portanto o produto fica sujeito à degradação do agente redutor, diminuindo a eficácia da marcação. Nesses casos, a ineficiência nos processos pode dar origem a impurezas radioquímicas, como o próprio pertecnetato $\left({ }^{99 \mathrm{~m}} \mathrm{TcO}_{4}\right)$, decorrente da sua não-reação; o óxido de tecnécio $\left({ }^{99 \mathrm{~m}} \mathrm{TcO}_{2}\right)$, também denominado de tecnécio hidrolisado ou reduzido $\left({ }^{99 \mathrm{~m}} \mathrm{TcO}_{2}\right)$, decorrente da redução e não-complexação com o radionuclídeo; e outras espécies reduzidas e complexadas com arranjos diferentes do desejado. Devido aos possíveis problemas que podem ocorrer durante a preparação dos radiofármacos marcados com ${ }^{99 \mathrm{~m}} \mathrm{Tc}$, é importante que o próprio utente seja capaz de certificar a qualidade do eluato do gerador e do produto marcado, ainda que 
caiba à radiofarmácia industrial produtora a garantia da qualidade dos geradores

a)

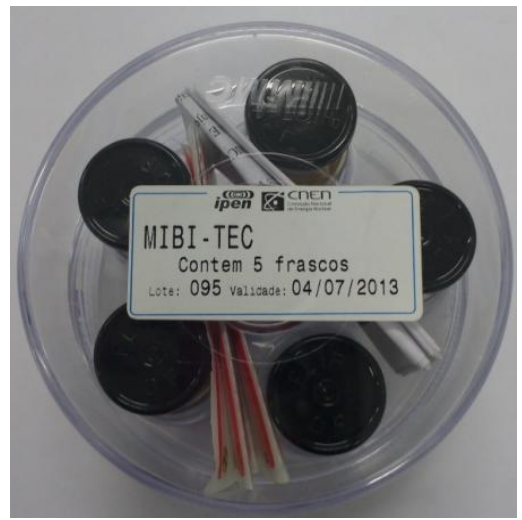

b)

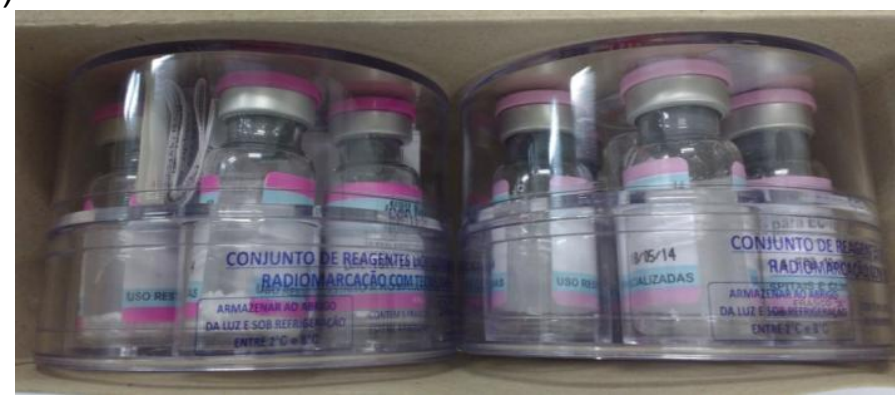

c)

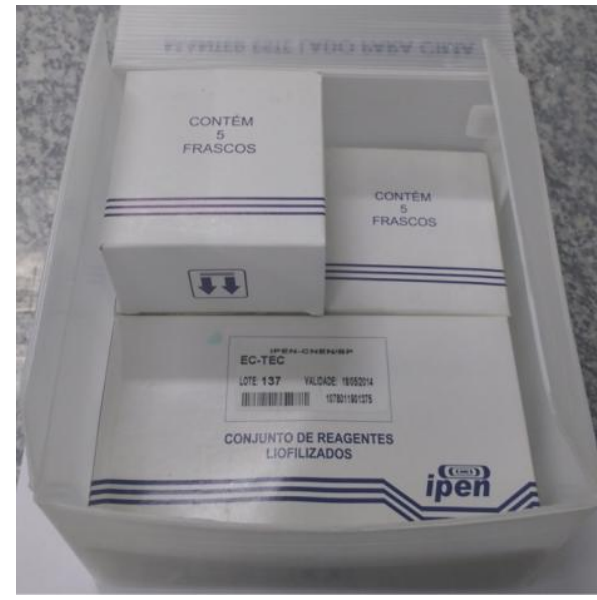

de ${ }^{99} \mathrm{Mo} / 99 \mathrm{~m}$ Tc e dos RL (Marques, Okamoto, \& Buchpiguel, 2001).

Figura 3. A) Kit com cinco reagentes liofilizados - MIBI-TEC B) Kit contendo os reagentes liofilizados e o kit com a solução tampão na embalagem acrílica - CISTEC C) Kit na embalagem de plástico polionda.

Alguns dos RL produzidos no Centro de Radiofarmácia (CR) do IPEN e que são utilizados neste trabalho estão listados na Tab. 1:

Tabela 1. Alguns reagentes liofilizados e suas aplicações (INSTITUTO DE PESQUISAS ENERGÉTICAS E NUCLEARES, 2015).

\section{Reagente liofilizado}

Nome comercial

\section{Aplicações}

ALBUMINA-TEC Linfocintilografia e perda proteica intestinal.


Tabela 1. Alguns reagentes liofilizados e suas aplicações - continuação. (INSTITUTO DE PESQUISAS ENERGÉTICAS E NUCLEARES, 2015).

\begin{tabular}{cl}
\hline $\begin{array}{c}\text { Reagente liofilizado } \\
\text { Nome comercial }\end{array}$ & \multicolumn{1}{c}{ Aplicações } \\
\hline DEX-500-TEC & $\begin{array}{l}\text { Linfocintilografia para avaliação de drenagem } \\
\text { linfática e linfocintilografia para pesquisa de } \\
\text { linfonodo sentinela. } \\
\text { Linfocintilografia para avaliação de drenagem }\end{array}$ \\
DEX-70-TEC & $\begin{array}{l}\text { linfática e linfocintilografia para pesquisa de } \\
\text { linfonodo sentinela. }\end{array}$ \\
DISI-TEC & $\begin{array}{l}\text { Cintilografia do fígado e vias biliares. } \\
\text { Cintilografia renal. }\end{array}$ \\
DMSA-TEC & $\begin{array}{l}\text { Morfologia renal, avaliação do fluxo renal e taxa } \\
\text { de filtração glomerular. Detecção de lesões } \\
\text { cerebrais vasculares e neoplásicas. }\end{array}$ \\
Cintilografia cerebral. \\
FITA-TEC & Cintilografia hepática. \\
PUL-TEC & $\begin{array}{l}\text { Avaliação da circulação pulmonar. Avaliação do } \\
\text { sistema circulatório. }\end{array}$ \\
Detecção de zonas com osteogênese alterada e \\
MDP-TEC
\end{tabular}

Em uma radiofarmácia, o controle de qualidade realiza diversos ensaios específicos (físicos, físico-químicos, químicos e biológicos), a fim de verificar se 
um produto atende às especificações estabelecidas e para assegurar a identificação do produto, pureza, segurança e eficácia. No caso de radiofármacos, as clínicas e centros de medicina nuclear também têm a responsabilidade da qualidade do produto administrado ao paciente. É também atribuição do controle de qualidade, juntamente com a garantia da qualidade avaliar a estabilidade de produto acabado e de outros radiofármacos, além de estabelecer as datas de validade em condições específicas de armazenamento (Saha, 2010). 


\section{OBJETIVOS}

O objetivo do trabalho foi simular uma condição mais crítica de transporte (dois dias em $40{ }^{\circ} \mathrm{C}$ de temperatura e $75 \%$ de umidade relativa) e avaliar a pureza radioquímica (\% PRq) e a biodistribuição na estabilidade de alguns $\mathrm{RL}$.

\subsection{OBJETIVOS ESPECÍFICOS}

- Comparar resultados de \% $\mathrm{PRq}$ e biodistribuição de alguns $\mathrm{RL}$, a saber: CIS-TEC, DEX-500-TEC, DEX-70-TEC, DISI-TEC, DMSA-TEC, DTPA-TEC, ECDTEC, FITA-TEC, PUL-TEC, MIBI-TEC, MDP-TEC, PIRO-TEC, SAH-TEC e TINTEC mantidos na câmara climática por 48 horas a $40{ }^{\circ} \mathrm{C}$ a $75 \%$ de umidade relativa com aqueles mantidos em $2-8^{\circ} \mathrm{C}$;

- Avaliar a estabilidade dos RL;

- Avaliar a variação de temperatura na embalagem utilizada para alguns $R L$ e na embalagem do tipo blindagem para uso em radiofármacos de uso em PET. 


\section{REVISÃO DA LITERATURA}

A radioatividade foi descoberta por Henri Becquerel enquanto estudava materiais que emitiam luz ao serem irradiados com raios $\mathrm{X}$ e luz ultravioleta. $\mathrm{O}$ cientista queria verificar se os sais de urânio emitiam luz quando submetidos à radiação solar. Para isso, preparou uma amostra e a deixou guardada em uma gaveta, à espera de um dia ensolarado. A amostra foi colocada sobre uma chave, que por sua vez repousava em algumas placas fotográficas embrulhadas em papel que estava usando para testar o poder de penetração dos raios X. Quando revelou as placas, Becquerel viu uma imagem da chave e concluiu que tinha sido produzida por uma radiação emitida pelo sais de urânio. Por isso, passou a chamar sais de urânio "radioativos". Como estava mais interessado nos raios X do que na radiação misteriosa emitida pelo urânio, transferiu a missão de investigar a radioatividade à Marie Curie, uma de suas alunas. Marie Curie, que veio se tornar uma cientista famosa, ganhadora de dois prêmios Nobel, descobriu que as outras substâncias encontradas na natureza também emitiam radiação, incluindo dois elementos até então desconhecidos, polônio e rádio (Breithaupt, 2012; Atkins \& Loretta, 2007)

Ernest Rutherford mostrou que as substâncias radioativas emitiam três tipos de radiação: um tipo, que chamou radiação alfa $(\alpha)$, é facilmente absorvido pela matéria enquanto outro, que chamou de radiação beta $(\beta)$, é mais penetrante e o terceiro tipo, conhecido como radiação gama ( $\mathrm{Y}$ ), é ainda mais penetrante que a radiação beta (Breithaupt, 2012).

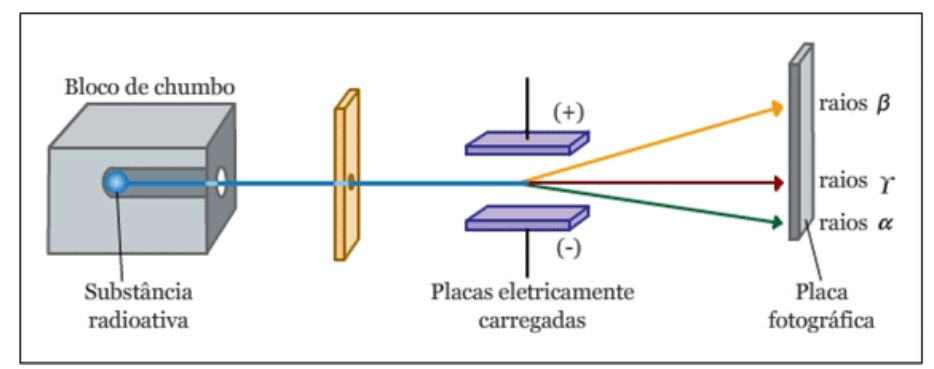

Figura 4. Tipos de radiação (Sousa, 2000). 
As descobertas de Becquerel, Curie e Rutherford e o desenvolvimento posterior do modelo nuclear atômico, feito por Rutherford, mostraram que a radioatividade é produzida pelo decaimento nuclear, e a decomposição parcial de um núcleo. A desintegração nuclear de um dado radionuclídeo obedece a uma lei exponencial descrita pela equação: (Okuno, 2013)

$$
N(t)=N_{\mathrm{o}} \exp (-\lambda t)=N_{\mathrm{o}} \mathrm{e}^{-\lambda t}=\frac{N_{\mathrm{o}}}{2^{\frac{t}{T_{1 / 2}}}}
$$

Onde $n_{\mathrm{o}}$ é o número de átomos inicialmente presentes (no instante $t=0$ ) e $\boldsymbol{N}(\boldsymbol{t})$, o número de átomos que ainda não se desintegraram após um intervalo de tempo $\boldsymbol{t}$, e a base dos logaritmos naturais ou neperianos e $\boldsymbol{\lambda}$ é a constante de decaimento que é característica de cada radionuclídeo (Okuno, 2013).

$$
\lambda=\frac{\ln 2}{T_{1 / 2}} \cong \frac{0,693}{T_{1 / 2}} .
$$

Os radiofármacos historicamente começaram a ser utilizados em 1905, após a descoberta em 8 de novembro de 1895 do Raio-X por Wilhelm Conrad Roentgen em seu laboratório, com apresentação pública de sua descoberta em 6 de janeiro de 1896. O primeiro uso de radionuclídeos em humanos ocorreu em 1927, quando Blumgart e Yens mediram a radiação emitida pela circulação humana-após injeção de um solução salina exposta ao radônio (Blumgart, Yens apud Oliveira \& Carneiro, 1926). Mais tarde, em 1938, estudos como os de Hertz, Roberts, Evan sobre a função da tiróide com o uso de iodo-121 marcaram o início do uso sistemático dos radionuclídeos na clínica médica (Hertz, Roberts, Evans apud Oliveira \& Carneiro, 1938).

Os radiofármacos tiveram duas divisões históricas bem marcantes, comumente denominadas de Fase I ou Fase Pré-Tecnécio e Fase II ou Fase PósTecnécio. A Fase I foi marcada pela publicação na Revista Science, em 14 de 
junho de 1945, de um artigo do Oak Ridge National Laboratories anunciando a disponibilidade de radionuclídeos ao setor privado. Pouco tempo depois ao anúncio do Oak Ridge National Laboratories, o Brookhaven National Laboratories também disponibilizou ao setor privado os radionuclídeos por eles produzidos (Oak Ridge National Laboratories 1945). Nesta época, os radionuclídeos eram disponibilizados sem nenhuma garantia de esterilidade e apirogenicidade, sendo incluídos estes parâmetros somente mais tarde, quando a Abbot Laboratories decidiu comprar a produção de radionuclídeos desses laboratórios e transformá-los em radiofármacos (radionuclídeo devidamente preparado) para uso médico, tornando-se a primeira produtora de radiofármacos no mundo. Somente após cinco anos, outras empresas começaram a se interessar pelo setor, a Squibb Co. e a Nuclear Consultants Corporation (Early apud Oliveira \& Carneiro, 1995).

O primeiro radiofármaco comercialmente disponível foi o lodo-131 e sua comercialização só começou em 1950. Em relação à Fase II, iniciou-se com a descoberta do tecnécio (Tc-99m), naquela época denominado Elemento Número 43. No início, o tecnécio não se mostrou um bom candidato para uso na medicina nuclear, pela meia-vida física de 6 horas. Contudo, este possuía uma energia gama ideal para formação de imagens $(140 \mathrm{keV})$ e enquadrou-se de forma perfeita no projeto de desenvolvimento de metodologia para a formação de radionuclídeos de meia-vida física curta, liderado pelo Brookhaven National Laboratories. Em 1957, foi então anunciado o desenvolvimento do gerador de tecnécio, pelo sistema ${ }^{99} \mathrm{Mo} /{ }^{99 \mathrm{~m}} \mathrm{Tc}$ (Oliveira \& Carneiro, 2008).

\subsection{A HISTÓRIA DA PRODUÇÃO DE RADIOFÁRMACOS NO IPEN}

No Brasil, os primeiros passos nesse sentido foram, dados a partir de 1956, quando pelo convênio entre o CNPq (Conselho Nacional de Pesquisa) e USP (Universidade de São Paulo) foi criado o IEA (Instituto de Energia Atômica). Em 1959, por meio do seu antigo Departamento de Processamento de Material 
Radioativo (TP), atual Centro de Radiofarmácia (CR), começaram-se os trabalhos pioneiros do IEA no campo dos radionuclídeos com a produção de lodo-131 para aplicação médica. A produção experimental do radiofármaco ${ }^{131} \mathrm{I}$, usado no diagnóstico e terapia de doenças da tireóide, foi fundamental para a viabilização e consolidação da medicina nuclear no país. Entre 1956 até 2006, o monopólio de produção de radioisótopos e radiofármacos pertenceu à Comissão Nacional de Energia Nuclear, pela promulgação na Constituição do Brasil (INSTITUTO DE PESQUISAS ENERGÉTICAS E NUCLEARES, 2015).

Com mais de 20 anos de experiência na área de produção de radionuclídeos em Reator Nuclear, o IPEN iniciou, com a aquisição de um acelerador cíclotron, modelo CV-28, a produção de ${ }^{67} \mathrm{Ga}$ e ${ }^{123} \mathrm{I}$, utilizados em diagnóstico. No final de 1980, médicos nucleares consultaram o IPEN sobre a possibilidade de produção no país dos geradores de ${ }^{99} \mathrm{Mo}-{ }^{99 M} \mathrm{Tc}$, até então importados em virtude do seu crescente uso. O IPEN estabeleceu um programa de desenvolvimento e iniciou os trabalhos experimentais com ${ }^{99} \mathrm{Mo}$ importado do Canadá (INSTITUTO DE PESQUISAS ENERGÉTICAS E NUCLEARES, 2015).

Em 1981, iniciou o atendimento às hospitais e clínicas do país com geradores de ${ }^{99} \mathrm{Mo} /{ }^{99 \mathrm{M}} \mathrm{Tc}$, preparados com tecnologia nacional, atendendo uma demanda inicial de 10 geradores por semana. Esta demanda cresceu anualmente e atingiu em 2005 a marca de 260 geradores distribuídos por semana. Nos anos seguintes, outros radiofármacos foram desenvolvidos, produzidos e distribuídos, como o cloreto de ${ }^{201} \mathrm{TI}$ e o ${ }^{153} \mathrm{Sm}$, na forma de EDTMP- ${ }^{153} \mathrm{Sm}$ (INSTITUTO DE PESQUISAS ENERGÉTICAS E NUCLEARES, 2015)

A partir de 1995, o IPEN iniciou um programa de nacionalização, com objetivo de passar a produzir parte dos radioisótopos importados. Esse programa promoveu a instalação de um cíclotron de $30 \mathrm{MeV}$ com investimentos superiores a US\$ 6 milhões. Em 1999 foi iniciada a produção e distribuição de Fluordesoxiglicose ${ }^{18} \mathrm{~F}$ (FG-IPEN) com grande aceitação pela classe médica nuclear. $\mathrm{O}^{18} \mathrm{~F}$ foi o primeiro radionuclídeo produzido no País, para uso na técnica de PET, que permite maior sensibilidade nas imagens obtidas e diagnósticos mais precisos (INSTITUTO DE PESQUISAS ENERGÉTICAS E NUCLEARES, 2015). 
O programa de nacionalização, associado ao desenvolvimento de novos produtos propiciou ao IPEN produzir e distribuir para todo o território nacional, diversos produtos radioativos para diagnóstico e tratamentos, entre eles, radioisótopos primários, moléculas marcadas e reagentes liofilizados para pronta marcação com 99m Tc, com qualidade controlada para administração em seres humanos na forma de radiofármacos injetáveis ou na forma oral. Desde então, o $\mathrm{CR}$ tem aperfeiçoando suas instalações, equipamentos, recursos humanos $\mathrm{e}$ atualizando as tecnologias envolvidas, para atender ao crescimento do mercado brasileiro de radionuclídeos e radiofármacos, tanto para diagnóstico como para a terapia (INSTITUTO DE PESQUISAS ENERGÉTICAS E NUCLEARES, 2015). 


\section{ESTUDO DE ESTABILIDADE}

A estabilidade pode ser definida como o período de tempo compreendido entre a fabricação e o momento em que a potência do medicamento está reduzida a não mais do que $10 \%$, estando todos os produtos gerados seguramente identificados e os efeitos previamente conhecidos. Considerando que a degradação do medicamento pode gerar alguma substância tóxica ou perda de atividade, que em casos mais extremos pode conduzir à falha na terapia ou até mesmo resultar na morte do paciente, as agências reguladoras criaram normas obrigando fabricantes de medicamentos a realizarem testes de estabilidade, antes da aprovação de um novo produto. O estudo de estabilidade desempenha um papel importante no processo de desenvolvimento (Silva et al., 2009).

No âmbito do MERCOSUL, os esforços para harmonizar os procedimentos para registro de medicamentos entre os países membros, Argentina, Brasil, Paraguai e Uruguai, resultou na elaboração, em 1996, do regulamento técnico Estabilidade de Produtos Farmacêuticos. Este regulamento, MERCOSUR/GMC/RES n 53/96 teve por objetivo estabelecer diretrizes para determinação do prazo de validade de produtos farmacêuticos destinados à comercialização no MERCOSUL (MERCOSUR, 1996 apud Leite, 2005, p. 37).

Segundo a RDC 45/2009, para realização do estudo estabilidade, há cinco parâmetros que devem ser avaliados, nos quais não podem ocorrer mudanças significativas (Tab. 2) (AGÊNCIA NACIONAL DE VIGILÂNCIA SANITÁRIA, 2009).

Tabela 2. Parâmetros dos fármacos a serem avaliados durante o período de estabilidade (Ansel, Loyd, \& Popovich, 1999).

Tipos de Condição a manter dentro dos limites especificados durante o

Estabilidade prazo de validade do produto farmacêutico

\begin{tabular}{ll}
\hline Química & $\begin{array}{l}\text { A integridade química e a potência (doseamento } \\
\text { impurezas/produtos de degradação), indicadas na embalagem. }\end{array}$
\end{tabular} 
Tabela 2. Parâmetros dos fármacos a serem avaliados durante o período de estabilidade - continuação (Ansel, Loyd, \& Popovich, 1999).

Tipos de Condição a manter dentro dos limites especificados durante o

Estabilidade prazo de validade do produto farmacêutico

Física

As propriedades físicas originais, incluindo aparência, palatabilidade, uniformidade, dissolução, dispersibilidade, entre outras.

Microbiológica A esterilidade ou resistência ao crescimento microbiológico e a eficácia dos agentes antimicrobianos, quando presentes.

Terapêutica $\quad$ O efeito terapêutico deve permanecer inalterado.

Toxicológica Não deve ocorrer aumento da toxicidade.

Para medicamentos, a estabilidade depende de fatores ambientais como temperatura, umidade e luz, e de outros relacionados ao próprio produto como propriedades físicas e químicas de ingredientes farmacêuticos ativos (IFA, ou do inglês, API), excipientes farmacêuticos, forma farmacêutica e sua composição, processo de fabricação, tipo e propriedades dos materiais de embalagem (AGÊNCIA NACIONAL DE VIGILÂNCIA SANITÁRIA, 2002). Outros fatores de risco que também que podem impactar na estabilidade dos produtos são: (Huynh$\mathrm{Ba}, 2009)$.

Os riscos causados pelos fatores externos como calor e umidade, luz, pH, oxigênio podem ser reduzidos por testes de longa duração, acelerados e de estresse, para identificar a embalagem adequada, prazo de validade e recomendações de armazenamento;

$\checkmark \quad$ Os riscos de possíveis interações entre IFA, excipientes e materiais de embalagem podem ser reduzidos através dos testes de estresse como parte do desenvolvimento do produto;

$\checkmark \quad$ O procedimento padrão para reduzir riscos relativos à produção, como tamanhos dos lotes, equipamentos, qualidade dos componentes são as validações de processos, incluindo Boas Práticas de Fabricação (BPF), 
qualificação de instalações (QI), qualificação operacional (QO) e aplicação de novas tecnologias; colocar todas estas siglas na lista de abreviaturas;

$\checkmark \quad$ Os riscos causados pelos danos físicos durante o transporte/ distribuição e armazenamento podem ser reduzidos por embalagens secundárias adequadas (tambores, caixas e recipientes).

Sabe-se que a temperatura acelera grande maioria dos processos de degradação, pois aumenta a energia cinética das moléculas e fornece energia de ativação necessária para que ocorram as reações químicas. A descaboxilação e a desidratação são as principais reações que ocorrem na termólise. Por outro lado, as reações fotoquímicas, que envolvem baixas energias de ativação, e as reações de decomposição, que envolvem processos de difusão, não são influenciadas pela ação de temperatura, mas afetam igualmente a estabilidade dos medicamentos (Breier, 2007).

A equação de Arrhenius (Pombal et al., 2010) permite que resultados do estudo de estabilidade acelerada sejam extrapolados para que se possa avaliar o efeito da temperatura de armazenamento na velocidade de degradação do medicamento, relacionando as duas temperaturas em um gráfico - Figura 3. (Lachman et al., 2001, apud Porto, 2012).

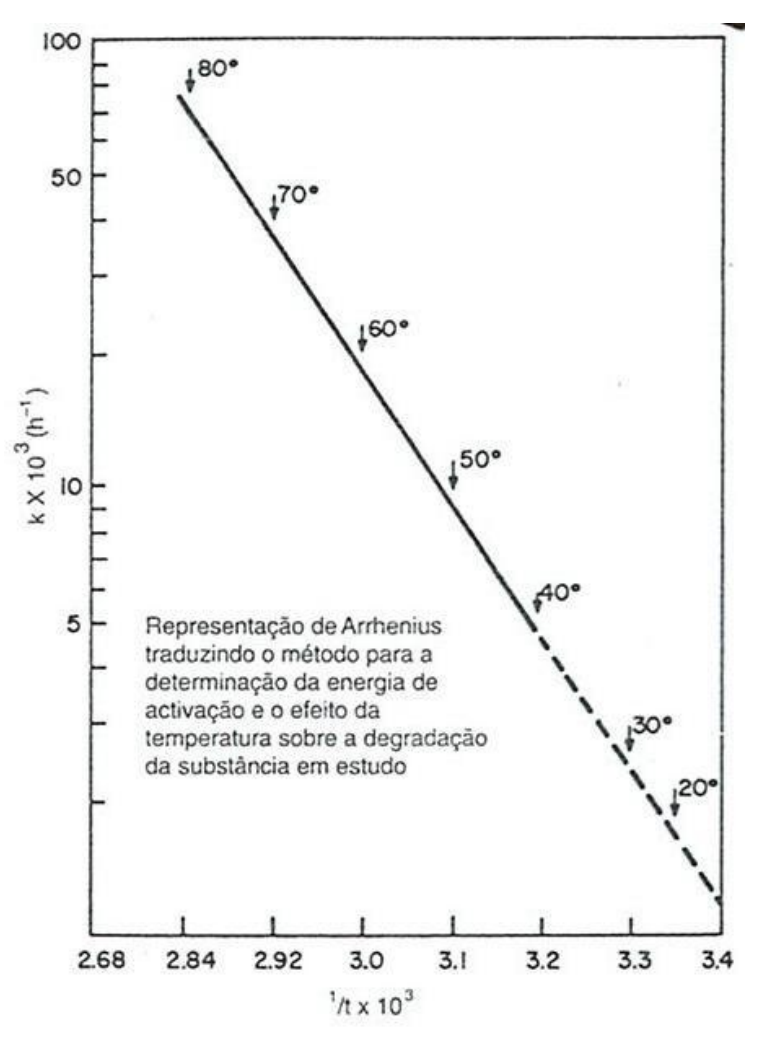


Figura 5. Influência da temperatura sobre a velocidade de degradação do produto Influência da temperatura sobre a velocidade de degradação do produto (Lachman et al., 2001).

A maioria das reações ocorre mais rapidamente em temperaturas mais elevadas do que em temperaturas mais baixas (Yoshioka \& Stella, 2002, apud, Porto, 2012). A velocidade de uma reação duplica a cada de $10^{\circ} \mathrm{C}$ de aumento de temperatura. Contudo este aumento não se aplica à maioria dos casos, sendo necessário estabelecer protocolos de estudo de estabilidade para cada formulação (Lachman et al., 2001 apud, Porto 2012). É possível concluir que a temperatura é um fator muito importante e a sua influência pode ser minimizada selecionando-se a temperatura adequada de armazenamento (Yoshioka \& Stella, 2002, apud Porto, 2012). É natural assumir que os processos ocorrem da mesma forma, em temperaturas elevadas e mais baixas; entretanto, isso nem sempre se verifica, o que faz com que a equação de Arrhenius não possa ser aplicada em todos os casos para a previsão de estabilidade (International Conference on Harmonisation, 2000; Beezer et al., 1999, apud, Porto, 2012). 
Tabela 3. Exemplos do efeito da temperatura em medicamentos (Bajaj, Singla, \& Neha, 2012)..

\begin{tabular}{|c|c|c|c|}
\hline Potencial efeito adverso & Explicação/ razão & Exemplo & $\begin{array}{c}\text { Parâmetro de teste de } \\
\text { estabilidade }\end{array}$ \\
\hline Perda do IFA & Degradação resultando em teor de IFA < $90 \%$ & $\begin{array}{l}\text { Comprimido de } \\
\text { nitroglicerina } \\
\text { (vasodilatador) }\end{array}$ & $\begin{array}{l}\text { Teor de IFA > } 90 \% \\
\text { durante a validade }\end{array}$ \\
\hline $\begin{array}{l}\text { Aumento na concentração do } \\
\text { IFA }\end{array}$ & Perda do solvente por temperatura/umidade & Lidocaína gel & $\begin{array}{l}\text { Estabilidade na } \\
\text { embalagem final }\end{array}$ \\
\hline $\begin{array}{l}\text { Alteração na } \\
\text { biodisponibilidade }\end{array}$ & $\begin{array}{c}\text { Mudanças na absorção por causa do } \\
\text { armazenamento. }\end{array}$ & --- & Estudo de dissolução \\
\hline $\begin{array}{l}\text { Perda da uniformidade no } \\
\text { conteúdo }\end{array}$ & Perda de conteúdo em função de tempo & Suspensão & $\begin{array}{l}\text { Facilidade na } \\
\text { redispersão ou } \\
\text { sedimentação }\end{array}$ \\
\hline Aumento da carga microbiana & $\begin{array}{l}\text { Aumento do número de microrganismos causado } \\
\text { pelo comprometimento da embalagem durante a } \\
\text { distribuição/armazenamento }\end{array}$ & Creme multiuso & $\begin{array}{l}\text { Avaliação da carga } \\
\text { microbiana após } \\
\text { armazenamento }\end{array}$ \\
\hline $\begin{array}{l}\text { Aparência do fármaco } \\
\text { alterada }\end{array}$ & $\begin{array}{l}\text { Mancha causada pela interação do fármaco } \\
\text { contendo um grupo amina com a lactose, } \\
\text { resultando na formação de um cromóforo }\end{array}$ & $\begin{array}{l}\text { Manchas leves } \\
\text { amarelas ou marrons } \\
\text { na superfície do } \\
\text { comprimido contendo } \\
\text { spray- dried de lactose }\end{array}$ & Inspeção visual \\
\hline
\end{tabular}


Tabela 3. Exemplos do efeito da temperatura em medicamentos - continuação (Bajaj, Singla, \& Neha, 2012).

\begin{tabular}{|c|c|c|c|}
\hline Potencial efeito adverso & Explicação/ razão & Exemplo & $\begin{array}{c}\text { Parâmetro de teste de } \\
\text { estabilidade }\end{array}$ \\
\hline $\begin{array}{l}\text { Formação de produtos de } \\
\text { degradação tóxicos }\end{array}$ & Degradação dos componentes do fármaco & $\begin{array}{l}\text { Formação a partir da } \\
\text { tetraciclina a } \\
\text { epianidrotetraciclina }\end{array}$ & $\begin{array}{l}\text { Quantificação de } \\
\text { produtos de degradação } \\
\text { durante a validade }\end{array}$ \\
\hline $\begin{array}{l}\text { Perda de integridade da } \\
\text { embalagem }\end{array}$ & $\begin{array}{c}\text { Mudança na integridade da embalagem durante a } \\
\text { distribuição/armazenamento }\end{array}$ & $\begin{array}{l}\text { Perda da capacidade } \\
\text { de rosqueamento }\end{array}$ & $\begin{array}{l}\text { Ensaios específicos de } \\
\text { integridade da } \\
\text { embalagem }\end{array}$ \\
\hline Perda da qualidade do rótulo & $\begin{array}{c}\text { Deterioração da etiqueta com o tempo com } \\
\text { aparecimento de manchas de tinta, afetando a } \\
\text { legibilidade }\end{array}$ & $\begin{array}{l}\text { Migração de aditivos } \\
\text { dos polímeros para a } \\
\text { etiqueta }\end{array}$ & Inspeção visual do rótulo \\
\hline $\begin{array}{l}\text { Modificação de parâmetros } \\
\text { funcionais do produto }\end{array}$ & $\begin{array}{c}\text { Mudança dependente do tempo de qualquer } \\
\text { parâmetro funcional relevante do produto, que } \\
\text { altera negativamente a segurança, eficácia ou } \\
\text { facilidade de utilização }\end{array}$ & $\begin{array}{l}\text { Perda da adesão de } \\
\text { sistemas transdérmicos }\end{array}$ & $\begin{array}{l}\text { Monitoramento de } \\
\text { mudanças }\end{array}$ \\
\hline
\end{tabular}


As condições para condução do estudo de estabilidade estão divididas em cinco grandes grupos, baseadas nas zonas climáticas, para que cada lugar do mundo possa realizar o estudo em condições de temperatura e umidade mais apropriadas ao clima local em que está sendo fabricado e avaliado (Tab. 4). O clima do Brasil é caracterizado por ser quente e muito úmido, Cerca de $92 \%$ do território brasileiro localiza-se na zona tropical, entre os trópicos de Câncer e de Capricórnio. Essa localização faz com que a maior parte do território seja bem iluminada e aquecida pelos raios solares no decorrer do ano, tornando o clima geral quente (Adas apud Leite, 2006, p.47). Segundo ANVISA o Brasil situa-se na Zona Climática IVb (quente/muito úmida) (AGÊNCIA NACIONAL DE VIGILÂNCIA SANITÁRIA, 2011).

Tabela 4. Divisão do globo para estabelecimento das condições nos estudos de estabilidade (INTERNATIONAL CONFERENCE ON HARMONISATION, 2000; AGÊNCIA NACIONAL DE VIGILÂNCIA SANITÁRIA, 2005).

\begin{tabular}{cc}
\hline Divisão das zonas climáticas & Temperatura/Umidade \\
\hline Zona I & Temperado \\
Zona II & Sub-tropical, com alta umidade \\
Zona III & Quente e seco \\
Zona IVa & Quente e úmido \\
Zona IVb & Quente e muito úmido \\
\hline
\end{tabular}


Tabela 5. Condições de temperatura e umidade para realização dos estudos de estabilidade no Brasil, considerando-se a forma farmacêutica. (AGÊNCIA NACIONAL DE VIGILÂNCIA SANITẢRIA, 2005).

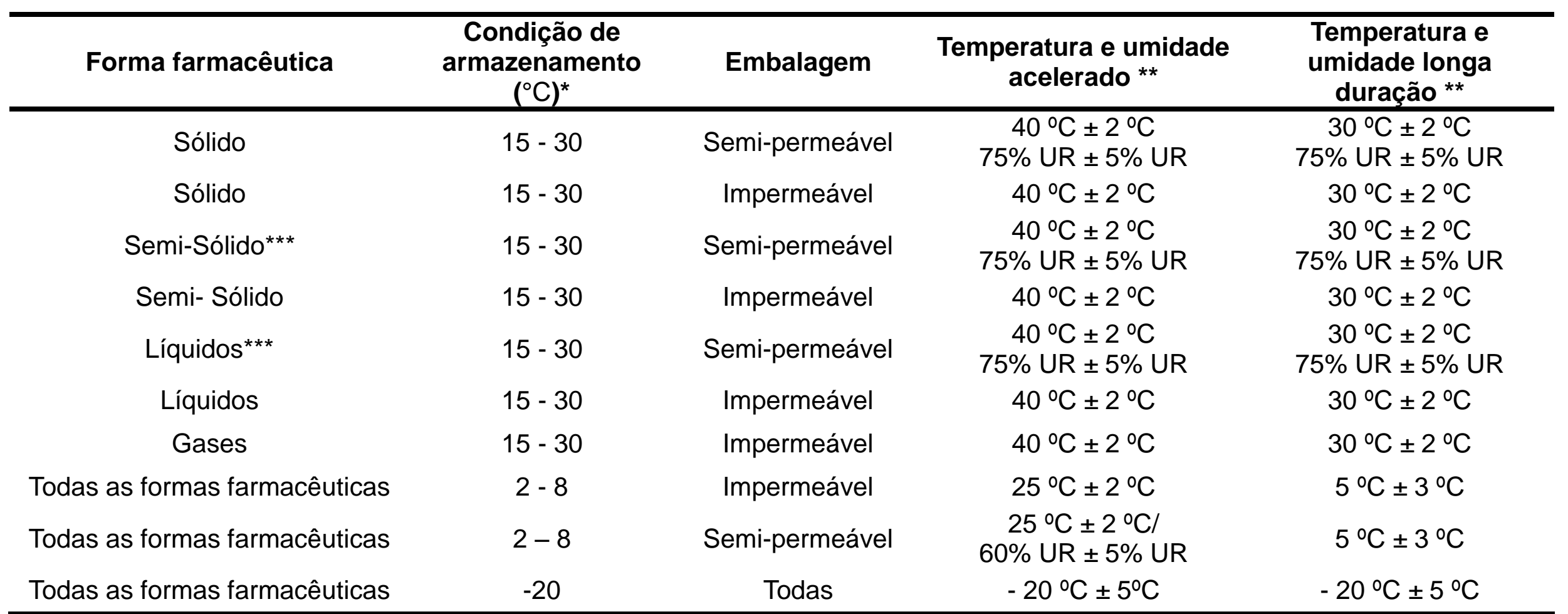

Observações: $\left(^{*}\right)$ Qualquer recomendação de armazenamento em temperatura dentro destas faixas deve constar de bulas e rótulos. A temperatura recomendada não exime de que os testes de estabilidade sejam realizados com as temperaturas definidas nas duas últimas colunas da tabela.

$\left.{ }^{* *}\right)$ Os valores de temperatura e umidade são fixos e as variações são inerentes às oscilações esperadas pela câmara climática e por eventuais aberturas para retirada ou colocação de material.

$\left.{ }^{\star * *}\right)$ Líquidos e semi-sólidos de base aquosa devem realizar o estudo com umidade a $25 \%$ UR ou $75 \%$ UR. Caso se opte por $75 \%$ UR, o valor da perda de peso deverá ser multiplicado por 3,0. 


\subsection{VARIAÇÕES DE TEMPERATURA NO BRASIL}

As análises dos indicadores climáticos dos últimos 400 anos mostram que os anos da década de 1990 foram os mais quentes do milênio, e que o século XX foi o mais quente. A década de 1990 registrou as maiores temperaturas no planeta Terra desde o período de 1860. O ano mais quente foi de 1998, o segundo ano mais quente foi o de 2002, e o mais frio, provavelmente foi 1601 (INSTITUTO NACIONAL DE METEREOLOGIA, 2014).

No Brasil, a temperatura máxima foi registrada na cidade do Bom Jesus do Piauí, em 21 de novembro de 2005, chegando a 44,7 ${ }^{\circ} \mathrm{C}$. A temperatura mínima foi na cidade de Xanxerê, Estado de Santa Catarina, chegando a $-11,1{ }^{\circ} \mathrm{C}$, em 20 de julho de 1953. O menor índice de U.R. do ar registrado no Brasil foi de $10 \%$, nas cidades de Uberaba-MG, em setembro de 1994 e em Brasília-DF, em 07 de agosto de 2002 (INSTITUTO NACIONAL DE METEREOLOGIA, 2014).

O Brasil, por ser um país de grande extensão territorial, possui regimes de precipitação e temperatura diferenciados. De norte a sul encontra-se uma grande variedade de climas com distintas características regionais. No Norte do país verifica-se um clima equatorial chuvoso, praticamente sem estação seca. No Nordeste, a estação chuvosa restringe-se a poucos meses, com baixos índices pluviométricos, caracterizando um clima semi-árido. As regiões Sudeste e CentroOeste sofrem influência tanto de sistemas tropicais como de latitudes médias, com estação seca bem definida no inverno e estação chuvosa de verão com chuvas convectivas (INSTITUTO NACIONAL DE METEREOLOGIA, 2014).

O Sul do Brasil, devido à sua localização latitudinal, sofre mais influência dos sistemas de latitudes médias, onde os sistemas frontais são os principais causadores de chuvas durante 0 ano. Com relação às temperaturas, observa-se nas regiões Norte e Nordeste temperaturas elevadas, com pouca variabilidade durante 0 ano, caracterizando o clima quente nestas regiões. Nas médias latitudes, a variação da temperatura no decorrer do ano é muito importante na definição do clima. No período de inverno há maior penetração de massas de ar frio de altas latitudes, o que contribui para a predominância de baixas temperaturas, apresentam as climatologias de temperaturas máximas e mínimas, 
respectivamente, sobre o Brasil (INSTITUTO NACIONAL DE METEREOLOGIA, 2014).

A)

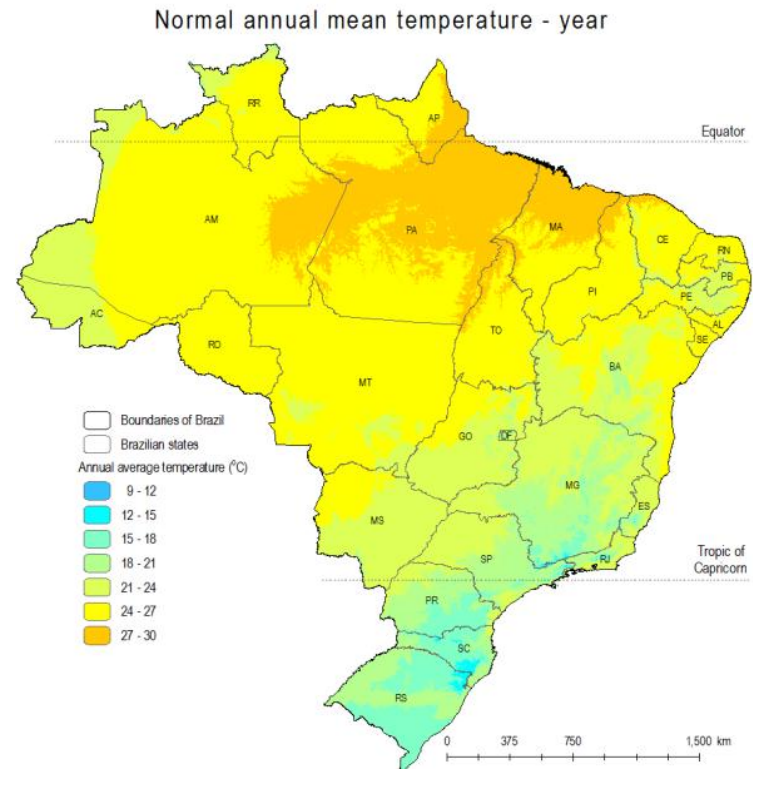

C)

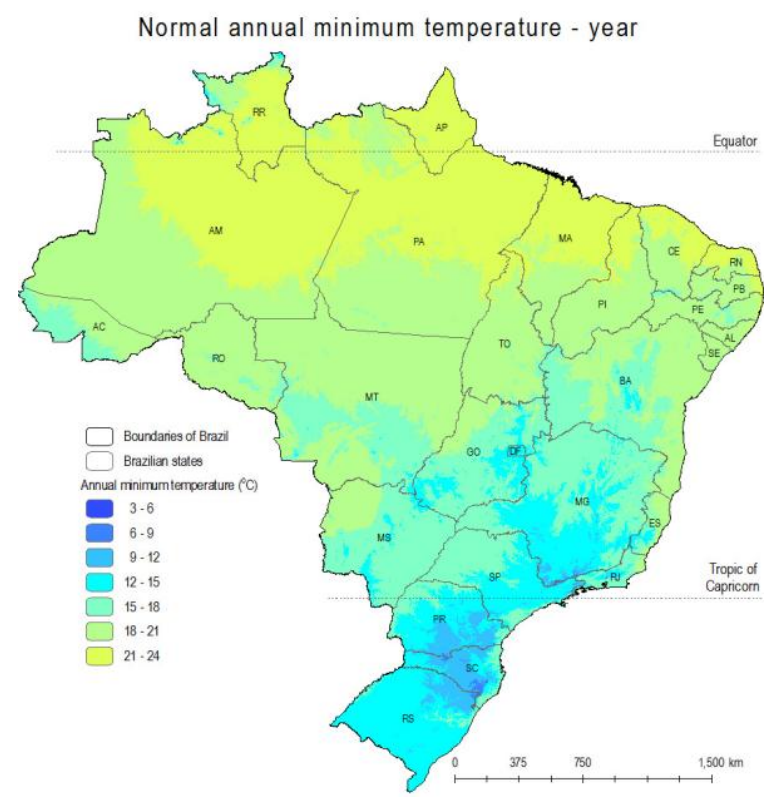

B)

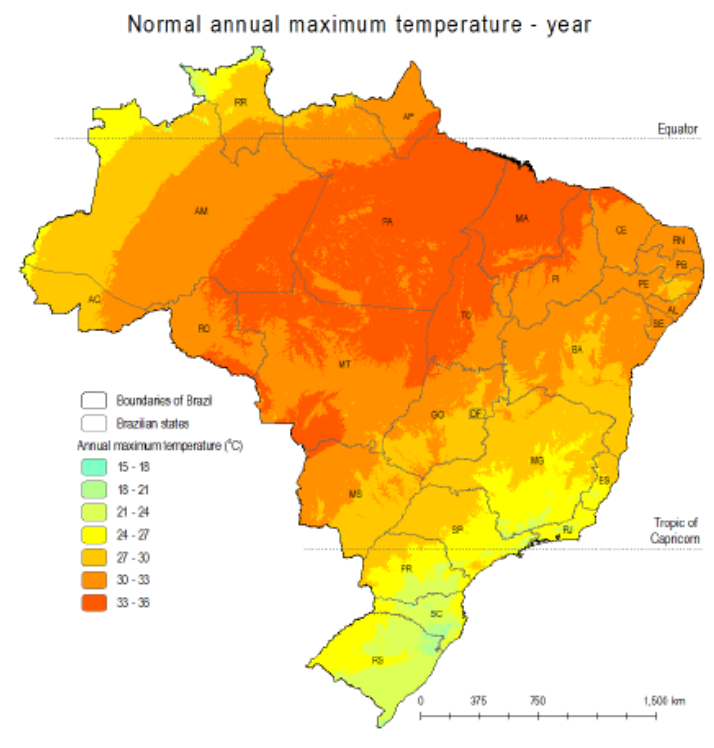

Figura 6. Variação de temperatura no Brasil em 2004: A) Média; B) Máxima e C) Mínima (INSTITUTO NACIONAL DE METEREOLOGIA, 2014). 


\subsection{TIPOS DE ESTUDO DE ESTABILIDADE}

O uso de métodos indicadores de estabilidade seletivos aos IFA e seus produtos de degradação são altamente recomendados pela ANVISA, para acompanhamento de resultados provenientes de estudos de estabilidade de medicamentos. No entanto, poucas monografias existentes em farmacopeias incluem metodologias para análise de produtos de degradação, e poucos fabricantes conhecem e desenvolvem metodologias validadas para detecção e quantificação desses produtos (AGÊNCIA NACIONAL DE VIGILÂNCIA SANITÁRIA, 2002). Para o desenvolvimento e validação de metodologias indicadoras de estabilidade, preconiza-se a realização de testes de estresse, para obtenção de padrões, para fins de análise. (Silva et al., 2009).

Tabela 6. Classificação dos estudos de estabilidade conforme etapa do processo de lançamento do fármaco. (AGÊNCIA NACIONAL DE VIGILÂNCIA SANITÁRIA, 2005).

\begin{tabular}{|c|c|c|}
\hline $\begin{array}{l}\text { Classificação } \\
\text { do estudo de } \\
\text { estabilidade }\end{array}$ & Fase & Objetivo \\
\hline Acelerado & Desenvolvimento do produto & $\begin{array}{l}\text { Selecionar formulações e } \\
\text { recipientes adequados (do } \\
\text { ponto de vista da } \\
\text { estabilidade). }\end{array}$ \\
\hline $\begin{array}{l}\text { Acelerado e } \\
\text { Longa } \\
\text { Duração }\end{array}$ & $\begin{array}{l}\text { Desenvolvimento do Produto e } \\
\text { Documentação de Registro }\end{array}$ & $\begin{array}{l}\text { Determinar o prazo de } \\
\text { validade e das condições de } \\
\text { estocagem. }\end{array}$ \\
\hline Longa duração & Documentação de registro & $\begin{array}{l}\text { Substanciar vida-média da } \\
\text { estabilidade declarada. }\end{array}$ \\
\hline Longa duração & $\begin{array}{l}\text { Garantia da Qualidade em geral, } \\
\text { incluindo Controle de Qualidade. }\end{array}$ & $\begin{array}{l}\text { Verificar se não foi introduzida } \\
\text { nenhuma mudança na } \\
\text { formulação ou no processo de } \\
\text { fabricação que possa afetar } \\
\text { adversamente a estabilidade } \\
\text { do produto. }\end{array}$ \\
\hline
\end{tabular}




\subsection{ESTUDOS DE ESTABILIDADE ACELERADA}

São estudos projetados para acelerar a degradação química ou mudanças físicas de um produto farmacêutico pelo uso de condições de estocagem forçadas. Os dados assim obtidos, juntamente com aqueles derivados dos estudos de longa duração, podem ser usados para avaliar efeitos químicos prolongados em condições não aceleradas e para avaliar o impacto de curtas exposições em condições fora daquelas estabelecidas no rótulo, como podem ocorrer durante o transporte. Os resultados dos estudos acelerados nem sempre são indicativos de mudanças físicas e devem ser realizados após 0,3 e 6 meses a partir da fabricação (AGÊNCIA NACIONAL DE VIGILÂNCIA SANITÁRIA, 2005).

\subsection{ESTUDOS DE ESTABILIDADE DE LONGA DURAÇÃO}

Estudos projetados para verificação das características físicas, químicas, biológicas e microbiológicas de um produto farmacêutico, durante e depois do prazo de validade esperado. Os resultados são usados para estabelecer ou confirmar a vida média projetada e recomendar as condições de estocagem. $O$ estudo é realizado no período de: 0, 3, 6, 9, 12 e 24 meses, e anualmente após o primeiro ano até o tempo de vida de prateleira declarado no registro (AGÊNCIA NACIONAL DE VIGILÂNCIA SANITÁRIA, 2005).

\subsection{ESTUDOS DE ESTABILIDADE DE ACOMPANHAMENTO}

Estudos realizados para verificar que o produto farmacêutico mantém suas características físicas, químicas, biológicas, e microbiológicas conforme os estudos iniciais realizados. Para estudos de acompanhamento, as amostras devem ser testadas 1 lote anual para produção acima de 15 lotes e 1 lote a cada 2 anos para lotes abaixo de 15 lotes/ano (AGÊNCIA NACIONAL DE VIGILÂNCIA SANITÁRIA, 2005) 


\subsection{ESTUDO DE ESTABILIDADE NO TRANSPORTE}

O estudo de estabilidade no transporte tem por finalidade descobrir se possíveis variações de temperatura e umidade no transporte de medicamentos podem provocar perda da ação farmacológica (Teresa, Bishara, \& Seevers, 2004).

Considerando o tamanho do Brasil, a falta de infraestrutura adequada no transporte de produtos farmacêuticos faz com que o veículo que carregue este tipo de mercadoria passe por temperaturas externas adversas, especialmente quando um medicamento é fornecido entre várias zonas climáticas. A temperatura é sempre o foco principal dos estudos porque quase todos os produtos farmacêuticos e biotecnológicos são sensíveis à temperatura. Além disso, o transporte em condições controladas não é sempre confiável. Há um número de problemas que podem surgir:

- Sistemas de controle de temperatura podem funcionar mal;

- Sensores de temperatura podem estar com defeito;

- As condições atmosféricas podem ser sofrer mudanças imprevisíveis;

- A rota utilizada para o transporte pode não ser como planejada inicialmente;

- As informações sobre as condições reais de transporte podem ser incorretas;

- Acidentes podem causar perturbações;

- Procedimentos aduaneiros podem levar mais tempo do que o previsto; e

- Problemas na comunicação entre uma cadeia de empresas envolvidas no transporte podem acontecer, incluindo os carregadores, prestadores de serviços, transportadores aéreos, entre outros. Assim, o modo de transporte e as mudanças sazonais são variáveis que devem ser consideradas dentro da cadeia de transporte dos medicamentos (SINDICATO DAS INDÚSTRIAS FARMACÊUTICAS, 2015). 
Como decorrência dos vários problemas que podem estar sujeitos os medicamentos, em virtude da amplitude de temperatura, assim, a necessidade de estudo de estabilidade por parte do fabricante quanto à exposição a temperaturas diversas. (Teresa, Bishara, \& Seevers, 2004).

Os riscos associados ao produto incluem exposição à temperatura, umidade, luz e gases presentes no meio ambiente. As principais preocupações são as temperaturas extremas, às quais o produto poderá ser exposto durante armazenagem, transporte e manuseio. É recomendável observar as condições de temperatura nas diferentes estações do ano e a área geográfica do local de armazenamento. As condições de embalagem tornam-se fatores importantes, já que tais cuidados podem evitar exposição a temperaturas extremas, especialmente no caso de produtos sensíveis (CONSELHO REGIONAL DE FARMÁCIA, 2015).

Os medicamentos que exigem temperatura controlada ou condições especiais de armazenamento devem ser distribuídos de uma forma que se garanta que a qualidade dos produtos. A Cadeia a Frio entre $2-8^{\circ} \mathrm{C}$ é um método de distribuição e transporte de medicamentos com especificação de temperatura para a faixa de 2 a $8{ }^{\circ} \mathrm{C}$, ou, ainda, faixas abaixo de $0{ }^{\circ} \mathrm{C}$. Os medicamentos transportados são extremamente sensíveis à temperatura acima e/ou abaixo da faixa especificada, podendo ter sua qualidade e ação terapêutica seriamente comprometida. O transporte deste tipo de produto, com condições especiais de temperatura deve ser controlado e monitorado durante toda a cadeia logística, desde a indústria produtora, transportadora, centro de distribuição e consumo pelo cliente final, para garantir a rastreabilidade dos produtos em processo reverso (Encina, 2012). Existem parâmetros técnicos básicos que objetivam garantir a segurança e a qualidade dos produtos farmacêuticos em sua armazenagem, transporte e distribuição. As medidas implantadas devem ser validadas e todo o processo documentado, em um trabalho de aperfeiçoamento contínuo. (CONSELHO REGIONAL DE FARMÁCIA, 2015).

Outro fator importante é o tempo de exposição em que o produto é submetido às condições fora dos parâmetros. Os produtos termolábeis devem ser conservados de 2 - $8{ }^{\circ} \mathrm{C}$, acondicionados em embalagens apropriadas com elementos frios para sua conservação, e devido a essa peculiaridade, 
normalmente são utilizados trajetos curtos ou transporte aéreo para sua entrega. O uso de embalagens apropriadas faz com que o controle de temperatura, no âmbito da Cadeia a Frio seja facilitado, porém as recomendações quanto ao critério de aceitação são tão rigorosas quanto para os produtos conservados sob temperatura ambiente (INFARMA, 2007).

O uso de medidores de temperatura e umidade (termoigrômetros) é extremamente necessário, devendo a medição ser realizada dentro da área onde o produto farmacêutico é armazenado ou transportado. Os registros dessas medições deverão ser realizados com frequência apropriada para garantir a confiabilidade dos resultados do perfil climático, e esses dados deverão ser protegidos. Todos os equipamentos utilizados deverão ser calibrados periodicamente e rastreados pela Rede Brasileira de Calibração (CONSELHO REGIONAL DE FARMÁCIA, 2015).

\subsubsection{ESTUDO DE EXCURSÃO DE CURTO PRAZO OU CICLO DE EXCURSÃO TÉRMICA}

Os testes necessários para avaliar os efeitos de transporte no produto devem ser diferenciados dos testes destinados a avaliar o efeito das variações de temperatura fora dos limites de temperatura. $O$ fabricante define as condições de transporte após uma análise de risco, com base nos dados disponíveis a partir de sua experiência, para atestar que o produto atende aos requisitos de qualidade (Teresa, Bishara, \& Seevers, 2004).

O estudo de excursão de curto prazo ou ciclo de excursão térmica deve ser projetado para antecipar as variações de temperatura que podem ocorrer com o produto durante a sua distribuição até seu destino final, visando simular as condições ambientais e promover condições extremas de temperatura (tanto alta como baixa). Estes estudos devem ser executados na formulação final e na embalagem comercializada (Teresa, Bishara, \& Seevers, 2004).

Segundo os documentos do FDA e Teresa et al., se a temperatura de transporte for diferente da temperatura de armazenamento, os estudos de 
estabilidade deverão avaliar o impacto das variações de temperatura no transporte. Para atingir esse objetivo, pode ser necessário realizar testes para avaliar a adequação do transporte do produto em um ambiente com temperatura controlada.

A situação mais simples é quando os produtos são transportados entre dois locais, tais como o local de fabricação e local de distribuição. Neste caso, o fabricante pode simular as condições de transporte conhecendo-se as estradas percorridas e as variações de temperatura. Estudos clássicos usam dois perfis, um simulando condições de inverno e outro simulando condições de verão. $O$ produto é colocado em uma embalagem de transporte durante um período de tempo correspondente a mais longa duração de transporte. A temperatura é mantida em valores simulando temperaturas externas, obtidas de dados históricos meteorológicos. Uma situação especial ocorre quando o local de partida é no hemisfério norte e a localização na recepção é no hemisfério sul ou o inverso. Neste caso, deve ser utilizada uma mistura de condições de teste, simulando as reais condições sazonais nos locais de partida e de destino. Estes tipos de perfis são chamados de perfis de verão-inverno ou inverno-verão. Quando os perfis são definidos, o produto embalado em sua caixa de transporte é testado por um período definido nestas condições, a temperatura do produto deve manter-se dentro dos limites especificados em todos os momentos. Uma outra situação é representada pelo transporte de produtos a partir de um centro de distribuição para muitos locais que não possuem temperatura controlada, neste modelo, o fabricante não tem o controle total para assegurar que as instruções fornecidas para a central de distribuição sejam claras o suficiente para garantir a qualidade do produto (Ammann, 2011).

Segundo Teresa et al. (2004), o estudo de estabilidade de transporte poderá ser projetado considerando as condições de armazenamento descritas no ICH Q1D, em um ou mais lotes do produto (Tab. 7). Se ocorrerem mudanças na formulação ou na embalagem primária, estes estudos deverão ser repetidos, a não ser que se justifique cientificamente (Teresa, Bishara \& Seevers, 2004; WORLD HEALTH ORGANIZATION, 2004).

Tabela 7. Proposta de ciclo de excursão térmica (Teresa, Bishara, \& Seevers, 2004). 
Condição de armazenamento Condição de estudo/teste
$20-25{ }^{\circ} \mathrm{C}$
1) $-20^{\circ} \mathrm{C} / 2$ dias
$2-8{ }^{\circ} \mathrm{C}$
2) $60{ }^{\circ} \mathrm{C}$ e $75 \%$ UR / 2 dias
1) $-20^{\circ} \mathrm{C} / 2$ dias
2) $40{ }^{\circ} \mathrm{C}$ e $75 \%$ UR /2 dias

Tabela 8. Proposta de ciclo de excursão térmica - continuação (Teresa, Bishara, \& Seevers, 2004).

\begin{tabular}{cc}
\hline Condição de armazenamento & \multicolumn{1}{c}{ Condição de estudo/teste } \\
\hline$-20-10{ }^{\circ} \mathrm{C}$ & 1) $40^{\circ} \mathrm{C}$ e $75 \%$ UR/ 2 dias \\
& 2) $25^{\circ} \mathrm{C}$ e $60 \%$ UR/ 2 dias \\
\hline
\end{tabular}

Niazi (2004) sugere uma proposta de ciclo de excursão térmica diferente do descrito por Teresa et al:

- Medicamentos armazenados em temperatura entre 20 - $25{ }^{\circ} \mathrm{C}$ podem ser avaliados por três ciclos de dois dias em temperatura de $2-8^{\circ} \mathrm{C}$, seguido por dois dias sob condição de armazenamento a $40^{\circ} \mathrm{C}$;

- Medicamentos armazenados em temperatura $-20^{\circ} \mathrm{C}$ podem ser avaliados por três ciclos de dois dias em temperatura entre -10 e $-20^{\circ} \mathrm{C}$, seguido por 2 dias sob condição de armazenamento a $40^{\circ} \mathrm{C}$;

- Para aerossóis, são recomendados três ou quatro ciclos de seis horas por dia em temperatura entre $-20^{\circ} \mathrm{C}$ e $40{ }^{\circ} \mathrm{C}$ e $75-85 \%$ U.R, durante um período de até seis semanas (Niazi, 2004).

Em um exemplo de estudo de ciclo térmico de 52 dias, no transporte de testes para diagnóstico rápido para malária em alguns países de clima tropical (Nigéria, Uganda e Tailândia), foi constatado que dentro das embalagens, a temperatura variou entre $-3,5$ a $33,6{ }^{\circ} \mathrm{C}$ durante a viagem para Lagos (Nigéria), de $-2,3$ a $42,4{ }^{\circ} \mathrm{C}$ durante a viagem para Kampala (Uganda), e 1,9 a 37,5 ${ }^{\circ} \mathrm{C}$ durante a viagem a Bangkok (Tailândia) e a umidade relativa variou entre 20 e 88 \%. A temperatura dentro das embalagens de teste variou entre 3 a $12{ }^{\circ} \mathrm{C}$ acima da temperatura ambiente (British Medical Association, 1992). 
Em outro exemplo, ao longo de um período de 13 meses, a temperatura e umidade em testes rápidos para malária foram monitorados durante as cadeias logísticas de armazenamento e de transporte rodoviário e aéreo em Senegal, Burkina Faso e Filipinas. Os medicamentos foram enviados de um armazém central para diferentes vilarejos regionais. Em todos os três casos, a temperatura média manteve-se dentro dos limites aceitáveis (mínima de $22,1^{\circ} \mathrm{C}$ e máxima de $29,1^{\circ} \mathrm{C}$ ), com exceção de um trecho onde a temperatura máxima alcançou $41,5^{\circ} \mathrm{C}$. Os dados relativos às condições de transporte estão apresentados naTab. 8 (Albertini et al., 2012).

Tabela 9. Exemplo de condições de transporte e armazenamento para teste rápido para malária (Albertini et al., 2012).

\begin{tabular}{cccc}
\hline $\begin{array}{c}\text { Local de } \\
\text { armazenamento }\end{array}$ & $\begin{array}{c}\text { Faixa de } \\
\text { temperatura } \\
\left({ }^{\circ} \mathrm{C}\right)\end{array}$ & $\begin{array}{c}\text { Duração do } \\
\text { transporte }\end{array}$ & $\begin{array}{c}\text { Condições/ Tipo } \\
\text { de transporte }\end{array}$ \\
\hline
\end{tabular}

\section{Senegal}

Armazém regional médio/grande porte

$27,3-38,8$

25 horas

Armazém regional médio porte

$31,6-34,4$

2 horas

Armazém regional de pequeno/médio porte

1 hora

Armazém regional de pequeno porte

$31,1-42,9$

4 - 6 horas

\section{Burkina Faso}

Armazém regional central

$24,4-43,0$

$3-9$ horas

Armazém regional de médio porte

$$
\begin{gathered}
26,6-41,0 / \\
-3,2-32
\end{gathered}
$$

$3-9$ horas

\section{Filipinas}

Armazém regional central
Sem sistema de ar condicionado/

Caminhão

Sem sistema de ar condicionado/ Carro

Sem sistema de ar condicionado/ Carro

Sem sistema de ar condicionado/

Bicicleta

Sem sistema de ar condicionado/

Caminhão

Sem sistema de ar condicionado/

Caminhão

Sem sistema de ar condicionado/ 
Aéreo

Sem sistema de

Armazém regional

de pequeno porte

$24,6-32 \quad 1$ hora

ar condicionado/

Veículo de carga

leve

No estudo, apenas uma amostra das condições de transporte e armazenamento em cada país foi coletada, e portanto, os resultados não podem ser considerados totalmente representativos das condições às quais os medicamentos são transportados e armazenados, mas ilustram a falta de controle nas cadeias produtivas e potencial da temperatura e umidade diminuir a eficácia do medicamento (Albertini et al., 2012).

No Brasil, foi feito um levantamento pelas transportadoras de medicamentos de médio e grande porte, da variação de temperatura observada durante o trajeto de viagens que originadas na Grande São Paulo para as principais capitais do país, no período de 1961 a 1990 (Tab. 9).

Tabela 10. Levantamento das temperaturas média e máxima em trajetos de São Paulo até as principais capitais do Brasil no período de 1961-1990 (INFARMA, 2007).

\begin{tabular}{cccc}
\hline $\begin{array}{c}\text { Principais } \\
\text { capitais por } \\
\text { região }\end{array}$ & $\begin{array}{c}\text { Temperatura } \\
\text { média }\left({ }^{\circ} \mathrm{C}\right)\end{array}$ & $\begin{array}{c}\text { Temperatura } \\
\text { máxima }\left({ }^{\circ} \mathrm{C}\right)\end{array}$ & $\begin{array}{c}\text { Média de duração de } \\
\text { trajeto com origem em } \\
\text { São Paulo }\end{array}$ \\
\hline Norte & 22,7 & 32,0 & 254 horas \\
Manaus & 29,9 & 32,5 & 72 horas \\
Belém & & & \\
Nordeste & 29,0 & 36,9 & 72 horas \\
Teresina & 27,3 & 31,9 & 28 horas \\
São Luís & 26,7 & 30,9 & 60 horas \\
Recife & 27,5 & 30,8 & 72 horas \\
Fortaleza & 26,0 & 30,0 & 48 horas \\
Salvador & &
\end{tabular}

Centro-Oeste 


\begin{tabular}{|c|c|c|c|}
\hline Brasília & 23,5 & 28,9 & 24 horas \\
\hline Cuiabá & 27,9 & 34,2 & 36 horas \\
\hline Campo Grande & 24,8 & 31,0 & 36 horas \\
\hline Goiânia & 24,5 & 31,9 & 21 horas \\
\hline \multicolumn{4}{|l|}{ Sudeste } \\
\hline Rio de Janeiro & 26,8 & 30,4 & 6 horas \\
\hline Belo Horizonte & 23,8 & 29,1 & 12 horas \\
\hline \multicolumn{4}{|c|}{$\begin{array}{l}\text { Tabela 11. Levantamento das temperaturas média e máxima em trajetos de São } \\
\text { Paulo até as principais capitais do Brasil no período de 1961-1990 - continução } \\
\text { (INFARMA, 2007). }\end{array}$} \\
\hline $\begin{array}{l}\text { Principais } \\
\text { capitais por } \\
\text { região }\end{array}$ & $\begin{array}{c}\text { Temperatura } \\
\text { média }\left({ }^{\circ} \mathrm{C}\right)\end{array}$ & $\begin{array}{c}\text { Temperatura } \\
\text { máxima }\left({ }^{\circ} \mathrm{C}\right)\end{array}$ & $\begin{array}{l}\text { Média de duração de } \\
\text { trajeto com origem em } \\
\text { São Paulo }\end{array}$ \\
\hline \multicolumn{4}{|l|}{ Sul } \\
\hline Porto Alegre & 24,9 & 30,2 & 24 horas \\
\hline Florianópolis & 25,0 & 28,7 & 20 horas \\
\hline Curitiba & 20,9 & 26,9 & 6 horas \\
\hline
\end{tabular}

A temperatura de conservação e manuseio dos medicamentos recomendada é de 15 - $30 \stackrel{\circ}{\circ}$ (ANVISA, 2005), porém foram mostrados que capitais como Belém, Cuiabá, Manaus e Teresina apresentaram temperaturas acima de $32 \stackrel{\circ}{\circ}$ no período abordado. Existe falta de informações atualizadas das temperaturas nas capitais, todavia, os dados obtidos já fornecem pontos importantes para discussão, especialmente se considerarmos o aquecimento global ocorrido nas últimas décadas (INFARMA, 2007; INSTITUTO NACIONAL DE METEREOLOGIA, 2014).

Os cinco tipos de transporte brasileiros são: aéreo, ferroviário, aquaviário, dutoviário e rodoviário. A importância relativa de cada tipo pode ser medida pela distância coberta pelo sistema, pelo volume de tráfego, pelas vantagens e desvantagens. No Brasil, o modelo rodoviário, que passou a predominar no transporte no Brasil por oferecer rapidez e agilidade, possibilita retirada e entrega de mercadorias nas regiões mais distantes desde a última década do século $X X$. A malha rodoviária é elemento fundamental nas cadeias produtivas, pelo nível de 
integração atingido entre mercados produtores e os pontos de consumo, e promove a integração de estados, regiões, municípios, distritos e propriedade rurais (Stettiner, Nakamoto, Santos, Silva, \& Santos, 2011).

O transporte rodoviário brasileiro é composto por, aproximadamente, $1.300 .000 \mathrm{~km}$ de estradas, e, deste total, cerca de $390.000 \mathrm{~km}$ (30\%), apresentam problemas de estrutura e falta de conservação (estão danificados). Apenas $140.000 \mathrm{~km}$ (11\%) estão pavimentados e $770.000 \mathrm{~km}$ (59\%, ou seja, a maior parte) são de estradas de terra ou estradas com pavimentação quase inexistente. Vários fatores comprometem a qualidade das estradas. Por exemplo, durante a época de chuvas, grande parte das estradas brasileiras, a pavimentação fica deteriorada por falhas, fissuras, deformações, sendo comum, ainda que em menor quantidade, os deslizamentos de terra e as quedas de pontes, provocando prejuízos e atrasos para o transporte de cargas. A falta de boa infraestrutura gera problemas na rede logística de distribuição, como, por exemplo, aumento de desgastes nos veículos, avarias nas cargas transportadas, ampliação do tempo de viagem, comprometimento da logística, elevação de custos e aumento do risco da qualidade da carga em movimentação. No Brasil, conforme dados do Ministério dos Transportes (2012) 61,8\% de toda a carga é transportada por rodovias, e, consequentemente, esse tipo de transporte também é o mais utilizado para os medicamentos (Encina, 2012).

O transporte rodoviário de medicamentos em caminhões baú é o mais comum no transporte rodoviário nacional. Neste tipo de transporte, as diferenças nos valores de temperatura externa e interna, a temperatura ao qual fica submetido o veículo em movimento ou em estado estacionário, se fica sob ação da umidade do ar ou velocidade do vento, são estudos que podem ser realizados para determinar mais fielmente as condições críticas. Estudos realizados na Região Nordeste observaram que, em algumas áreas no interior do baú dos veículos, os valores de temperatura passam $50 \stackrel{\circ}{\mathrm{C}}$ e atingem $90 \%$ UR. No entanto, como já referido anteriormente, tais valores oscilam ao longo do ano e do percurso, o que dificulta fazer avaliações climáticas exatas do processo de transporte (INFARMA, 2007).

O transporte aéreo é o mais adequado para mercadorias de alto valor agregado e/ou pequenos volumes, ou com urgência na entrega. Estas 
características são integralmente aplicadas aos medicamentos. Este transporte possui algumas vantagens sobre os demais pela rapidez, segurança e redução do custo com o seguro. Suas desvantagens são a menor capacidade de carga, o valor do frete mais elevado em relação aos outros e o reduzido número de aeroportos disponíveis (Stettiner, Nakamoto, Santos, Silva, \& Santos, 2011). O transporte ferroviário não é ágil e possui reduzidas vias de acesso dentro do território nacional. Entretanto, este transporte de menor custo, propicia menor valor de frete, transporte de quantidades maiores e não é sujeito a riscos de congestionamentos de trânsito (Encina, 2012). O transporte aquaviário é o meio de transporte mais utilizado no comércio internacional e na Região Norte do Brasil. As vantagens são a maior capacidade de carga e o menor custo de transporte. Sua principal desvantagem é a necessidade de complexas instalações portuárias para embarcar e receber cargas (Stettiner et al., 2011).

\subsection{ENSAIOS REALIZADOS NO ESTUDO DE ESTABILIDADE}

\subsubsection{ESTABILIDADE TÉRMICA}

O teste de estabilidade térmica possibilita a caracterização de fármacos e produtos farmacêuticos, sendo possível identificar e quantificar os eventos de perdas de massas, e identificar os processos endotérmicos ou exotérmicos. Assim, as substâncias quando submetidas a tratamentos térmicos, podem sofrer transformações físicas e químicas tais como: fusão, recristalização e decomposição térmica. Em todos estes processos, ocorre a alteração de defeitos cristalinos na rede cristalina. As reações de decomposição térmica nos sólidos são processos onde os constituintes que pertencem à rede cristalina, após sofrerem tratamento térmico, desfazem-se e dão origem a outras substâncias. Estas transformações podem ocorrer mesmo abaixo do ponto de fusão normal do sólido, mesmo que as equações estequiométricas que as descrevem sejam simples, e frequentemente, ocorrem diversos estágios intermediários, o que requer bastante atenção nas análises cinéticas (Oliveira, Yoshida, \& Gomes, 2011). 


\subsubsection{OXIDAÇÃO}

A degradação oxidativa é uma das principais causas de instabilidade de fármacos, dentre os mais conhecidos e estudados têm-se os esteróides, antibióticos, vitaminas, óleos e gorduras. A oxidação envolve a remoção de um átomo eletropositivo, radical ou elétron, ou a adição de um átomo eletronegativo ou radical. Muitas oxidações são reações em cadeia, que procedem lentamente sob a influência do oxigênio molecular. Tal processo de reação é referido como uma auto-oxidação (Silva et al., 2009).

A estabilização de fármacos frente às condições oxidativas envolve a observação de um número de precauções durante a manufatura e estocagem. $\mathrm{O}$ oxigênio em recipientes farmacêuticos deve ser substituído por nitrogênio ou dióxido de carbono; assim como o contato com íons de metais pesados, que catalisam a oxidação, devem ser evitados e a estocagem deve ser a temperaturas reduzidas (Silva et al., 2009).

\subsubsection{FOTÓLISE}

Esta reação resulta da absorção de radiação pela substância ativa. As moléculas que absorvem a radiação podem ser os reagentes principais da reação fotoquímica ou os reagentes fotossensibilizadores. Neste caso, as moléculas transferem a energia absorvida da radiação para outras moléculas que participarão da reação. Praticamente, todas as substâncias terapeuticamente ativas são capazes de absorver radiações eletromagnéticas, situadas na região do espectro correspondente ao UV e visível. Os compostos com grupamentos cromóforos são mais sensíveis às radiações (LIEBERMAN \& KANIG, 2001).

A proteção da luz visível é mais difícil que a da luz UV, portanto, as substâncias cujos máximos de absorção se encontram mais próximas da luz visível serão mais fotolábeis em um produto farmacêutico, como por exemplo, fármacos ou medicamentos que possuem moléculas que contêm oxigênio, nitrogênio e/ou enxofre. Os compostos com grupos cromóforos, tais como nitro, 
nitroso, cetonas, sulfonas, duplas ou triplas ligações conjugadas também são sensíveis à radiação, tanto mais quanto maior o número desses cromóforos na molécula e especialmente se estão conjugados (Leite, 2005).

\subsubsection{HIDRÓLISE}

A água é considerada como um dos principais catalisadores em reações de degradação. Muitos fármacos são considerados como instáveis nesse meio e necessitam de intervenções durante a formulação e armazenamento, para que a eficácia e sua estabilidade e da forma farmacêutica final não sejam comprometidas. Para a avaliação da instabilidade sob a condição de hidrólise, também deve ser levado em consideração o pH do meio, pois íons hidrogênio e hidroxila podem acelerar ou retardar o processo de degradação (Ansel, Loyd, \& Popovich, 1999).

\subsection{ESTABILIDADE DE RADIOFÁRMACOS}

Cada radiofármaco exige um tipo de controle, segundo sua natureza, os ensaios de controle de qualidade são classificados em duas categorias: testes físico-químicos e biológicos. Na primeira categoria, incluem-se ensaios de pureza química, pureza radioquímicas, osmolaridade, $\mathrm{pH}$, condutividade e estado físico, principalmente em se tratando de um colóide, enquanto na segunda abrangem-se ensaios de esterilidade, apirogencidade e toxicidade (Andrade, Santos, \& Lima, 2011).

A estabilidade do radiofármaco é definida como o tempo durante no qual o radionuclídeo pode ser usado com segurança para a finalidade pretendida. Segundo a RDC 63/2009 (AGÊNCIA NACIONAL DE VIGILÂNCIA SANITÁRIA, 2009), para a comprovação de eficácia dos radiofármacos, devem ser efetuados ensaios de estabilidade, em que os radiofármacos são expostos a situações extremas para verificar sua eficácia. Os estudos de estabilidade radioquímica devem ser conduzidos para representar a utilização eficaz do medicamento. Os 
controles de pureza radioquímica (\% PRq) e radionuclídica são importantes ensaios a serem realizados nos estudos de estabilidade radiofarmacêuticas. Os métodos para avaliação da estabilidade do radiofármaco devem ser rápidos, de fácil execução, capaz de separar todos os componentes possíveis, sem mudanças na composição da amostra e precisos e sensíveis (Martins, 2011).

A determinação da \% PRq é um dos aspectos mais importantes no controle de qualidade de radiofármacos. A \% PRq pode ser definida como a fração da radioatividade total na forma química desejada presente no radiofármaco (Eq. 3 e 4). Os métodos analíticos mais usados para detectar e determinar as impurezas radioquímicas de um radiofármaco são: cromatografia em papel (CP), cromatografia em camada delgada (CCD ou TLC) e em gel, cromatografia líquida de alta eficiência (CLAE), extração por solvente e extração em fase sólida, que faz uso de cartuchos de extração (Saha, 2010).

$$
\begin{gathered}
\text { \% Impureza }=\frac{\text { Contagemde Radioativdade no } \mathrm{R}_{\mathrm{f}} \text { da impureza }}{\text { Contagemda Radioativdade Total }} \times 100 \\
\% \text { Pureza Radioquímica }=100-\% \text { Impurezas }
\end{gathered}
$$

Cromatografia é um método de separação dos componentes de uma mistura provocado pelas diferenças de afinidades (coeficientes de distribuição) entre a fase estacionária e a fase móvel (solvente). Os componentes mais fortemente retidos na fase estacionária movem-se mais lentamente, enquanto os componentes que se ligam mais fracamente à fase estacionária movem-se mais rapidamente. As diferentes solubilidades dos componentes fazem com que apresentem diferentes velocidades de migração ao longo do suporte. A polaridade do solvente também tem influência na separação cromatográfica dos componentes da amostra (Saha, 2010; Monteiro E. G., 2012)

Cada componente da amostra é caracterizado por um valor de $\mathbf{R}_{\mathbf{f}}$ (fator de retardamento), definido pela relação da distância percorrida por cada componente da amostra e a distância percorrida pelo solvente (Eq. 5) (Saha, 2010; Monteiro E. G., 2012). 


$$
R_{f}=\frac{\text { distância percorrida pela amostra }}{\text { distância percorrida pelo solvente }}
$$

Os métodos cromatográficos podem ser classificados conforme o meio físico em que está contida a fase estacionária. Na cromatografia planar, a fase estacionária é suportada sobre uma superfície plana ou nos interstícios de um papel. Na cromatografia planar, geralmente, a fase estacionária é mais polar que a fase móvel, com algumas aplicações com utilização da cromatografia de fase reversa, onde a fase estacionária é menos polar que a fase móvel (Saha, 2010; Monteiro E. G., 2012)

CP e CCD são técnicas que se baseiam na cromatografia por adsorção. adsorvente em cromatografia de papel é uma tira ou fita de papel pela qual ocorre a migração da fase móvel. Sistemas de solventes ascendente, descendente e horizontal podem ser usados, com o solvente movendo por capilaridade ou gravidade. Os componentes da amostra migram por apresentarem diferentes solubilidades nos solventes e diferentes atrações (adsorção) com a fibra do papel. O mecanismo de separação primária é o da partição, onde a celulose torna-se suporte da água adsorvida. Como o papel é feito de celulose, os componentes da amostra migram mais rapidamente quando são menos polares Whatman 1MM (W1MM) e Whatman 3MM (W3MM) são os papéis cromatográficos mais utilizados na prática da cromatografia. O papel W3MM tem algumas vantagens quando comparado ao W1MM: maior resistência mecânica aos solventes aquosos evitando que a fita rasgue ou despedace facilmente; permite a absorção de uma quantidade de amostra com menor espalhamento (Saha, 2010; Monteiro E. G., 2012)

Em CCD, a fase estacionária é uma camada delgada de adsorvente seco aplicada em alumínio, polímero ou vidro. Sílica gel e alumina são os adsorventes mais utilizados. O sistema de solvente é semelhante à CP. Para aumentar a velocidade de migração das fases móveis, alguns materiais foram desenvolvidos e ganharam aceitação mundial, como foi o caso das fitas de instant thin layer chromatography (ITLC). Esta fase estacionária é composta de fibra de vidro impregnada com sílica modificada, conhecido como sílica-gel (ITLC-SG) ou ácido silicílico (ITLC-SA). A cromatografia de camada delgada de alta eficiência (CCDAE ou em inglês high performance thin layer chromatography (HPTLC) 
apresenta resolução comparável à CLAE. CCDAE é especialmente útil para amostras com pouco volume. As propriedades das placas de CCDAE que diferem das placas de TLC convencionais são: partículas de sílica de 5-6 $\mu \mathrm{m}$, comparadas com 10-12 um usadas em placas de CCD; partículas e espessura de filme menores $(200 \mu \mathrm{m})$ proporcionam melhor separação que em placas convencionais. As bandas de difusão das amostras são reduzidas e há aumento de sensibilidade e redução de tempo de análises (Zolle, 2007 apud Monteiro E. G., 2012).

Ambos, CP e CCD são de fácil desenvolvimento e de baixo custo quando comparada à CLAE, mas apresentam resolução menor. A velocidade de separação dos analitos por CP e CCD pode variar de minutos até dias, dependendo dos compostos a serem separados, do grau de pureza desejado, bem como das propriedades do solvente e adsorvente e das condições operacionais do sistema. Alguns aspectos devem ser considerados antes e durante a realização do ensaio: tamanho da gota, condições do suporte cromatográfico e pureza do solvente (Saha, 2010; Monteiro E. G., 2012).

As impurezas químicas ou radioquímicas podem ser resultantes da degradação das matérias-primas ou do produto armazenado, sob condições adversas do insumo farmacêutico, ou pela reação com um excipiente e/ou com a embalagem primária e também pela ação do tempo e/ou pela ação de agentes externos, a saber: luz, temperatura, pH, umidade (Saha, 2010):

- Pertecnetato livre $\left({ }^{99 m} \mathrm{TcO}_{4}{ }^{-}\right)$: Impureza produzida quando o pertecnetato de sódio adicionado não se complexa com o fármaco, ficando livre em solução (Zolle, 2007 apud Monteiro E. G., 2012);

- Tecnécio coloidal $\left({ }^{99 m} \mathrm{TcO}_{2}\right)$ : Impureza produzida quando durante a reação de complexação/marcação com o fármaco, o ${ }^{99 \mathrm{~m}} \mathrm{TcO}_{4}{ }^{-}$se estabiliza em um estado de oxidação menor, formando um colóide (Zolle, 2007 apud Monteiro E. G., 2012). 


\section{MATERIAIS E MÉTODOS}

\subsection{MATERIAIS}

Os RL e o gerador de ${ }^{99} \mathrm{Mo} /{ }^{99 m}$ Tc utilizados foram produzidos e obtidos do Centro de Radiofármacia, IPEN-CNEN/SP:

- CIS-TEC, DEX-70-TEC, DEX-500-TEC, DISI-TEC, DMSA-TEC, DTPA-TEC, ECD-TEC, FITA-TEC, MDP-TEC, MIBI-TEC, PIRO-TEC, PUL-TEC, SAH-TEC e TIN-TEC.

- Suportes cromatográficos (Tab.10) e solventes.

Tabela 12. Tipos e dimensões de suportes cromatográficos (Monteiro E. G., 2012).

\begin{tabular}{cc}
\hline Tipo de suporte & Dimensões - comprimento x largura (cm) \\
\hline TLC-SG & $12,5 \times 1,5 ; 17,5 \times 1,5$ \\
TLC-SG fase reversa & $12,5 \times 1,5$ \\
HPTLC - Celulose & $9,0 \times 1,0$ \\
ITLC-SG & $17,5 \times 1,5$ \\
W3MM & $8,0 \times 1,0 ; 12,5 \times 1,5$ \\
W1MM & $17,5 \times 1,5$ \\
\hline
\end{tabular}

Os solventes utilizados em CP e CCD foram:

- Acetonitrila, Ácido acético glacial, Acetato de etila, Acetona, Etanol, Metanol, Tetraidrofurano, da Merck Millipore

As soluções foram preparadas com água purificada:

- Ácido acético 0,5 mol L-1, Acetato de amônio 0,5 $\mathrm{mol} \mathrm{L}^{-1}$, Metanol 70\% (v/v), Metanol 85\% (v/v), $\mathrm{NaCl}$ 0,9\% (p/v) NaCl 20\% (p/v), $\mathrm{NaCl} 30 \%$ (p/v).

Os equipamentos utilizados foram:

- Purificador de água Elix 10 Merck Millipore.

- Câmara de ionização Capintec modelo CRC-35R. 
- Banho de bloco Mol-Image modelo Hot Pot.

- Contador gama Perkin Elmer modelo Cobra D-5002.

- Câmara climática Weiss Gallemkamp acoplada a reservatório de água purificada/ circulador/ purificador, com filtro deionizador e luz UV Fistreem Aquarec UV.

- Gama câmara Nucline TH 22 Mediso.

\subsection{MÉTODOS}

O trabalho consistiu em duas partes conforme a tab 7 , na primeira foi realizado o monitoramento da temperatura no interior de duas embalagens utilizadas para acondicionamento de alguns radiofármacos, produzidos pelo $\mathrm{CR}$ do IPEN para avaliação da temperatura quando submetidos à determinada temperatura e umidade externas, e na segunda parte foi avaliada a pureza radioquímica (\% $\mathrm{PRq}$ ) de vários $\mathrm{RL}$ marcados com $99 \mathrm{~m}$ Tc, após serem submetidos a uma temperatura e umidade superiores à temperatura descrita na bula dos mesmos, recomendada para a conservação da estabilidade dos produtos.

No monitoramento da temperatura no interior da embalagem secundária utilizada no FG-IPEN e na embalagem de transporte do CIS-TEC e ECD-TEC, foi colocado um dispositivo de monitoramento no formato de uma bateria (Fig. 5) no interior da caixa acrílica. A temperatura foi monitorada por 24 horas. Após o término do tempo de exposição, o dispositivo de monitoramento foi colocado em um acessório de leitura, e o software permitiu visualizar o perfil de temperatura a que foi submetido o dispositivo.

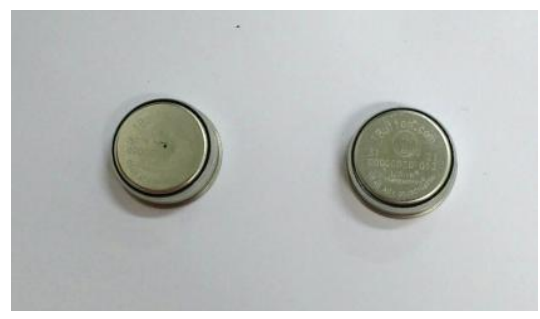

Figura 7. Dispositivo para monitoramento de temperatura. 
O monitoramento de temperatura foi feito no interior da blindagem de chumbo utilizada para acondicionar o radiofármaco FG-IPEN, que consiste de uma blindagem de chumbo, e é revestida com um material plástico. A segunda embalagem monitorada foi a embalagem pequena de isopor disponível comercialmente e utilizada para despacho dos RL de CIS-TEC e ECD-TEC, juntamente com uma barra de gelo reciclável.

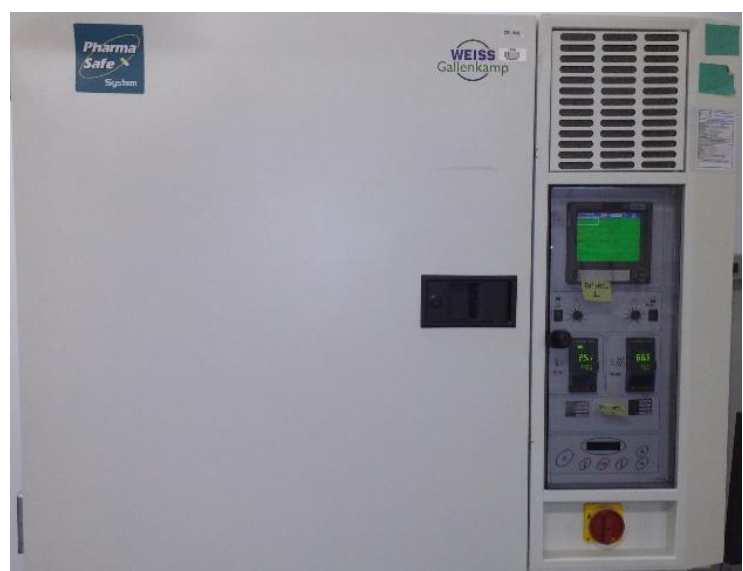

Figura 8. Câmara climática

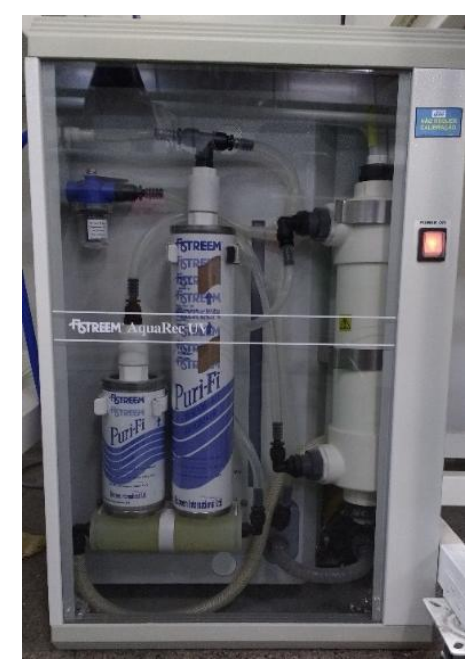

Figura 9. Reservatório/circulador/purificador de água acoplada à câmara climática. Contém filtros de purificação e luz UV.

Para condicionamento da temperatura e umidade, foi utilizada uma câmara climática Weiss Gallenkamp da PharmaSafe, qualificada (Fig. 6), acoplada a um reservatório/ circulador/ purificador de água (Fig. 7).

Na segunda parte do trabalho, frascos dos RL CIS-TEC, DEX-500-TEC, DEX-70, DISI-TEC, DMSA-TEC, DTPA-TEC, ECD-TEC, FITA-TEC, PIRO-TEC, PUL-TEC, MDP-TEC, SAH-TEC e TIN-TEC, cujas composições estão relacionadas na Tab. 11, foram colocados no interior da câmara climática (Fig. 10) para expor condição de temperatura e umidade descritos na Tab. 15. 


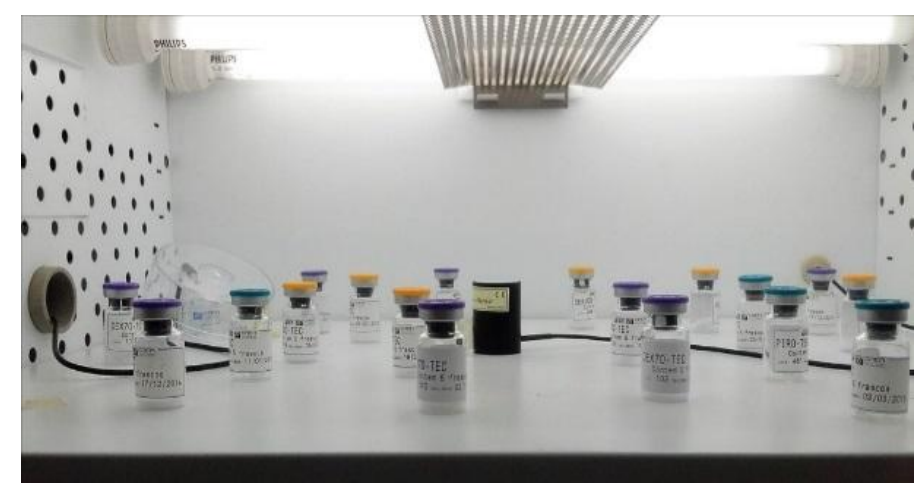

Figura 10. Representação da disposição de frascos de $R L$ no interior da câmara de climática (não foi utilizada iluminação durante o período de exposição dos frascos).

Tabela 13. Composição de alguns $R L$ produzidos no $C R$, IPEN e utilizados neste trabalho.

\begin{tabular}{|c|c|c|}
\hline $\mathbf{R L}$ & Composição & Massa (mg) \\
\hline \multirow{4}{*}{ CIS-TEC } & Etilenodicisteína & 0,50 \\
\hline & $\mathrm{Na}_{2} \mathrm{HPO}_{4}$ & 10,00 \\
\hline & $\mathrm{Na}_{3} \mathrm{PO}_{4} \cdot 12 \mathrm{H}_{2} \mathrm{O}$ & 45,00 \\
\hline & $\mathrm{SnCl}_{2} \cdot 2 \mathrm{H}_{2} \mathrm{O}$ & 0,30 \\
\hline \multirow{2}{*}{ DEX-500-TEC } & Dextran 500 & 100,00 \\
\hline & $\mathrm{SnCl}_{2} \cdot 2 \mathrm{H}_{2} \mathrm{O}$ & 1,50 \\
\hline \multirow{2}{*}{ DEX-70-TEC } & Dextran 70 & 50,00 \\
\hline & $\mathrm{SnCl}_{2} \cdot 2 \mathrm{H}_{2} \mathrm{O}$ & 0,75 \\
\hline \multirow{3}{*}{ DISI-TEC } & Disofenina & 20,00 \\
\hline & $\mathrm{SnCl}_{2} \cdot 2 \mathrm{H}_{2} \mathrm{O}$ & 0,50 \\
\hline & Ácido dimercaptosuccínico & 1,00 \\
\hline \multirow{3}{*}{ DMSA-TEC } & Ácido ascórbico & 0,70 \\
\hline & Inositol & 50,00 \\
\hline & $\mathrm{SnCl}_{2} \cdot 2 \mathrm{H}_{2} \mathrm{O}$ & 0,44 \\
\hline \multirow{4}{*}{ DTPA-TEC } & Ácido dietilenotriaminopentacético & 10,00 \\
\hline & Ácido p-aminobenzóico & 2,00 \\
\hline & $\mathrm{SnCl}_{2} \cdot 2 \mathrm{H}_{2} \mathrm{O}$ & 1,00 \\
\hline & Éster de dietilenodicisteína & 1,00 \\
\hline \multirow{3}{*}{ ECD-TEC } & Manitol & 24,00 \\
\hline & EDTA & 0,36 \\
\hline & $\mathrm{SnCl}_{2} \cdot 2 \mathrm{H}_{2} \mathrm{O}$ & 0,12 \\
\hline \multirow[t]{2}{*}{ FITA-TEC } & Ácido fítico & 20,00 \\
\hline & $\mathrm{SnCl}_{2} \cdot 2 \mathrm{H}_{2} \mathrm{O}$ & 1,00 \\
\hline
\end{tabular}


Tabela 11. Composição de alguns $R L$ produzidos no $C R$, IPEN e utilizados neste trabalho - continuação.

\begin{tabular}{|c|c|c|}
\hline$\overline{\mathbf{R L}}$ & Composição & Massa (mg) \\
\hline \multirow{3}{*}{ MDP-TEC } & Ácido medrônico & 10,00 \\
\hline & $\mathrm{SnCl}_{2} .2 \mathrm{H}_{2} \mathrm{O}$ & 1,20 \\
\hline & Ácido p-aminobenzóico & 2,00 \\
\hline \multirow{4}{*}{ MIBI-TEC } & Tetrafluorborato tetramibi cuproso & 1,00 \\
\hline & Cloridrato de cisteína monoidratada & 5,00 \\
\hline & Manitol & 20,00 \\
\hline & $\mathrm{SnCl}_{2} .2 \mathrm{H}_{2} \mathrm{O}$ & 0,10 \\
\hline \multirow{6}{*}{ PUL-TEC } & Macroagregado de albumina & 2,20 \\
\hline & $\mathrm{SnCl}_{2} \cdot 2 \mathrm{H}_{2} \mathrm{O}$ & 0,22 \\
\hline & Ácido ascórbico & 4,60 \\
\hline & Glicose & 18,70 \\
\hline & Acetato de sódio & 22,00 \\
\hline & Cloreto de sódio & 8,10 \\
\hline \multirow{2}{*}{ PIRO-TEC } & Pirofosfato de sódio & 10,00 \\
\hline & $\mathrm{SnCl}_{2} \cdot 2 \mathrm{H}_{2} \mathrm{O}$ & 2,00 \\
\hline \multirow{3}{*}{ SAH-TEC } & Albumina humana & 10,00 \\
\hline & $\mathrm{SnCl}_{2} \cdot 2 \mathrm{H}_{2} \mathrm{O}$ & 0,04 \\
\hline & Fluoreto estanoso & 0,125 \\
\hline \multirow[t]{2}{*}{ TIN-TEC } & Fluoreto de sódio & 1,00 \\
\hline & Povidona & 0,45 \\
\hline
\end{tabular}

Tabela 12. Condições de tempo, temperatura e umidade aplicados aos $R L$ em câmara climática.

\begin{tabular}{lcc}
\hline Tempo (dias) & Temperatura e umidade & Embalagem \\
\hline 2 dias & $40{ }^{\circ} \mathrm{C} / 75 \%$ UR & Primária \\
\hline O eluato de ${ }^{99 \mathrm{~m}} \mathrm{TcO}_{4}{ }^{-}$foi obtido pela eluição do gerador de ${ }^{99} \mathrm{Mo} /{ }^{99 m} \mathrm{Tc}$. Para \\
análise da \% PRq e biodistribuição, foi feita a marcação de um ou dois frascos do \\
$\mathrm{RL}$ com o eluato do gerador, de modo a obter as máximas atividades definidas na \\
bula dos produtos 1853,3710 e $11100 \mathrm{MBq}$ em & $3-5 \mathrm{~mL}$ & (INSTITUTO DE \\
PESQUISAS ENERGÉTICAS E NUCLEARES, 2015). Preferencialmente, ambos \\
controles foram realizados a partir de um único frasco do RL marcado. A Fig. 9 \\
representa o fluxuograma simplificado de marcação dos $\mathrm{RL} \mathrm{com}{ }^{99 \mathrm{~m}} \mathrm{TcO}{ }_{4}^{-}$ \\
(Monteiro, 2012, adaptada).
\end{tabular}




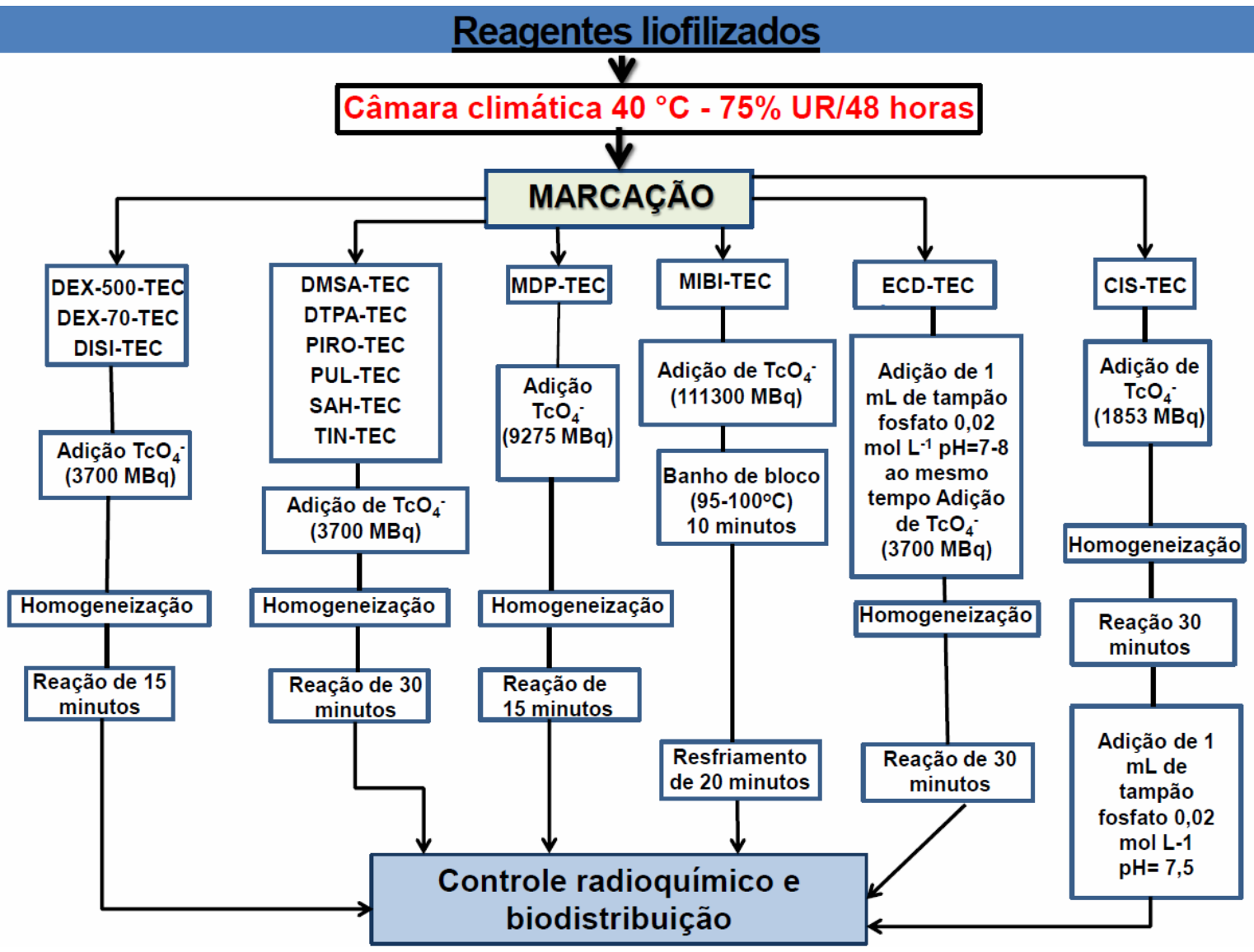

Figura 11. Esquema geral das condições de marcação de $R L$ com eluato de ${ }^{99 \mathrm{~m}^{\mathrm{TCO}}}{ }_{4}^{-}$(Almeida, 2009, adaptada).

O controle radioquímico para determinação das impurezas $\left(\%{ }^{99 \mathrm{~m}} \mathrm{TcO}_{2}\right.$, $\%{ }^{99 \mathrm{~m}} \mathrm{TcO}_{4}{ }^{-}$) e \%PRq foi realizado com os sistemas relacionados na Tab. 13. As fitas cromatográficas foram cortadas em segmentos de um $\mathrm{cm}$ cada e a radioatividade (cpm) em cada um dos segmentos foi contada em contador gama Perkin Elmer modelo Cobra D-5002.

A \% PRq foi determinada pelo cálculo \% Impureza (Eq. 3) e pela equação de balanço de massa (Eq. 4). Os resultados foram expressos com a média \pm considerando análises em duplicata de dois frascos, quando foram utilizados 2 frascos e triplicata de um frasco, para marcação com mais de $11100 \mathrm{Mbq}$, em cada um dos tempos de marcação do RL com 99m Tc. 
Tabela 14. Sistemas cromatográficos para determinar as impurezas ${ }^{99 m} \mathrm{TcO}_{4}{ }^{-}$e/ou ${ }^{99 \mathrm{~m}} \mathrm{TcO}_{2}$ no controle radioquímico de $\mathrm{RL}$ (IPEN).

\begin{tabular}{|c|c|c|c|c|}
\hline Produto & Impureza & Rf & $\begin{array}{c}\text { Suporte } \\
\text { (fase estacionária) }\end{array}$ & $\begin{array}{c}\text { Solvente } \\
\text { (fase móvel) }\end{array}$ \\
\hline \multirow{3}{*}{ CIS-TEC } & ${ }^{99 m} \mathrm{TcO}_{4}^{-}$ & 1,0 & ITLC-SG & Acetona \\
\hline & ${ }^{99 m} \mathrm{TcO}_{2}$ & 0,0 & ITLC-SG & Ácido acético 0,5 M \\
\hline & ${ }^{99 \mathrm{~m}} \mathrm{TcO}_{2}$ & 0,0 & TLC-SG & $\mathrm{NaCl} 0,9 \%$ \\
\hline \multirow{2}{*}{ DISI-TEC } & ${ }^{99 m} \mathrm{TcO}_{4}^{-}$ & 1,0 & Whatman 3MM & $\mathrm{NaCl} 30 \%$ \\
\hline & ${ }^{99 m} \mathrm{TcO}_{2}$ & 0,0 & HPTLC-Celulose & Metanol 85\% \\
\hline \multirow{2}{*}{ DTPA-TEC } & ${ }^{99 m} \mathrm{TcO}_{4}^{-}$ & 1,0 & Whatman 3MM & Acetona \\
\hline & ${ }^{99 m} \mathrm{TcO}_{2}$ & 0,0 & Whatman 3MM & $\mathrm{NaCl} 0,9 \%$ \\
\hline \multirow{2}{*}{ ECD-TEC } & ${ }^{99} \mathrm{~m}_{\mathrm{TcO}_{4}}^{-}$ & 1,0 & TLC-SG & $\mathrm{NaCl} 20 \%$ \\
\hline & ${ }^{99 m} \mathrm{TcO}_{2}$ & 0,0 & HPTLC-Celulose & Acetato de etila: etanol (3:7) \\
\hline FITA-TEC & ${ }^{99} \mathrm{TcO}_{4}^{-}$ & 1,0 & Whatman 3MM & Metanol 85\% \\
\hline \multirow{2}{*}{ MDP-TEC } & ${ }^{99 \mathrm{~m} \mathrm{TcO}_{4}{ }^{-}}$ & 1,0 & Whatman 3MM & Acetona \\
\hline & ${ }^{99 m} \mathrm{TcO}_{2}$ & 0,0 & Whatman 3MM & $\mathrm{NaCl} 0,9 \%$ \\
\hline \multirow{2}{*}{ MIBI-TEC } & ${ }^{99 \mathrm{~m}} \mathrm{TcO}_{4}{ }^{-}$ & $0,9-1,0$ & TLC-SG 60 fase & Acetonitrila: metanol: acetato \\
\hline & ${ }^{99 m} \mathrm{TcO}_{2}$ & 0,0 & reversa & tetaidrofurano $(4: 3: 2: 1)$ \\
\hline \multirow{2}{*}{ PIRO-TEC } & ${ }^{99 m} \mathrm{TcO}_{4}^{-}$ & 1,0 & Whatman 3MM & Acetona \\
\hline & ${ }^{99 \mathrm{~m}} \mathrm{TcO}_{2}$ & 0,0 & HPTLC-Celulose & $\mathrm{NaCl} 0,9 \%$ \\
\hline PUL-TEC & ${ }^{99 \mathrm{~m}_{\mathrm{TcO}}{ }^{-}}$ & 1,0 & Whatman 3MM & Metanol 70\% \\
\hline SAH-TEC & ${ }^{99 \mathrm{~m}_{\mathrm{TcO}}{ }^{-}}$ & 1,0 & TLC-SG & Acetona \\
\hline
\end{tabular}

Na Tab. 14 estão relacionados os $R L$, os respectivos limites especificados nas farmacopeias e no IPEN para a \% PRq e a condição de armazenamento utilizada no estudo de estabilidade e estabelecida pelo IPEN para obtenção da \% PRq especificada.

Tabela 15. Limites de \% PRq e a condição de armazenamento para os RL.

\begin{tabular}{cccc}
\hline Produto & $\%$ PRq & Referência & $\begin{array}{c}\text { Condição de } \\
\text { armazenamento } \\
\text { IPEN }\end{array}$ \\
\hline $\begin{array}{c}\text { CIS-TEC; DEX-500-TEC; } \\
\text { DEX-70-TEC; DMSA-TEC; FITA- } \\
\text { TEC }\end{array}$ & $\geq 90 \%$ & IPEN & $2-8{ }^{\circ} \mathrm{C}$ \\
\hline
\end{tabular}


Tabela 14. Limites de \% PRq e a condição de armazenamento para os RL continuação.

\begin{tabular}{cccc}
\hline Produto & $\%$ PRq & Referência & $\begin{array}{c}\text { Condição de } \\
\text { armazenamento } \\
\text { IPEN }\end{array}$ \\
\hline $\begin{array}{c}\text { DISI-TEC; DTPA-TEC; MDP-TEC; } \\
\text { MIBI-TEC; PIRO-TEC; PUL-TEC } \\
\text { ECD-TEC }\end{array}$ & $\geq 90 \%$ & USP & \\
SAH-TEC; TIN-TEC & & FI & $2-8^{\circ} \mathrm{C}$ \\
\hline
\end{tabular}

USP: Farmacopeia Americana; FI: Farmacopeia Internacional; FE: Farmacopeia Europeia

Os ensaios de controle biológico foram realizados pelo controle de qualidade do $\mathrm{CR}$ em ratos Wistar ou camundongos Swiss obtidos do biotério do IPEN-CNEN/SP. Após o tempo de reação para obtenção do RL marcado com ${ }^{99 \mathrm{~m}}$ Tc (Fig. 9, fluxograma de marcação), o radiofármaco foi injetado nos animais, e aguardou-se o tempo necessário para a biodistribuição. Os animais foram mantidos anestesiados para a obtenção das imagens cintilográficas, que foram obtidas em gama câmara. A atividade em cada um dos órgãos foi medida em câmara de ionização. Os resultados foram expressos como média \pm desvio padrão da \% Dose Injetada (\%DI) nos diferentes órgãos. Esse procedimento foi realizado de acordo com a instrução de trabalho do centro de radiofarmácia para verificar a distribuição biológica em animais, na tabela 16 indica cálculo para o limite de aceitação em \% de dose injetada. (INSTITUTO DE PESQUISAS ENERGÉTICAS E NUCLEARES, 2015). 
Tabela 16. Limites de aceitação para a biodistribuição nos órgãos (\%DI) para cada um dos $\mathrm{RL}$ marcados com $99 \mathrm{~m}$ Tc e as respectivas referências (IPEN).

\begin{tabular}{|c|c|c|c|}
\hline \multirow{2}{*}{$\frac{\text { Produto }}{\text { CIS-TEC }}$} & \multicolumn{2}{|c|}{ Limites de aceitação (\%D.I.) } & \multirow{2}{*}{$\frac{\text { Referência }}{\text { IEAE }}$} \\
\hline & $\%$ D.I. rins $+\%$ D.I. bexiga $\geq 80$ & $\%$ D.I. fígado $\leq 5$ & \\
\hline DISI-TEC & $\begin{array}{c}\% \text { D.I. intestino } \geq 75 \\
\% \text { D.I. fígado } \leq 10\end{array}$ & $\%$ D.I. rins $\leq 5$ & $\mathrm{FI}$ \\
\hline DMSA-TEC & $\begin{array}{l}\% \text { D.I. rins } \geq 40 \\
\% \text { D.I. fígado } \leq 10\end{array}$ & \% D.I Rins/(\% D.I fígado+/\% baço) $\geq 6$ & IAEA \\
\hline DTPA-TEC & $\%$ D.I. (rins + bexiga) $\geq 65$ & $\%$ D.I. fígado $\leq 1$ & USP \\
\hline FITA-TEC & $\%$ D.I. fígado + baço $\geq 80$ & $\%$ D.I. pulmão $\leq 5$ & IAEA \\
\hline MDP-TEC & $\begin{array}{l}\% \text { D.I. fêmur } \geq 1 \\
\% \text { D.I. fígado } \leq 5\end{array}$ & $\%$ D.I. rins $\leq 5$ & USP \\
\hline MIBI-TEC & $\begin{array}{l}\text { \% D.I./g coração/ \% D.I./g pulmão > } 7 \\
\% \text { D.I./g coração/ \% D.I./g sangue > } 10\end{array}$ & \% D.I./g coração/ \%D.I./g músculo > 4 & IAEA \\
\hline TIN-TEC & $\%$ D.I. (fígado + baço) $\geq 80$ & $\%$ D.I. pulmão $\leq 5$ & IAEA \\
\hline
\end{tabular}

IAEA: Agência Internacional de Energia Atômica; IPEN: Instituto de Pesquisas Energética e Nucleares; EP: Farmacopeia Europeia; FI: Farmacopeia Internaciol; USP: Farmacopeia Americana. 
$\mathrm{Na}$ Tab.17 estão relacionados os ensaios que foram realizados para avaliação da estabilidade dos $\mathrm{RL}$. A estabilidade do radiofármaco foi avaliada comparando os resultados de \% PRq e biodistribuição obtidos imediatamente após a produção, para a liberação do lote e após a exposição à $40{ }^{\circ} \mathrm{C}$ e $75 \%$ UR por 48 horas. A Tab. 17 relaciona os meses após a fabricação em que os $\mathrm{RL}$ foram analisados.

Tabela 17. Validade dos reagentes liofilizados.

\begin{tabular}{cc}
\hline Reagentes Liofilzados & Validade (meses) \\
\hline CIS-TEC & 3 \\
DISI-TEC, DMSA-TEC,DTPA-TEC, \\
DEX-500-TEC, DEX-70-TEC, \\
PUL-TEC, MDP-TEC, PIRO-TEC, PUL- \\
TEC e TIN-TEC & 6 \\
ECD-TEC, MIBI-TEC, SAH-TEC & 12 \\
\hline
\end{tabular}

Tabela 18. Condição de experimentos para avaliar a estabilidade dos $\mathrm{RL}$, após exposição a $40{ }^{\circ} \mathrm{C}$ de temperatura e $75 \%$ umidade, por 48 horas.

\begin{tabular}{ccc}
\hline Condição & Período de análise & Ensaios \\
\hline 1 & Imediatamente após a produção, para a liberação & \\
do lote & \\
2 & Após alguns meses de fabricação, \\
após colocar na câmara climática & Pureza \\
& Após alguns meses de fabricação, & radioquímica e \\
& após colocar na câmara climática, & Biodistribuição \\
& e ser mantido em temperatura de $2-8{ }^{\circ} \mathrm{C}$ até a & \\
\end{tabular}

Tabela 19. Período após a fabricação em que os $\mathrm{RL}$ foram analisados

\begin{tabular}{ccc}
\hline $\mathbf{R L}$ & $\begin{array}{c}\text { No. lotes analisados } \\
\text { (total) }^{*}\end{array}$ & Meses após a fabricação do $\mathbf{R L}$ \\
\hline CIS-TEC & 1 & $9^{\circ}$ mês \\
DEX-500-TEC & 3 & $1^{\circ}$ mês \\
DEX-70-TEC & 2 & $3^{\circ}, 4^{\circ}$ mês \\
\hline
\end{tabular}


Tabela 20. Período após a fabricação em que os $R L$ foram analisados continuação.

\begin{tabular}{ccc}
\hline Condição & Período de análise & Ensaios \\
\hline DISI-TEC & 2 & $6^{\circ}$ mês, $6^{\circ}$ mês \\
DMSA-TEC & 3 & $3^{\circ}$ mês, $2^{\circ}$ mês, $3^{\circ}$ mês, \\
DTPA-TEC & 3 & $5^{\circ}$ mês, $3^{\circ}$ mês, $6^{\circ}$ mês \\
ECD-TEC & 3 & $3^{\circ}$ mês, $4^{\circ}$ mês, $5^{\circ}$ mês \\
MDP-TEC & 2 & $1^{\circ}$ mês, $6^{\circ}$ mês \\
MIBI-TEC & 3 & $1^{\circ}$ mês, $3^{\circ}$ mês, $5^{\circ}$ mês, \\
PIRO-TEC & 3 & $1^{\circ}$ mês, $6^{\circ}$ mês \\
PUL-TEC & 3 & $1^{\circ}$ mês, $1^{\circ}$ mês, $2^{\circ}$ mês, $6^{\circ}$ mês \\
SAH-TEC & 2 & $3^{\circ}$ mês, $8^{\circ}$ mês \\
TIN-TEC & 2 & $3^{\circ}$ mês, $2^{\circ}$ mês \\
\hline
\end{tabular}

* Cada lote foi analisado uma única vez. 


\section{RESULTADOS E DISCUSSÃO}

\subsection{MONITORAMENTO DA TEMPERATURA NO INTERIOR DE EMBALAGEM UTILIZADA}

Com o objetivo de conhecer a temperatura que a embalagem primária de um radiofármaco é submetido quando a temperatura externa é elevada, a blindagem de chumbo utilizada como embalagem secundária de radiofármacos para PET foi colocada em uma câmara climática conforme mostra a Fig. 10.

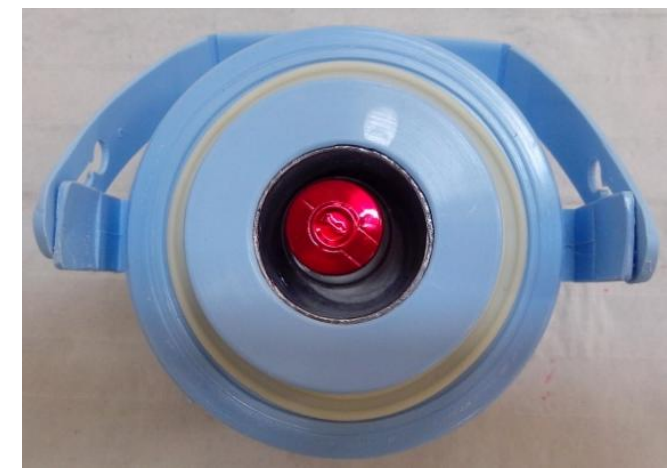

Vista superior

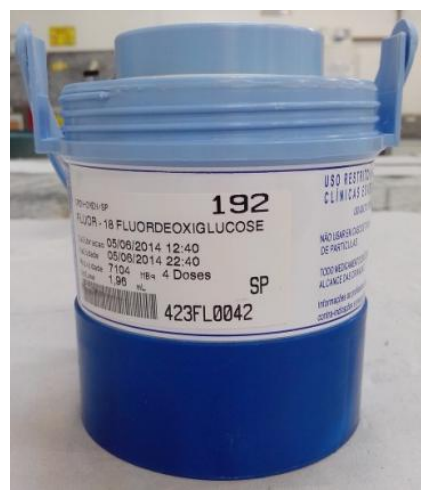

Vista lateral

Figura 12. Embalagem secundária para envio de radiofármacos utilizados em exames PET, mostrando a posição em que fica o frasco de embalagem primária, e onde foi colocado o sensor de temperatura.

O objetivo do experimento foi verificar se a embalagem de chumbo atuava como isolante, atenuando a temperatura durante o transporte, por exemplo, para locais no Brasil onde a temperatura máxima média é superior a $30^{\circ} \mathrm{C}$ (fig. 4 e tab. 9 que relaciona dados de temperatura máxima média). A embalagem de chumbo, colocada por 48 horas a $40{ }^{\circ} \mathrm{C}$ e $75 \%$ UR em câmara climática, com o sensor de temperatura posicionado no local em que é colocado o frasco do radiofármaco. 
O perfil de temperatura no interior da embalagem sem e com a colocação da tampa estão representados nas Fig.11 e 12.

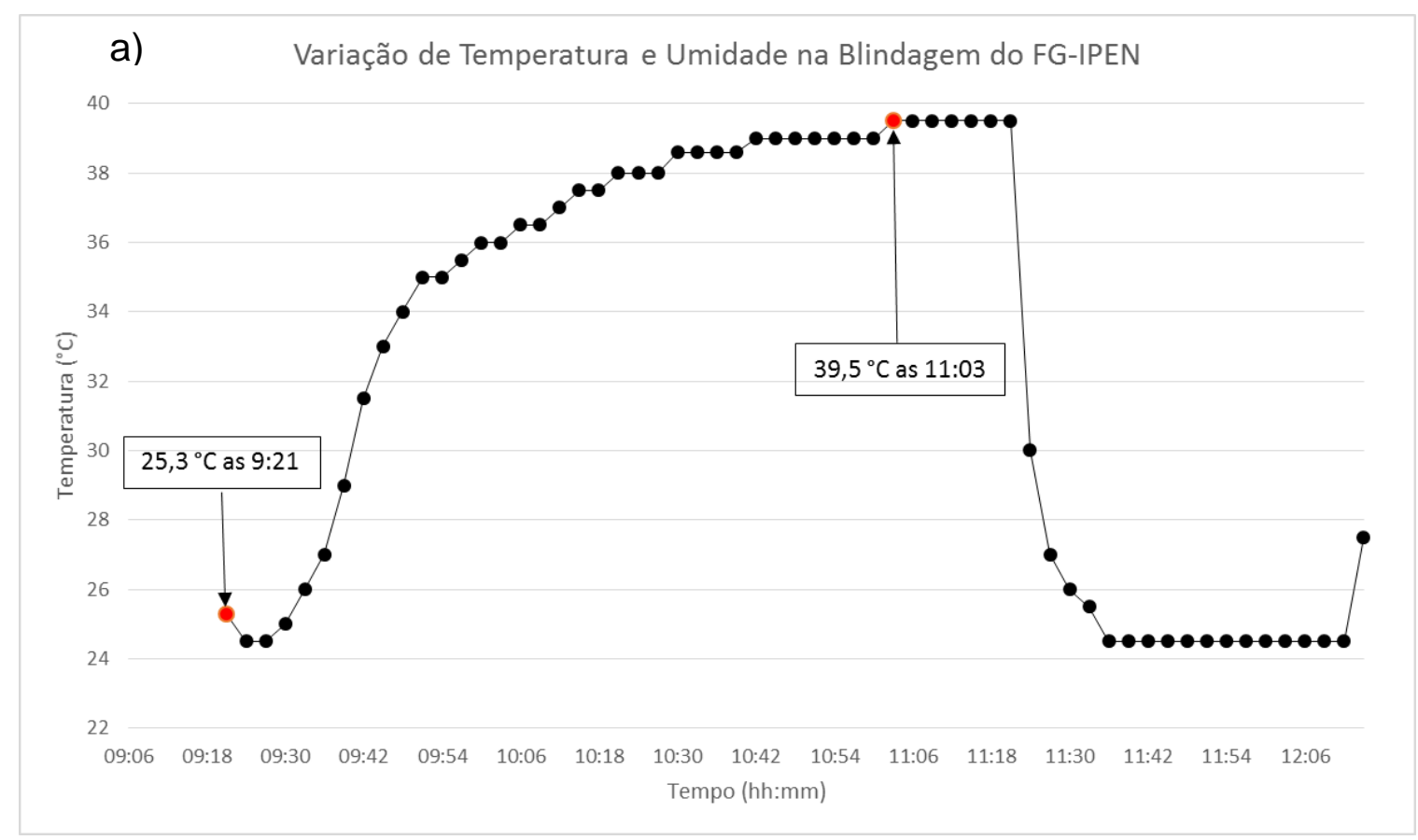

b)

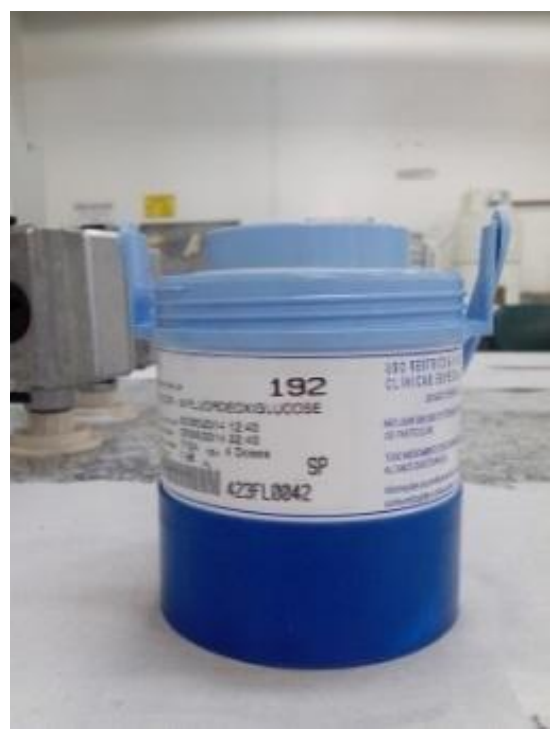

Figura 13. a) Perfil de variação de temperatura no interior da embalagem de chumbo b) Embalagem FDG sem tampa submetidos à temperatura de $40{ }^{\circ} \mathrm{C} e$ $75 \%$ UR por 48 horas em câmara climática. 
Variação de temperatura na embalagem FG-IPEN

a)

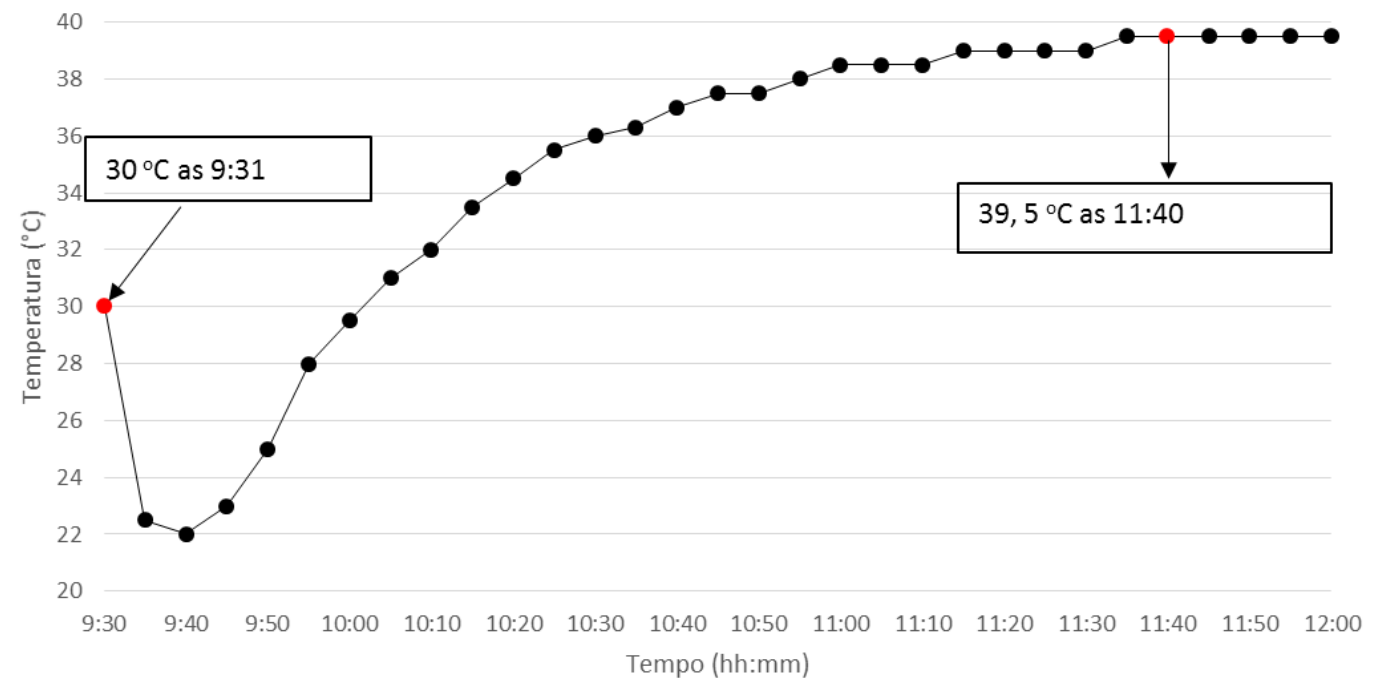

b)

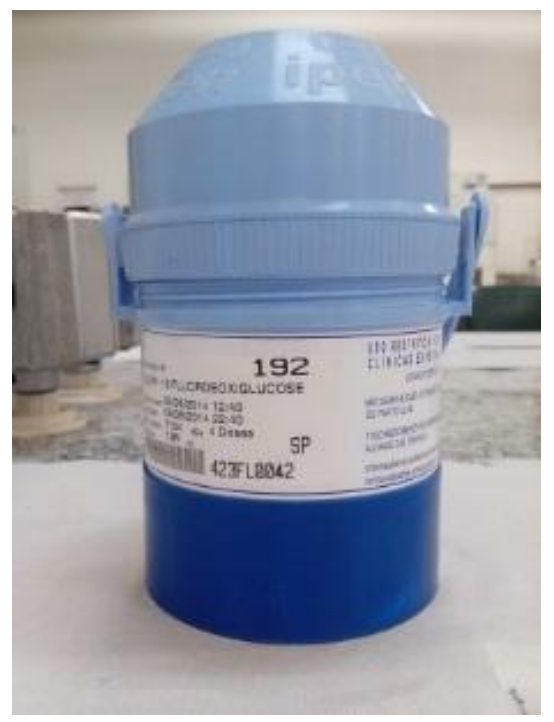

Figura 14. a) Perfil de variação de temperatura no interior da embalagem de chumbo. b) com tampa, quando submetidos à temperatura de $40{ }^{\circ} \mathrm{C}$ e $75 \%$ UR por 48 horas em câmara climática.

O início da medição de temperatura foi acionado pelo software do sensor, registrando-se no tempo inicial a temperatura do suporte em que se encontrava o sensor no laboratório. Na sequência, o sensor foi colocado no interior da blindagem de chumbo e o conjunto foi colocado no interior da câmara climática. Observou-se diminuição da temperatura, para cerca de $22-24{ }^{\circ} \mathrm{C}$, alguns minutos seguido por um aumento contínuo, causado pela temperatura aplicada à câmara climática. 
No caso de blindagem de chumbo sem tampa, após cerca de 1 hora e quarenta minutos, a temperatura no interior da blindagem é praticamente a temperatura aplicada à câmara. No caso da blindagem com tampa, o tempo para alcançar a mesma temperatura foi de cerca de 2 horas e 10 minutos, cerca de 30 minutos a mais do que no caso da blindagem sem tampa.

Tabela 21. Perfil de temperatura da blindagem do FDG com tampa.

\begin{tabular}{ccc}
\hline $\begin{array}{c}\text { Blindagem FDG com } \\
\text { tampa }\end{array}$ & $\begin{array}{c}\text { Diferença de tempo } \\
\text { entre as etapas } \\
\text { (em minutos/horas) }\end{array}$ & $\begin{array}{c}\text { Variação de } \\
\text { temperatura entre as } \\
\text { etapas }\left({ }^{\circ} \mathbf{C}\right)\end{array}$ \\
\hline $\begin{array}{c}\text { Tempo inicial-Tempo final } \\
1: 42\end{array}$ & Tempo inicial & Temperatura inicial \\
Temperatura inicial- & $9: 21$ & 25,3 \\
Temperatura final & Tempo final & Temperatura final \\
14,3 & $11: 03$ & 39,4 \\
\hline
\end{tabular}

Tabela 22. Perfil de temperatura da blindagem do FDG sem tampa.

\begin{tabular}{ccc}
\hline $\begin{array}{c}\text { Blindagem FDG sem } \\
\text { tampa }\end{array}$ & $\begin{array}{c}\text { Diferença de tempo } \\
\text { entre as etapas } \\
\text { (em minutos/horas) }\end{array}$ & $\begin{array}{c}\text { Variação de } \\
\text { temperatura entre as } \\
\text { etapas }\left({ }^{\circ} \mathbf{C}\right)\end{array}$ \\
\hline Tempo inicial-Tempo final & "Tempo inicial & Temperatura inicial \\
2:09 & $9: 31$ & 30,0 \\
Temperatura inicial- & Tempo final & Temperatura final \\
Temperatura final & $11: 40$ & 39,3 \\
9,3 &
\end{tabular}

Estes resultados foram importantes para viabilizar o uso da câmara climática em estudos com alguns radiofármacos comercializados em altas atividades. As altas atividades dos radiofármacos e as doses impediriam a realização do experimento e permanência de pessoas nas proximidades do equipamento, por motivo de proteção radiológica. Além disso, não seria possível realizar o estudo de estabilidade de transporte tal qual está sendo proposto caso 
a blindagem fosse totalmente hermética e atuasse como um isolante. Na prática, com este experimento, pode-se entender que a temperatura no interior e exterior serão as mesmas, atingindo o valor esperado após colocar a blindagem com tampa ou sem tampa e aguardar cerca de 2 horas.

No transporte de radiofármacos para uso em PET, o perfil de temperatura observado na Fig. 11 e 12 somente se a temperatura de $40{ }^{\circ} \mathrm{C}$ com $75 \%$ UR forem aplicados continuamente ao material.

Quando a mesma condição de temperatura e umidade foram aplicados à uma embalagem pequena de isopor de tamanho $18,5 \times 21,0 \times 12,5 \mathrm{~cm}$, contendo gelo reciclável que foi mantido em temperatura menor que $-20{ }^{\circ} \mathrm{C}$, conforme mostrado na Fig. 13 foi obtido o perfil de temperatura representado na Fig. 14.

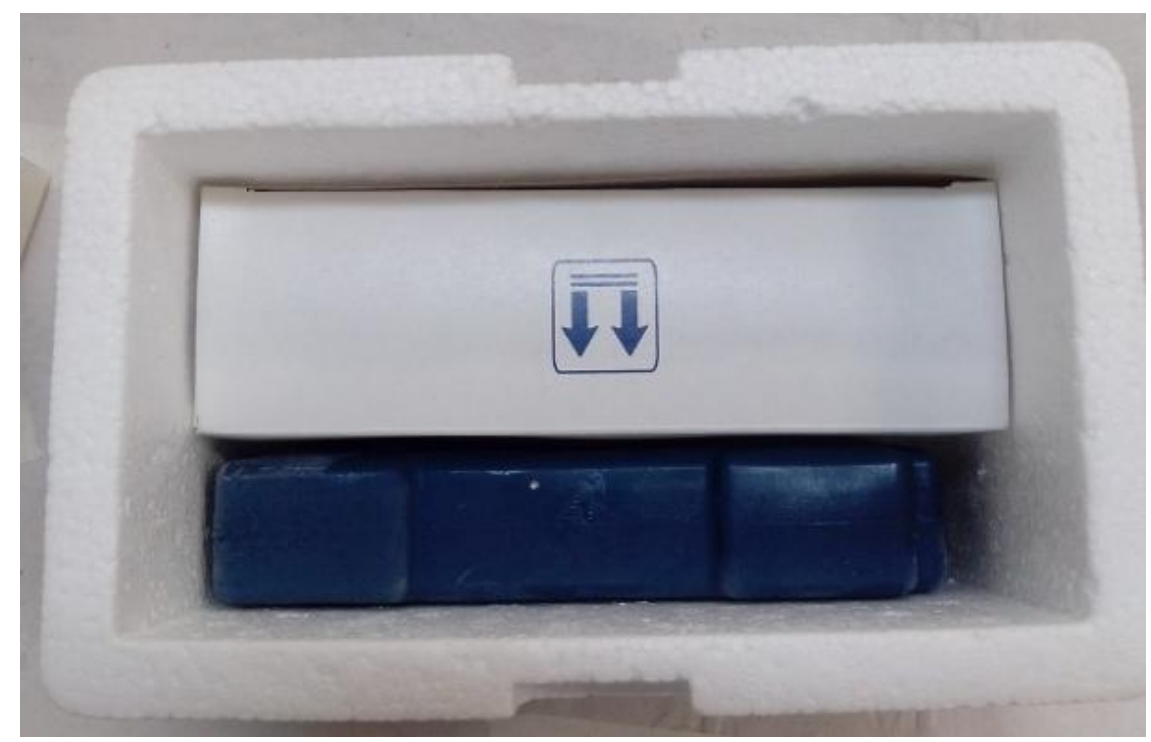

Vista superior

Figura 15. Embalagem para envio do CIS-TEC e ECD-TEC, mostrando a disposição interna da caixa de isopor contendo uma unidade de gelo reciclável e um kit de RL. Fazem parte do kit de $R L$ a caixa de papelão, duas embalagens acrílicas e cinco frascos de $R L$ em cada embalagem. 
Figura 16. Perfil de variação de temperatura na embalagem para transporte de alguns RL, quando submetidos à temperatura de $40^{\circ} \mathrm{C}$ e $75 \%$ UR por 48 horas em câmara climática.

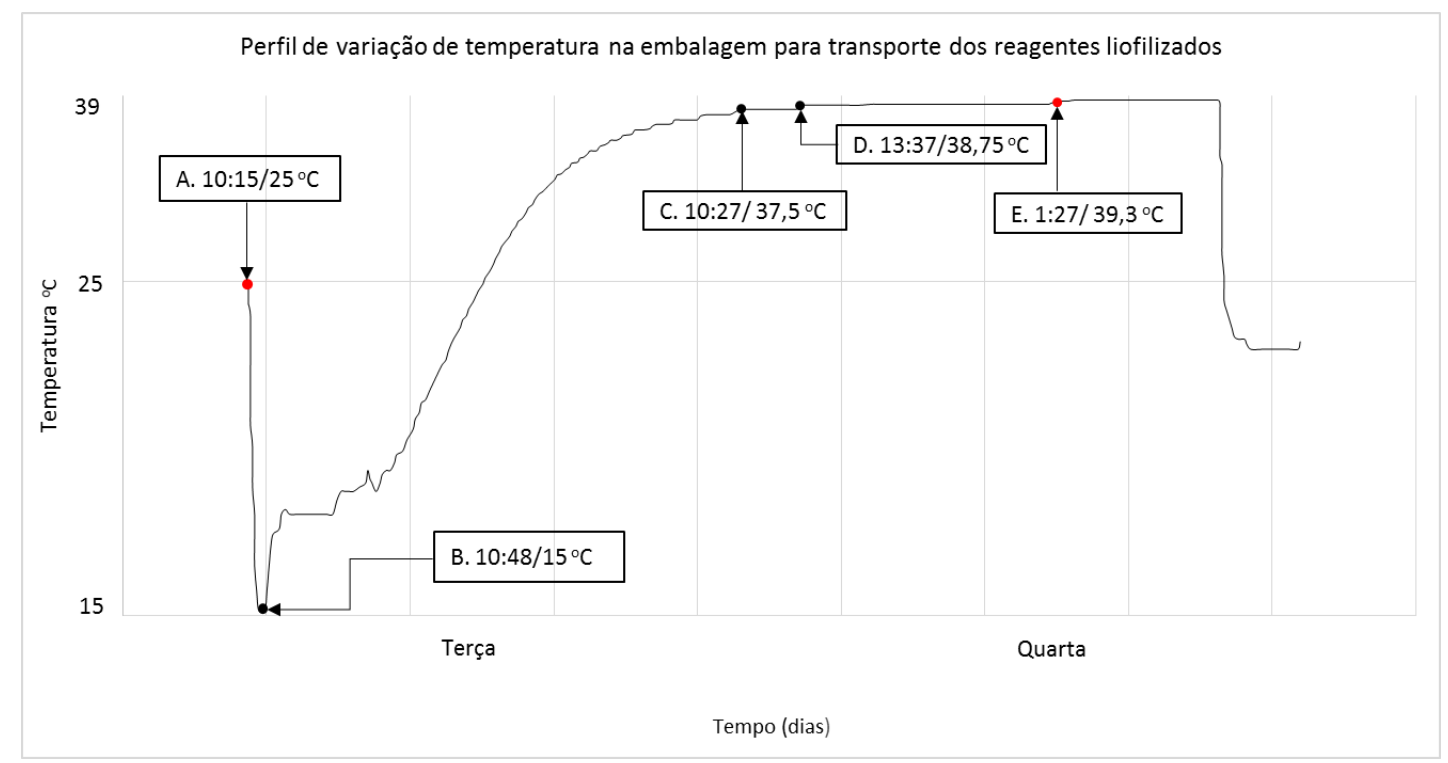

$\mathrm{Na}$ Fig. 14 observou-se durante as 48 horas de monitoramento de temperatura no interior da caixa de acrílico do kit de RL mantida com tampa o menor valor foi de $15{ }^{\circ} \mathrm{C}$, cerca de 30 minutos após a aplicação da condição de 40 ${ }^{\circ} \mathrm{C}$ e $75 \%$ UR. O experimento começou com temperatura de $25{ }^{\circ} \mathrm{C}$, que foi a temperatura do sensor antes de ser colocado no interior da embalagem em teste. Somente após cerca de 24 horas, a temperatura no interior da caixa de acrílico foi de $37,5{ }^{\circ} \mathrm{C}$, ou seja, próximo à temperatura externa. $\mathrm{O}$ perfil de temperatura mostrou que o isopor e a unidade de gelo reciclável foram importantes para isolar as condições externas da interna, pois o tempo para que a temperatura interna se aproximasse da temperatura foi de cerca de 24 horas, muito superior ao tempo de duas horas observado com uma blindagem de chumbo. Entretanto, não foram suficientes para manter a temperatura interna na faixa temperatura de armazenamento recomendada para os $\mathrm{RL}$, que é de $2-8^{\circ} \mathrm{C}$.

Da mesma forma que o observado para a embalagem formada por uma blindagem de chumbo, cabe ressaltar que o perfil de temperatura observado na Fig.14 somente será observado quando a temperatura de $4{ }^{\circ} \mathrm{C}$ com $75 \%$ UR forem aplicados continuamente ao material, na configuração proposta pelo experimento. 
Uma das maiores preocupações nos RL é a quantidade de estanho contida em cada frasco (descrita na Tab.11), que precisa estar presente no estado de oxidação 2+.no momento da marcação com o eluato de ${ }^{99 m} \mathrm{TcO}_{4}{ }^{-}$e que pode se degradar sob ação de fatores como temperatura e umidade. Na Tabela 11 é possível verificar que a quantidade de cloreto estanoso em alguns $\mathrm{RL}$ é menor, o que os torna mais suscetíveis à perda da qualidade do produto. Pode-se observar que ALBUMINA-TEC, CIS-TEC, ECD-TEC, MIBI-TEC, PUL-TEC e são os RL que apresentam a menor quantidade de cloreto estanoso.

\subsection{AVALIAÇÃO DA PUREZA RADIOQUÍMICA E DA BIODISTRIBUIÇÃO EM RL MANTIDOS POR 48 HORAS EM TEMPERATURA DE $40{ }^{\circ} \mathrm{C}$ E $75 \%$ UR}

Alguns frascos de $R L$ (embalagem primária composta por frasco, rolha de borracha e lacre de alumínio) foram submetidos à exposição em câmara climática durante 48 horas em temperatura de $40{ }^{\circ} \mathrm{C}$ e $75 \%$ UR conforme mostrado na Fig. 10.

Os resultados de \% PRq e distribuição biológica de ALBUMINA-TEC (SAHTEC), EC-TEC (CIS-TEC), ECD-TEC, DEX-70-TEC (DEX-70), DEX-500-TEC (DEX-500), DISIDA-TEC (DISI-TEC), DMSA-TEC, DTPA-TEC, ESTANHO-TEC (TIN-TEC), MACRO-TEC (PUL-TEC), PIRO-TEC, MDP-TEC e o que necessitam de ser mantidos de $2-8{ }^{\circ} \mathrm{C}$ e MIBI-TEC foram relacionados nas tabelas a seguir. Nas tabelas estão relacionados os resultados de controle de qualidade radioquímico e biológico, de frascos de alguns lotes de $R L$ expostos à $40{ }^{\circ} \mathrm{C}$ e $75 \%$ UR por 48 horas e frascos mantidos em 2 - $8{ }^{\circ} \mathrm{C}$, logo após a produção do lote. A estabilidade do RL foi avaliada até 4 horas após a marcação com ${ }^{99 \mathrm{~m}} \mathrm{TcO}_{4}{ }^{-}$.

A exposição dos frascos em temperatura superior à estabelecida como condição de armazenamento ocorreu após diferentes períodos em temperatura de 2 - $8{ }^{\circ} \mathrm{C}$ (Tab.14 tabela no final de materiais e métodos). Esta condição visou simular a situação em que o despacho do RL aos clientes, em uma condição adversa, ocorreu após diferentes tempos de armazenamento no centro produtor, seguido pelo uso imediato na clínica ou hospital que realizou a aquisição do RL. Outra condição avaliada teve como objetivo simular uma condição adversa de 
temperatura e umidade em transporte do $\mathrm{RL}$, mas posteriormente foi mantido em condição de armazenamento adequado, até a validade do produto.

Os resultados de pureza radioquímica e biodistribuição abaixo dos reagentes liofilzados avaliados:

Tabela 23. Resultados de pureza radioquímica e biodistribuição da ALBUMINATEC após exposição à temperatura de $40{ }^{\circ} \mathrm{C}$ e $75 \%$ UR, e resultados obtidos imediatamente após a produção de $\mathrm{RL}$ mantidos em temperatura de 2 - $8{ }^{\circ} \mathrm{C}$.

Lote 1: Resultados de ALBUMINA-TEC após 3 meses de fabricação, seguido de exposição à $40{ }^{\circ} \mathrm{C}$ e $75 \%$ UR por 48 horas.

\begin{tabular}{ccc|ccc}
\hline $\begin{array}{c}\text { Tempo } \\
\text { (minutos) }\end{array}$ & $\%{ }^{99 m} \mathrm{TcO}_{4}{ }^{-}$ & $\% \mathrm{PRq}$ & Órgão & Média \% D.I & Imagem \\
\hline 30 & 1,37 & 98,63 & Fígado & 13,91 & \\
60 & 0,49 & 99,51 & Sangue & 31,28 & \\
240 & 1,70 & 98,30 & Estômago & 0,63 & \\
Média & 1,19 & 98,81 & Carcaça & 27,22 & \\
\hline
\end{tabular}

Lote 1: Resultados de ALBUMINA-TEC após a fabricação, mantido em 2 - $8{ }^{\circ} \mathrm{C}$

\begin{tabular}{ccc|ccc}
\hline $\begin{array}{c}\text { Tempo } \\
\text { (minutos) }\end{array}$ & $\%{ }^{99 m} \mathrm{TcO}_{4}{ }^{-}$ & $\% \mathrm{PRq}$ & Órgão & Média \% D.I & Imagem \\
\hline 30 & 1,80 & 98,16 & Fígado & 13,23 & \\
60 & 1,56 & 98,18 & Sangue & 40,33 & \\
240 & 1,11 & 98,86 & Estômago & 0,91 & $8 \%$ \\
Média & 1,49 & 98,40 & Carcaça & 43,70 & \\
\hline
\end{tabular}

Lote 2: Resultados de ALBUMINA-TEC após 8 meses de fabricação, seguido de exposição à $40{ }^{\circ} \mathrm{C}$ e $75 \%$ UR por 48 horas.

\begin{tabular}{ccc|ccc}
\hline $\begin{array}{c}\text { Tempo } \\
\text { (minutos) }\end{array}$ & $\%{ }^{{ }^{99 m} \mathrm{TcO}_{4}{ }^{-}}$ & $\% \mathrm{PRq}$ & Órgão & Média \% D.I & Imagem \\
\hline 30 & 0,49 & 99,51 & Fígado & 12,73 & \\
60 & 0,10 & 99,90 & Sangue & 58,37 & \\
240 & 0,21 & 99,79 & Estômago & 0,74 & \\
Média & 0,27 & 99,73 & Carcaça & 23,23 & \\
\hline
\end{tabular}


Lote 2: Resultados de ALBUMINA-TEC após a fabricação, mantido em 2 - $8{ }^{\circ} \mathrm{C}$.

\begin{tabular}{ccc|ccc}
\hline $\begin{array}{c}\text { Tempo } \\
\text { (minutos) }\end{array}$ & $\%{ }^{99 m} \mathrm{TcO}_{4}{ }^{-}$ & $\% \mathrm{PRq}$ & Órgão & Média \% D.I & Imagem \\
\hline 30 & 2,41 & 98,63 & Fígado & 13,23 & \\
60 & 1,31 & 99,51 & Sangue & 40,33 & \\
240 & 1,20 & 98,30 & Estômago & 0,91 & \\
Média & 1,64 & 98,35 & Carcaça & 43,70 & \\
\hline
\end{tabular}

A exposição da ALBUMINA-TEC em uma condição adversa, 48 horas a $40{ }^{\circ} \mathrm{C}$ e $75 \%$ UR, três e oito meses após a sua fabricação não causou alteração no controle radioquímico até quatro horas após a marcação com 99m Tc, apresentando resultados acima de $90 \%$. A qualidade do produto não foi afetada, e não houve diferença significativa nos resultados de controle radioquímico obtidos em produto mantido em temperatura de $2-8^{\circ} \mathrm{C}$.

O resultado da biodistribuição da ALBUMINA-TEC mantido a $40{ }^{\circ} \mathrm{C}$ e $75 \%$ UR por 48 horas também apresentou resultados satisfatórios, atendendo aos limites especificados para o fígado, estômago e sangue. Em comparação ao produto mantido em temperatura de $2-8^{\circ} \mathrm{C}$, não houve diferença significativa nos resultados.

Tabela 23. Os resultados de pureza radioquímica e biodistribuição do CIS-TEC após exposição à temperatura de $40{ }^{\circ} \mathrm{C}$ e $75 \%$ UR, e resultados obtidos imediatamente após a produção de $\mathrm{RL}$ mantidos em temperatura de 2 - $8{ }^{\circ} \mathrm{C}$.

Lote 1: Resultados de CIS-TEC após 9 meses de fabricação, seguido de exposição à $40{ }^{\circ} \mathrm{C}$ e $75 \%$ U.R por 48 horas.

\begin{tabular}{cccc|ccc}
\hline $\begin{array}{c}\text { Tempo } \\
\text { (minutos) }\end{array}$ & $\%{ }^{99 m} \mathrm{TcO}_{4}{ }^{-}$ & $\%{ }^{99 m} \mathrm{TcO}_{2}$ & $\% \mathrm{PRq}$ & Órgão & Média \% D.I & Imagem \\
\hline 30 & 1,08 & 2,71 & 96,21 & Rins & 1,45 \\
60 & 1,28 & 3,50 & 95,20 & Fígado & 10,58 & \\
240 & 2,21 & 10,03 & 87,75 & Carcaça & 10,37 & \\
& & & & Bexiga & 77,60 & Rins+ \\
Média & 1,52 & 5,41 & 93,08 & Bexiga & 79,05 & \\
\hline
\end{tabular}

Lote 1: Resultados de CIS-TEC após 9 meses de fabricação, mantido em $2-8^{\circ} \mathrm{C}$. 


\begin{tabular}{|c|c|c|c|c|c|c|}
\hline $\begin{array}{l}\text { Tempo } \\
\text { (minutos) }\end{array}$ & $\%{ }^{99 \mathrm{~m}} \mathrm{TcO}_{4}$ & $\%{ }^{99 \mathrm{~m}} \mathrm{TcO}_{2}$ & $\% \mathrm{PRq}$ & Órgão & Média \% D.I & Imagem \\
\hline 30 & 35,19 & 4,14 & 60,65 & Rins & 0,53 & \\
\hline 60 & 11,69 & 1,96 & 86,34 & Fígado & 1,89 & \\
\hline 240 & 0,60 & 10,03 & 97,02 & $\begin{array}{c}\text { Carcaça } \\
\text { Bexiga }\end{array}$ & $\begin{array}{c}1,73 \\
95,85\end{array}$ & $8^{\prime}$ \\
\hline Média & 12,49 & 5,37 & 81,33 & $\begin{array}{l}\text { Rins+ } \\
\text { Bexiga }\end{array}$ & 96,38 & f \\
\hline
\end{tabular}

Lote 2: Resultados de RL após a fabricação, mantido em $2-8^{\circ} \mathrm{C}$.

\begin{tabular}{|c|c|c|c|c|c|c|}
\hline $\begin{array}{c}\text { Tempo } \\
\text { (minutos) }\end{array}$ & $\%{ }^{99 \mathrm{~m}} \mathrm{TcO}_{4}^{-}$ & $\%{ }^{99 \mathrm{~m}} \mathrm{TcO}_{2}$ & $\%$ PRq & Órgão & Média \% D.I & Imagem \\
\hline 30 & 1,32 & 0,83 & 97,85 & Rins & 1,94 & \\
\hline 60 & 1,34 & 1,70 & 96,96 & Fígado & 2,46 & 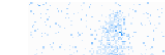 \\
\hline 240 & 1,13 & 1,33 & 97,54 & $\begin{array}{c}\text { Carcaça } \\
\text { Bexiga }\end{array}$ & $\begin{array}{c}5,05 \\
90,55\end{array}$ & 4 \\
\hline Média & 1,26 & 1,28 & 97,45 & $\begin{array}{l}\text { Rins+ } \\
\text { Bexiga }\end{array}$ & 92,49 & \\
\hline
\end{tabular}

O CIS-TEC não havia disponível lote na validade para avaliar o efeito da temperatura para este radiofármaco. Entretanto, havia amostras de um lote com nove meses após a fabricação, portanto, fora da validade, mas mantido em temperatura de $2-8{ }^{\circ} \mathrm{C}$ foram analisadas. As amostras expostas à condição de 40 ${ }^{\circ} \mathrm{C}$ e $75 \%$ UR por 48 horas foram analisadas. Ambas as amostras apresentaram resultados de \% PRq fora da especificação, mas resultados de biodistribuição alterados no fígado e na carcaça foram observados nas amostras submetidas ao aumento de temperatura e umidade. $\mathrm{O}$ aumento na captação hepática e na carcaça indicaram que a marcação com $99 \mathrm{~m}$ Tc foi comprometida. Outros experimentos precisam ser realizados para verificar o efeito da temperatura e umidade na estabilidade do $R L$ com o tempo de marcação e com o armazenamento. 
Tabela 24. Resultados de pureza radioquímica do RL DEX-70-TEC após exposição à temperatura de $40^{\circ} \mathrm{C}$ e $75 \%$ UR, e resultados obtidos imediatamente após a produção de $\mathrm{RL}$ mantidos em temperatura de $2-8{ }^{\circ} \mathrm{C}$.

Lote 1: Resultados de DEX-70 após três meses de fabricação.

\begin{tabular}{ccc|cc}
\hline & \multicolumn{2}{c|}{$\begin{array}{c}\text { Acondicionado a } 40{ }^{\circ} \mathrm{C} \text { e } 75 \% \\
\text { UR por 48 horas. }\end{array}$} & \multicolumn{2}{c}{ Acondicionado em $2-8{ }^{\circ} \mathrm{C}}$. \\
\hline $\begin{array}{c}\text { Tempo } \\
\text { (minutos) }\end{array}$ & $\%{ }^{99 \mathrm{~m}} \mathrm{TcO}_{4}{ }^{-}$ & $\% \mathrm{PRq}$ & $\%{ }^{99 \mathrm{~m}} \mathrm{TcO}_{4}{ }^{-}$ & $\% \mathrm{PRq}$ \\
\hline 30 & 2,96 & 97,04 & 0,20 & 99,80 \\
60 & 3,85 & 96,15 & 0,16 & 99,84 \\
240 & 2,58 & 97,42 & 0,14 & 99,86 \\
Média & 3,13 & 96,87 & 0,17 & 99,83 \\
\hline
\end{tabular}

Lote 2: Resultados de DEX-70 após quatro meses de fabricação, seguido de exposição à $40{ }^{\circ} \mathrm{C}$ e $75 \%$ UR por 48 horas.

\begin{tabular}{ccc|cc}
\hline & \multicolumn{2}{c|}{$\begin{array}{c}\text { Acondicionado a } 40{ }^{\circ} \mathrm{C} \text { e } 75 \% \\
\text { UR por 48 horas. }\end{array}$} & \multicolumn{2}{c}{ Acondicionado em $2-8{ }^{\circ} \mathrm{C}}$. \\
\hline $\begin{array}{c}\text { Tempo } \\
\text { (minutos) }\end{array}$ & $\%{ }^{99 \mathrm{~m}} \mathrm{TcO}_{4}{ }^{-}$ & $\% \mathrm{PRq}$ & $\%{ }^{99 \mathrm{~m}} \mathrm{TcO}_{4}{ }^{-}$ & $\% \mathrm{PRq}$ \\
\hline 30 & 0,98 & 99,02 & 1,00 & 99,00 \\
60 & 2,76 & 97,24 & 1,24 & 98,76 \\
240 & 3,98 & 96,02 & 3,72 & 96,28 \\
Média & 2,57 & 97,43 & 1,99 & 98,01 \\
\hline
\end{tabular}

As amostras dos dois lotes que foram expostas por 48 horas $40{ }^{\circ} \mathrm{C}$ e $75 \%$ UR apresentaram \% PRq maior que 90\% mesmo após quatro horas de marcação, indicando que a temperatura e umidade não interferiram na qualidade do produto, em comparação ao produto mantido em temperatura de $2-8{ }^{\circ} \mathrm{C}$. O DEX-70-TEC é um radiofármaco que não apresenta especificação descrita em farmacopeias para ensaio biológico e por isso não foi realizado. 
Tabela 25. Resultados de pureza radioquímica do $R L$ DEX-500-TEC após exposição à temperatura de $40{ }^{\circ} \mathrm{C}$ e $75 \%$ UR, e resultados obtidos imediatamente após a produção de $\mathrm{RL}$ mantidos em temperatura de 2 - $8{ }^{\circ} \mathrm{C}$.

Lote 1: Resultados de DEX-500-TEC obtidos na mesma semana da fabricação.

\begin{tabular}{ccc|cc}
\hline & \multicolumn{2}{c|}{$\begin{array}{c}\text { Acondicionado a } 40{ }^{\circ} \mathrm{C} \text { e } 75 \% \\
\text { UR por 48 horas. }\end{array}$} & \multicolumn{2}{c}{ Acondicionado em $2-8{ }^{\circ} \mathrm{C}}$. \\
\hline $\begin{array}{c}\text { Tempo } \\
\text { (minutos) }\end{array}$ & $\%{ }^{99 \mathrm{~m}} \mathrm{TcO}_{4}{ }^{-}$ & $\% \mathrm{PRq}$ & $\%{ }^{99 \mathrm{~m}} \mathrm{TcO}_{4}{ }^{-}$ & $\% \mathrm{PRq}$ \\
\hline 30 & 1,75 & 98,24 & 0,08 & 99,92 \\
60 & 0,70 & 99,30 & 0,10 & 99,90 \\
240 & 1,49 & 98,51 & 0,25 & 99,75 \\
Média & 1,32 & 98,68 & 0,14 & 99,86 \\
\hline
\end{tabular}

Lote 2: Resultados de DEX-500-TEC obtidos na mesma semana da fabricação.

\begin{tabular}{ccc|cc}
\hline & \multicolumn{2}{c|}{$\begin{array}{c}\text { Acondicionado a } 40{ }^{\circ} \mathrm{C} \text { e } 75 \% \\
\text { UR por 48 horas. }\end{array}$} & \multicolumn{2}{c}{ Acondicionado em $2-8{ }^{\circ} \mathrm{C}}$. \\
\hline $\begin{array}{c}\text { Tempo } \\
\text { (minutos) }\end{array}$ & $\%{ }^{99 \mathrm{~m}} \mathrm{TcO}_{4}{ }^{-}$ & $\% \mathrm{PRq}$ & $\%{ }^{99 \mathrm{~m}} \mathrm{TcO}_{4}{ }^{-}$ & $\% \mathrm{PRq}$ \\
\hline 30 & 0,40 & 99,59 & 0,04 & 99,94 \\
60 & 0,82 & 99,18 & 0,08 & 99,92 \\
240 & 1,15 & 98,84 & 0,14 & 98,86 \\
Média & 0,79 & 99,21 & 0,09 & 99,91 \\
\hline
\end{tabular}

Lote 3: Resultados de DEX-500-TEC obtidos na mesma semana da fabricação.

\begin{tabular}{ccc|cc}
\hline & \multicolumn{2}{c}{$\begin{array}{c}\text { Acondicionado a } 40{ }^{\circ} \mathrm{C} \text { e } 75 \% \\
\text { UR por 48 horas. }\end{array}$} & \multicolumn{2}{c}{ Acondicionado em $2-8{ }^{\circ} \mathrm{C}}$. \\
\hline $\begin{array}{c}\text { Tempo } \\
\text { (minutos) }\end{array}$ & $\%{ }^{99 \mathrm{~m}} \mathrm{TcO}_{4}{ }^{-}$ & $\% \mathrm{PRq}$ & $\%{ }^{99 \mathrm{~m}} \mathrm{TcO}_{4}{ }^{-}$ & $\% \mathrm{PRq}$ \\
\hline 30 & 0,46 & 99,53 & 0,08 & 99,53 \\
60 & 0,38 & 99,62 & 0,07 & 99,62 \\
240 & 0,75 & 99,24 & 0,08 & 99,24 \\
Média & 0,54 & 99,46 & 0,08 & 99,46 \\
\hline
\end{tabular}

Igualmente ao DEX-70-TEC, os resultados dos três lotes de DEX-500-TEC indicaram que a temperatura estudada não influenciou na estabilidade do $R L$ até quatro horas de marcação. O DEX-500-TEC também não apresenta ensaio de biodistribuição descrito em monografias oficiais e por isso não foi realizado. 
Tabela 26. Resultados de pureza radioquímica e biodistribuição do DISI-TEC da após exposição à temperatura de $40{ }^{\circ} \mathrm{C}$ e $75 \%$ UR, e resultados obtidos imediatamente após a produção de $\mathrm{RL}$ mantidos em temperatura de 2 - $8{ }^{\circ} \mathrm{C}$.

Lote 1: Resultados de DISI-TEC obtidos após 6 meses de fabricação.

\begin{tabular}{|c|c|c|c|c|c|c|}
\hline \multirow[b]{2}{*}{ Tempo } & \multicolumn{3}{|c|}{$\begin{array}{c}\text { Acondicionado a } 40^{\circ} \mathrm{C} \text { e } 75 \% \text { UR } \\
\text { por } 48 \text { horas. }\end{array}$} & \multicolumn{3}{|c|}{ Acondicionado em $2-8{ }^{\circ} \mathrm{C}$. } \\
\hline & $\%{ }^{99 m} \mathrm{TcO}_{4}$ & $\%{ }^{99 m} \mathrm{TcO}_{2}$ & $\% \mathrm{PRq}$ & $\%{ }^{99 m} \mathrm{TcO}_{4}$ & $\%{ }^{99 m} \mathrm{TcO}_{2}$ & $\%$ PRq \\
\hline 30 & 3,32 & 1,07 & 95,59 & 0,96 & 0,76 & 98,28 \\
\hline 60 & 2,65 & 2,22 & 95,12 & 1,27 & 0,54 & 98,18 \\
\hline 240 & 3,15 & 1,19 & 95,65 & 2,47 & 0,54 & 96,99 \\
\hline Média & 3,05 & 1,50 & 95,46 & 1,57 & 0,62 & 97,82 \\
\hline
\end{tabular}

Lote 2: Resultados de DISI-TEC após 6 meses de fabricação, seguido de exposição à $40^{\circ} \mathrm{C}$ e $75 \%$ UR por 48 horas.

\begin{tabular}{cccc|ccc}
\hline $\begin{array}{c}\text { Tempo } \\
\text { (minutos) }\end{array}$ & $\%{ }^{99 m} \mathrm{TcO}_{4}{ }^{-}$ & $\%{ }^{99 m} \mathrm{TcO}_{2}$ & $\% \mathrm{PRq}$ & Órgão & Média \% D.I & Imagem \\
\hline 30 & 1,75 & 2,51 & 95,73 & Intestino & 84,36 & \\
60 & 1,89 & 1,10 & 97,00 & Estômago & 0,16 & \\
240 & 3,34 & 5,46 & 91,19 & Fígado & 1,21 & \\
& & & & Rins & 3,06 & (y) \\
Média & 2,33 & 3,03 & 94,64 & Carcaça & 3,41 & \\
\hline
\end{tabular}

Lote 2: Resultados de DIS-TEC após a fabricação, mantido em 2 - $8{ }^{\circ} \mathrm{C}$.

\begin{tabular}{|c|c|c|c|c|c|c|}
\hline $\begin{array}{c}\text { Tempo } \\
\text { (minutos) }\end{array}$ & $\%{ }^{99 m} \mathrm{TcO}_{4}$ & $\%{ }^{99 \mathrm{~m}} \mathrm{TcO}_{2}$ & $\% \mathrm{PRq}$ & Órgão & Média \% D.I & Imagem \\
\hline 30 & 0,54 & 0,55 & 98,92 & Intestino & 89,45 & \\
\hline 60 & 0,76 & 0,70 & 98,55 & Estômago & 1,77 & \\
\hline \multirow[t]{2}{*}{240} & 1,25 & 0,47 & 98,28 & Fígado & 0,61 & 80 \\
\hline & & & & Rins & 1,33 & \\
\hline Média & 0,85 & 0,57 & 98,58 & Carcaça & 1,72 & \\
\hline
\end{tabular}

Dois lotes de DISI-TEC foram analisados no $6^{\circ}$ mês de validade, ou seja, no vencimento, após exposição por 48 horas a $40{ }^{\circ} \mathrm{C}$ e $75 \%$ UR apresentaram \% PRq maior que $90 \%$ em até quatro horas após a marcação com 99m Tc, indicando que a temperatura e umidade não interferiram na qualidade do produto. Resultados de biodistribuição e imagem do Lote 2 confirmaram os resultados do controle radioquímico, e atenderam aos limites de aceitação para intestino, fígado e rins. 
Tabela 27. Resultados de pureza radioquímica e biodistribuição do DMSA-TEC da após exposição à temperatura de $40{ }^{\circ} \mathrm{C}$ e $75 \%$ UR, e resultados obtidos imediatamente após a produção de $\mathrm{RL}$ mantidos em temperatura de 2 - $8{ }^{\circ} \mathrm{C}$.

Lote 1: Resultados de DMSA-TEC obtidos após três meses de fabricação.

Acondicionado a $40{ }^{\circ} \mathrm{C}$ e $75 \%$ UR por 48 horas.
Acondicionado em $2-8{ }^{\circ} \mathrm{C}$.

\begin{tabular}{cccc|ccc}
\hline $\begin{array}{c}\text { Tempo } \\
\text { (minutos) }\end{array}$ & $\%{ }^{99 \mathrm{~m}} \mathrm{TcO}_{4}{ }^{-}$ & $\%{ }^{99 \mathrm{~m}} \mathrm{TcO}_{2}$ & $\% \mathrm{PRq}$ & $\%{ }^{99 m} \mathrm{TcO}_{4}{ }^{-}$ & $\%{ }^{99 \mathrm{~m}} \mathrm{TcO}_{2}$ & $\% \mathrm{PRq}$ \\
\hline 30 & 0,44 & 2,87 & 96,68 & 0,19 & 5,16 & 94,65 \\
60 & 0,64 & 4,87 & 94,48 & 0,14 & 4,71 & 95,16 \\
240 & 1,49 & 6,55 & 91,96 & 0,13 & 4,70 & 95,47 \\
Média & 0,86 & 4,77 & 94,37 & 0,15 & 4,76 & 95,09 \\
\hline
\end{tabular}

Lote 2: Resultados de DMSA-TEC após dois meses de fabricação, seguido de exposição à $40^{\circ} \mathrm{C}$ e $75 \%$ UR por 48 horas.

\begin{tabular}{|c|c|c|c|c|c|c|}
\hline $\begin{array}{c}\text { Tempo } \\
\text { (minutos) }\end{array}$ & $\%{ }^{99 m} \mathrm{TcO}_{4}^{-}$ & $\%{ }^{99 \mathrm{~m}} \mathrm{TcO}_{2}$ & $\% \mathrm{PRq}$ & Órgão & Média \% D.I & Imagem \\
\hline 30 & 0,59 & 4,88 & 94,53 & Rins & 43,56 & \\
\hline 60 & 0,32 & 3,64 & 96,03 & Bexiga & 0,15 & \\
\hline \multirow[t]{3}{*}{240} & 5,21 & 3,16 & 91,63 & Fígado & 4,63 & \\
\hline & & & & Baço & 0,30 & \\
\hline & & & & $\begin{array}{l}\text { Rins/ } \\
\text { Fígado } \\
+ \text { Baço }\end{array}$ & 8,84 & \\
\hline Média & 2,04 & 3,90 & 94,06 & Carcaça & 39,85 & \\
\hline
\end{tabular}

Lote 2: Resultados de DMSA-TEC após a fabricação, mantido em 2 - $8{ }^{\circ} \mathrm{C}$.

\begin{tabular}{|c|c|c|c|c|c|c|}
\hline $\begin{array}{c}\text { Tempo } \\
\text { (minutos) }\end{array}$ & $\%{ }^{99 m} \mathrm{TcO}_{4}^{-}$ & $\%{ }^{99 m} \mathrm{TcO}_{2}$ & $\% \mathrm{PRq}$ & Órgão & Média \% D.I & Imagem \\
\hline 30 & 0,15 & 8,37 & 91,47 & Rins & 51,24 & \\
\hline 60 & 0,13 & 7,35 & 92,53 & Bexiga & 1,42 & \\
\hline \multirow[t]{5}{*}{240} & 0,12 & 5,36 & 94,52 & Fígado & 3,79 & \\
\hline & & & & Baço & 0,17 & \\
\hline & & & & Rins/ & & \\
\hline & & & & Fígado & 12,93 & \\
\hline & & & & + Baço & & \\
\hline Media & 0,13 & 1,03 & 92,82 & carcaça & 32,47 & \\
\hline
\end{tabular}


Lote 3: Resultados de DMSA-TEC após três meses de fabricação, seguido de exposição à $40^{\circ} \mathrm{C}$ e $75 \%$ UR por 48 horas.

\begin{tabular}{|c|c|c|c|c|c|c|}
\hline $\begin{array}{c}\text { Tempo } \\
\text { (minutos) }\end{array}$ & $\%{ }^{99 m} \mathrm{TcO}_{4}^{-}$ & $\%{ }^{99 m} \mathrm{TcO}_{2}$ & $\% \mathrm{PRq}$ & Órgão & Média \% D.I & Imagem \\
\hline 30 & 0,13 & 3,16 & 96,70 & Rins & 44,05 & \\
\hline 60 & 0,63 & 2,32 & 97,06 & Bexiga & 0,62 & \\
\hline \multirow[t]{3}{*}{240} & 0,68 & 3,37 & 95,95 & Fígado & 3,54 & \\
\hline & & & & $\begin{array}{l}\text { Baço } \\
\text { Rins/ }\end{array}$ & 0,20 & \\
\hline & & & & $\begin{array}{l}\text { Fígado } \\
+ \text { Baço }\end{array}$ & 11,78 & \\
\hline Média & 0,48 & 2,95 & 96,57 & Carcaça & 30,34 & \\
\hline
\end{tabular}

Lote 3: Resultados de DMSA-TEC após a fabricação, mantido em 2 - $8{ }^{\circ} \mathrm{C}$.

\begin{tabular}{|c|c|c|c|c|c|c|}
\hline $\begin{array}{c}\text { Tempo } \\
\text { (minutos) }\end{array}$ & $\%{ }^{99 m} \mathrm{TcO}_{4}^{-}$ & ${ }^{99 m} \mathrm{TcO}_{2}$ & $\% \mathrm{PRq}$ & Órgão & Média \% D.I & Imagem \\
\hline 30 & 0,18 & 7,78 & 92,04 & Rins & 43,05 & \\
\hline 60 & 0,17 & 8,04 & 91,79 & Bexiga & 3,44 & \\
\hline \multirow[t]{5}{*}{240} & 0,18 & 8,39 & 91,43 & Fígado & 2,72 & \\
\hline & & & & Baço & 0,11 & \\
\hline & & & & Rins/ & 15,18 & \\
\hline & & & & Fígado & & \\
\hline & & & & + Baço & & \\
\hline Média & 0,17 & 8,07 & 91,75 & Carcaça & 19,01 & \\
\hline
\end{tabular}

Os resultados de \% PRq e biodistribuição dos três lotes que foram expostos por 48 horas $40{ }^{\circ} \mathrm{C}$ e $75 \%$ UR indicaram que a temperatura e umidade não interferiram na qualidade do produto quando comparados com o produto mantido em temperatura de $2-8^{\circ} \mathrm{C}$. 
Tabela 28. Resultados de pureza radioquímica e biodistribuição do DTPA-TEC da após exposição à temperatura de $40{ }^{\circ} \mathrm{C}$ e $75 \%$ UR, e resultados obtidos imediatamente após a produção de $\mathrm{RL}$ mantidos em temperatura de 2 - $8{ }^{\circ} \mathrm{C}$.

Lote 1: Resultados de DTPA-TEC obtidos após cinco meses de fabricação, após a exposição a $40{ }^{\circ} \mathrm{C}$ e $75 \%$ UR por 48 horas e imediatamente após a fabricação.

\begin{tabular}{cccc|ccc}
\hline & \multicolumn{2}{c}{$\begin{array}{c}\text { Acondicionado a } 40{ }^{\circ} \mathrm{C} \text { e } 75 \% \text { UR } \\
\text { por } 48 \text { horas. }\end{array}$} & \multicolumn{2}{c}{ Acondicionado em 2} & $-8{ }^{\circ} \mathrm{C}$. \\
\hline $\begin{array}{c}\text { Tempo } \\
\text { (minutos) }\end{array}$ & $\%{ }^{99 \mathrm{~m}} \mathrm{TcO}_{4}{ }^{-}$ & $\%{ }^{99 \mathrm{~m}} \mathrm{TcO}_{2}$ & $\% \mathrm{PRq}^{2}$ & $\%{ }^{99 \mathrm{~m}} \mathrm{TcO}_{4}{ }^{-}$ & $\%{ }^{99 \mathrm{~m}} \mathrm{TcO}_{2}$ & $\% \mathrm{PRq}$ \\
\hline 30 & 0,18 & 0,99 & 98,81 & 0,07 & 0,40 & 99,54 \\
60 & 0,49 & 0,68 & 98,81 & 0,10 & 0,27 & 99,64 \\
240 & 0,13 & 0,72 & 99,14 & 0,07 & 0,14 & 99,79 \\
Média & 0,27 & 0,80 & 98,92 & 0,08 & 0,27 & 99,65 \\
\hline
\end{tabular}

Lote 2: Resultados de DTPA-TEC após três meses de fabricação, seguido de exposição à $40{ }^{\circ} \mathrm{C}$ e $75 \%$ UR por 48 horas.

\begin{tabular}{|c|c|c|c|c|c|c|}
\hline $\begin{array}{c}\text { Tempo } \\
\text { (minutos) }\end{array}$ & $\%{ }^{99 \mathrm{~m}} \mathrm{TcO}_{4}^{-}$ & $\%{ }^{99 m} \mathrm{TcO}_{2}$ & $\% \mathrm{PRq}$ & Órgão & Média \% D.I & Imagem \\
\hline 30 & $0,13 \pm$ & 0,27 & 99,60 & Rins & 1,93 & \\
\hline 60 & 0,30 & 0,16 & 98,54 & Fígado & 0,27 & \\
\hline 240 & 0,19 & 0,68 & 99,13 & $\begin{array}{c}\text { Carcaça } \\
\text { Bexiga }\end{array}$ & $\begin{array}{c}5,34 \\
92,46\end{array}$ & $0^{*}$ \\
\hline Média & 0,20 & 0,37 & 99,11 & $\begin{array}{l}\text { Rins + } \\
\text { Bexiga }\end{array}$ & 94,39 & \\
\hline
\end{tabular}

Lote 2: Resultados de DTPA-TEC após a fabricação, mantido em 2 - $8{ }^{\circ} \mathrm{C}$.

\begin{tabular}{cccc|ccc}
\hline $\begin{array}{c}\text { Tempo } \\
\text { (minutos) }\end{array}$ & $\%{ }^{99 \mathrm{~m}} \mathrm{TcO}_{4}{ }^{-}$ & $\%{ }^{99 m} \mathrm{TcO}_{2}$ & $\% \mathrm{PRq}$ & Órgão & Média \% D.I & Imagem \\
\hline 30 & 0,08 & 0,24 & 99,70 & Rins & 1,87 & \\
60 & 0,10 & 0,10 & 98,81 & Fígado & 0,28 & \\
240 & 0,08 & 0,24 & 99,78 & Carcaça & 6,68 & \\
& & & & Bexiga & 91,15 & \\
Média & 0,09 & 0,20 & 99,71 & Rins + & Bexiga & 93,03 \\
\hline
\end{tabular}


Lote 3: Resultados de DTPA-TEC após seis meses de fabricação, seguido de exposição à $40^{\circ} \mathrm{C}$ e $75 \%$ UR por 48 horas.

\begin{tabular}{cccc|ccc}
\hline $\begin{array}{c}\text { Tempo } \\
\text { (minutos) }\end{array}$ & $\%{ }^{99 m} \mathrm{TcO}_{4}^{-}$ & $\%{ }^{99 m} \mathrm{TcO}_{2}$ & $\% \mathrm{PRq}$ & Órgão & Média \% D.I & Imagem \\
\hline 30 & 0,10 & 3,05 & 96,85 & Rins & 0,95 & \\
60 & 0,22 & 0,40 & 99,38 & Fígado & 0,17 & \\
240 & 0,07 & 0,54 & 99,39 & Carcaça & 2,19 & \\
& & & & Bexiga & 96,65 & \\
Média & 0,13 & 1,33 & 98,54 & Rins + & 97,64 & \\
\hline
\end{tabular}

Lote 3: Resultados de DTPA-TEC após a fabricação, mantido em 2 - $8{ }^{\circ} \mathrm{C}$.

\begin{tabular}{cccc|ccc}
\hline $\begin{array}{c}\text { Tempo } \\
\text { (minutos) }\end{array}$ & $\%{ }^{99 m} \mathrm{TcO}_{4}{ }^{-}$ & $\%{ }^{99 \mathrm{~m}} \mathrm{TcO}_{2}$ & $\% \mathrm{PRq}$ & Órgão & Média \% DI & Imagem \\
\hline 30 & 0,09 & 1,37 & 98,53 & Rins & 1,03 & \\
60 & 0,14 & 0,45 & 99,41 & Fígado & 0,17 & \\
240 & 0,17 & 0,82 & 99,00 & Carcaça & 2,10 & \\
& & & & Bexiga & 96,70 & $\%_{0}$ \\
Média & 0,13 & 0,89 & 98,98 & Rins + & 97,73 & \\
\hline
\end{tabular}

Os resultados de \% PRq e biodistribuição dos três lotes que foram expostos por 48 horas $40{ }^{\circ} \mathrm{C}$ e $75 \%$ UR indicaram que a temperatura e umidade não interferiram na qualidade do produto quando comparados com o produto mantido em temperatura de $2-8^{\circ} \mathrm{C}$

Tabela 29. Os resultados de pureza radioquímica e biodistribuição do MDP-TEC após exposição à temperatura de $40{ }^{\circ} \mathrm{C}$ e $75 \%$ UR, e resultados obtidos imediatamente após a produção de RL mantidos em temperatura de 2 - $8{ }^{\circ} \mathrm{C}$.

Lote 1: Os resultados de MDP-TEC após um mês de fabricação, seguido de exposição à $40^{\circ} \mathrm{C}$ e $75 \%$ UR por 48 horas.

\begin{tabular}{cccc|ccc}
\hline $\begin{array}{c}\text { Tempo } \\
\text { (minutos) }\end{array}$ & $\%{ }^{99 m} \mathrm{TcO}_{4}{ }^{-}$ & $\%{ }^{99 m} \mathrm{TcO}_{2}$ & $\% \mathrm{PRq}$ & Órgão & Média \% D.I & Imagem \\
\cline { 1 - 5 } 60 & 0,86 & 1,76 & 97,37 & Fêmur & 2,16 & \\
60 & 0,50 & 1,43 & 98,06 & Fígado & 0,29 & \\
240 & 0,27 & 1,57 & 98,14 & Rins & 0,27 & \\
& & & & Intestino & 1,91 & \\
Média & 0,54 & 1,58 & 97,85 & Carcaça & 68,28 & \\
\hline
\end{tabular}


Lote 1:Os resultados do MDP-TEC após a fabricação, mantido em 2 - $8{ }^{\circ} \mathrm{C}$

\begin{tabular}{cccc|ccc}
\hline $\begin{array}{c}\text { Tempo } \\
\text { (minutos) }\end{array}$ & $\%{ }^{99 m} \mathrm{TcO}_{4}{ }^{-}$ & $\%{ }^{99 m} \mathrm{TcO}_{2}$ & $\% \mathrm{PRq}$ & Órgão & Média \% D.I & Imagem \\
\hline 30 & 0,08 & 0,62 & 99,29 & Fêmur & 1,55 & \\
60 & 0,09 & 0,47 & 99,43 & Fígado & 1,30 & \\
240 & 0,08 & 0,43 & 99,49 & Rins & 1,36 & \\
& & & & Intestino & 0,84 & \\
Média & 0,08 & 0,50 & 99,40 & Carcaça & 70,52 & \\
\hline
\end{tabular}

Lote 2: Os resultados de MDP-TEC após seis meses de fabricação, seguido de exposição à $40^{\circ} \mathrm{C}$ e $75 \%$ U.R por 48 horas.

\begin{tabular}{cccc|ccc}
\hline $\begin{array}{c}\text { Tempo } \\
\text { (minutos) }\end{array}$ & $\%{ }^{99 m} \mathrm{TcO}_{4}{ }^{-}$ & $\%{ }^{99 m} \mathrm{TcO}_{2}$ & $\% \mathrm{PRq}$ & Órgão & Média \% D.I & Imagem \\
\hline 30 & 0,47 & 0,11 & 99,42 & Fêmur & 1,71 & \\
60 & 0,57 & 0,20 & 99,23 & Fígado & 1,38 & \\
240 & 0,69 & 0,19 & 99,12 & Rins & 1,08 & \\
& & & & Intestino & 0,51 & \\
Média & 0,57 & 0,16 & 99,25 & Carcaça & 73,36 & \\
\hline
\end{tabular}

Lote 2: Os resultados do MDP-TEC após a fabricação, mantido em 2 - $8{ }^{\circ} \mathrm{C}$.

\begin{tabular}{|c|c|c|c|c|c|c|}
\hline $\begin{array}{c}\text { Tempo } \\
\text { (minutos) }\end{array}$ & $\%{ }^{99 \mathrm{~m}} \mathrm{TcO}_{4}^{-}$ & $\%{ }^{99 m} \mathrm{TcO}_{2}$ & $\% \mathrm{PRq}$ & Órgão & Média \% D.I & Imagem \\
\hline 30 & 0,13 & 1,84 & 98,03 & Fêmur & 1,63 & \\
\hline 60 & 0,19 & 0,65 & 99,15 & Fígado & 0,81 & \\
\hline 240 & 0,10 & 0,57 & 99,32 & Rins & 1,36 & \\
\hline & & & & Intestino & 0,60 & \\
\hline Média & 0,14 & 1,02 & 98,83 & Carcaça & 73,31 & \\
\hline
\end{tabular}

O MDP-TEC foi analisado no início da fabricação e na validade do produto após ser exposto a $40^{\circ} \mathrm{C}$ e $75 \%$ UR por 48 horas e não apresentou os parâmetros de análise alterados, indicando que a qualidade do produto foi mantida. A \% PRq foi maior que $90 \%$ e a biodistribuição no fêmur foi maior que $1 \%$ e a captação hepática e renal foram menores que $5 \%$. 
Tabela 30. Resultados de pureza radioquímica e biodistribuição do MIBI-TEC da após exposição à temperatura de $40{ }^{\circ} \mathrm{C}$ e $75 \%$ UR, e resultados obtidos imediatamente após a produção de $\mathrm{RL}$ mantidos em temperatura de 2 - $8{ }^{\circ} \mathrm{C}$.

Lote 1: Resultados de MIBI-TEC após 1 mês de fabricação, seguido de exposição à $40{ }^{\circ} \mathrm{C}$ e $75 \%$ UR por 48 horas.

\begin{tabular}{|c|c|c|c|c|c|c|}
\hline $\begin{array}{c}\text { Tempo } \\
\text { (minutos) }\end{array}$ & $\%{ }^{99 m} \mathrm{TcO}_{4}^{-}$ & $\%{ }^{99 m} \mathrm{TcO}_{2}$ & $\%$ PRq & Órgão & Média \% D.I & Imagem \\
\hline 30 & 1,02 & 0,54 & 98,45 & $\begin{array}{c}\text { Coração/ } \\
\text { Pulmão }\end{array}$ & 7,38 & \\
\hline 60 & 0,44 & 0,25 & 99,32 & $\begin{array}{l}\text { Coração/ } \\
\text { Músculo }\end{array}$ & 5,24 & \\
\hline 240 & 0,34 & 0,26 & 99,40 & $\begin{array}{c}\text { Coração/ } \\
\text { Sanque }\end{array}$ & 106,32 & \\
\hline Média & 0,60 & 0,35 & 94,78 & & & \\
\hline
\end{tabular}

Lote 1: Resultados de MIBI-TEC após a fabricação, mantido em 2 - $8{ }^{\circ} \mathrm{C}$.

\begin{tabular}{|c|c|c|c|c|c|c|}
\hline $\begin{array}{c}\text { Tempo } \\
\text { (minutos) }\end{array}$ & $\%{ }^{99 \mathrm{~m}} \mathrm{TcO}_{4}^{-}$ & $\%{ }^{99 m} \mathrm{TcO}_{2}$ & $\% P R q$ & Órgão & Média \% D.I & Imagem \\
\hline 30 & 0,88 & 0,48 & 98,63 & $\begin{array}{c}\text { Coração/ } \\
\text { Pulmão }\end{array}$ & 7,13 & \\
\hline 60 & 0,67 & 0,22 & 99,10 & $\begin{array}{l}\text { Coração/ } \\
\text { Músculo }\end{array}$ & 4,49 & \\
\hline 240 & 0,66 & 0,27 & 99,05 & $\begin{array}{c}\text { Coração/ } \\
\text { Sangue }\end{array}$ & 193,53 & \\
\hline Média & 0,74 & 0,35 & 98,93 & & & \\
\hline
\end{tabular}

Lote 2: Resultados de MIBI-TEC após três meses de fabricação, seguido de exposição à $40^{\circ} \mathrm{C}$ e $75 \%$ UR por 48 horas.

\begin{tabular}{cccc|ccc}
\hline $\begin{array}{c}\text { Tempo } \\
\text { (minutos) }\end{array}$ & $\%{ }^{99 m \mathrm{TcO}_{4}{ }^{-}}$ & ${ }^{99 m} \mathrm{TcO}_{2}$ & $\% \mathrm{PRq}$ & Órgão & Média \% D.I & Imagem \\
\hline 30 & 0,50 & 0,16 & 99,34 & $\begin{array}{l}\text { Coração/ } \\
\text { Pulmão }\end{array}$ & 7,40 \\
60 & 0,75 & 0,18 & 99,07 & $\begin{array}{l}\text { Coração/ } \\
\text { Músculo }\end{array}$ & 5,44 & $\begin{array}{l}\text { Coração/ } \\
\text { Sangue }\end{array}$ \\
Média & 0,64 & 0,60 & 99,19 & 17,90 & \\
\hline
\end{tabular}


Lote 2: Resultados de RL após a fabricação, mantido em 2 - $8{ }^{\circ} \mathrm{C}$.

\begin{tabular}{cccc|ccc}
\hline $\begin{array}{c}\text { Tempo } \\
\text { (minutos) }\end{array}$ & $\%{ }^{99 \mathrm{~m} \mathrm{TcO}_{4}{ }^{-}}$ & $\%{ }^{99 \mathrm{~m}} \mathrm{TcO}_{2}$ & $\% \mathrm{PRq}$ & Órgão & Média \% D.I & Imagem \\
\hline 30 & 1,35 & 1,30 & 97,34 & $\begin{array}{l}\text { Coração/ } \\
\text { Pulmão }\end{array}$ & 7,63 & \\
60 & 0,22 & 0,29 & 99,49 & $\begin{array}{l}\text { Coração/ } \\
\text { Músculo }\end{array}$ & 7,30 & \\
240 & 0,47 & 0,23 & 99,30 & $\begin{array}{l}\text { Coração/ } \\
\text { Sangue }\end{array}$ & 130,90 & \\
Média & 0,68 & 0,60 & 98,71 & & \\
\hline
\end{tabular}

Lote 3: Resultados de MIBI-TEC após 4 meses de fabricação, seguido de exposição à $40^{\circ} \mathrm{C}$ e $75 \%$ UR por 48 horas.

\begin{tabular}{cccc|ccc}
\hline $\begin{array}{c}\text { Tempo } \\
\text { (minutos) }\end{array}$ & $\%{ }^{99 m} \mathrm{TcO}_{4}{ }^{-}$ & $\%{ }^{99 m} \mathrm{TcO}_{2}$ & $\% \mathrm{PRq}$ & Órgão & Média \% D.I & Imagem \\
\hline 30 & 0,49 & 0,18 & 99,32 & $\begin{array}{l}\text { Coração/ } \\
\text { Pulmão }\end{array}$ & 8,40 \\
60 & 0,60 & 0,32 & 99,08 & $\begin{array}{l}\text { Coração/ } \\
\text { Músculo }\end{array}$ & 6,68 & $\begin{array}{l}\text { Coração/ } \\
\text { Sangue }\end{array}$ \\
240 & 0,56 & 0,29 & 99,15 & 117,79 & \\
Média & 0,54 & 0,26 & 99,18 & & \\
\hline
\end{tabular}

Lote 3: Resultados de RL após a fabricação, mantido em 2 - $8{ }^{\circ} \mathrm{C}$.

\begin{tabular}{|c|c|c|c|c|c|c|}
\hline $\begin{array}{c}\text { Tempo } \\
\text { (minutos) }\end{array}$ & $\%{ }^{99 m} \mathrm{TcO}_{4}^{-}$ & $\%{ }^{99 m} \mathrm{TcO}_{2}$ & $\% \mathrm{PRq}$ & Órgão & Média \% D.I & Imagem \\
\hline 30 & 0,50 & 0,61 & 99,32 & $\begin{array}{l}\text { Coração/ } \\
\text { Pulmão }\end{array}$ & 7,66 & \\
\hline 60 & 0,50 & 0,44 & 99,08 & $\begin{array}{l}\text { Coração/ } \\
\text { Músculo }\end{array}$ & 5,71 & \\
\hline 240 & 0,50 & 1,08 & 99,15 & $\begin{array}{l}\text { Coração/ } \\
\text { Sanque }\end{array}$ & 173,48 & \\
\hline Média & 0,50 & 0,71 & 99,18 & & & \\
\hline
\end{tabular}

* refere-se relação de \%Dl/g de um órgão/ \%Dl/g de um outro órgão.

Apesar do MIBI-TEC também ser um dos $R L$ que apresenta massa de cloreto estanoso menores (Tab. 33), não foi observado influência negativa da temperatura e umidade na estabilidade da marcação até quatro horas e na 
estabilidade radioquímica e biológica, quando os frascos do $\mathrm{RL}$ foram expostos a $40{ }^{\circ} \mathrm{C}$ e $75 \%$ UR por 48 horas.

Tabela 31. Resultados de pureza radioquímica e biodistribuição do PIRO-TEC após exposição à temperatura de $40{ }^{\circ} \mathrm{C}$ e $75 \%$ UR, e resultados obtidos imediatamente após a produção de $\mathrm{RL}$ mantidos em temperatura de 2 - $8{ }^{\circ} \mathrm{C}$.

Lote 1: Resultados de PIRO-TEC obtidos após um mês de fabricação, após a exposição a $40{ }^{\circ} \mathrm{C}$ e $75 \%$ UR por 48 horas e imediatamente após a fabricação.

$$
\begin{aligned}
& \begin{array}{c}
\text { Acondicionado a } 40{ }^{\circ} \mathrm{C} \text { e } 75 \% \text { UR } \\
\text { por } 48 \text { horas. }
\end{array} \\
& \text { Acondicionado em } 2-8{ }^{\circ} \mathrm{C} .
\end{aligned}
$$

\begin{tabular}{cccc|ccc}
\hline $\begin{array}{c}\text { Tempo } \\
\text { (minutos) }\end{array}$ & $\%{ }^{99 m} \mathrm{TcO}_{4}{ }^{-}$ & $\%{ }^{99 m} \mathrm{TcO}_{2}$ & $\% \mathrm{PRq}$ & $\%{ }^{99 m} \mathrm{TcO}_{4}{ }^{-}$ & $\%{ }^{99 m} \mathrm{TcO}_{2}$ & $\% \mathrm{PRq}$ \\
\hline 30 & 0,46 & 1,41 & 98,11 & 0,11 & 0,63 & 99,25 \\
60 & 0,62 & 2,65 & 96,72 & 0,18 & 0,79 & 99,02 \\
240 & 2,29 & 6,02 & 91,67 & 0,40 & 1,81 & 97,78 \\
Média & 1,13 & 3,37 & 95,50 & 0,24 & 1,08 & 98,68 \\
\hline
\end{tabular}

Lote 2: Resultados de PIRO-TEC após seis meses de fabricação, seguido de exposição à $40{ }^{\circ} \mathrm{C}$ e $75 \%$ UR por 48 horas.

\begin{tabular}{cccc|ccc}
\hline $\begin{array}{c}\text { Tempo } \\
\text { (minutos) }\end{array}$ & ${ }^{99 m} \mathrm{TcO}_{4}{ }^{-}$ & $\%{ }^{99 m} \mathrm{TcO}_{2}$ & $\% \mathrm{PRq}$ & Órgão & Média \% D.I & Imagem \\
\hline 30 & 0,16 & 1,55 & 98,29 & Fêmur & 1,31 & \\
60 & 0,21 & 1,83 & 97,95 & Fígado & 0,55 & \\
240 & 1,72 & 1,77 & 95,52 & $\begin{array}{c}\text { Rins } \\
\text { Intestino }\end{array}$ & 2,73 \\
& & & & 1,38 & \\
Média & 0,69 & 1,71 & 97,25 & Carcaça & 64,90 & \\
\hline
\end{tabular}

Lote 2: Resultados de PIRO-TEC após a fabricação, mantido em 2 - $8{ }^{\circ} \mathrm{C}$.

\begin{tabular}{cccc|ccc}
\hline $\begin{array}{c}\text { Tempo } \\
\text { (minutos) }\end{array}$ & $\%{ }^{99 \mathrm{~m}} \mathrm{TcO}_{4}^{-}$ & $\%{ }^{99 \mathrm{~m}} \mathrm{TcO}_{2}$ & $\% \mathrm{PRq}$ & Órgão & Média \% D.I & Imagem \\
\hline 30 & 0,25 & 1,47 & 98,27 & Fêmur & 1,61 & \\
60 & 0,49 & 2,50 & 97,00 & Fígado & 0,56 & \\
240 & 2,39 & 1,84 & 95,76 & Rins & 1,92 & \\
& & & & Intestino & 1,41 & \\
Média & 1,05 & 1,88 & 97,01 & Carcaça & 71,52 & \\
\hline
\end{tabular}


O PIRO-TEC é um radiofármaco de composição parecida ao MDP-TEC e os resultados do $\mathrm{RL}$ após exposição a $40^{\circ} \mathrm{C}$ e $75 \%$ UR por 48 horas, no início da fabricação e na validade do produto não alteraram a qualidade do produto. A pureza radioquímica foi maior que $90 \%$.

Tabela 32. Resultados de pureza radioquímica e biodistribuição do PUL-TEC da após exposição à temperatura de $40{ }^{\circ} \mathrm{C}$ e $75 \%$ UR, e resultados obtidos imediatamente após a produção de $\mathrm{RL}$ mantidos em temperatura de $2-8^{\circ} \mathrm{C}$.

Lote 1: Resultados de PUL-TEC obtidos após um mês de fabricação, após a exposição a $40{ }^{\circ} \mathrm{C}$ e $75 \%$ UR por 48 horas e imediatamente após a fabricação.

\begin{tabular}{ccc|cc}
\hline & \multicolumn{2}{c|}{$\begin{array}{c}\text { Acondicionado a } 40{ }^{\circ} \mathrm{C} \text { e } 75 \% \\
\text { UR por } 48 \text { horas. }\end{array}$} & \multicolumn{2}{c}{ Acondicionado em $2-8{ }^{\circ} \mathrm{C}}$. \\
\hline $\begin{array}{c}\text { Tempo } \\
\text { (minutos) }\end{array}$ & $\%{ }^{99 \mathrm{~m}} \mathrm{TcO}_{4}{ }^{-}$ & $\% \mathrm{PRq}$ & $\%{ }^{99 \mathrm{~m}} \mathrm{TcO}_{4}{ }^{-}$ & $\% \mathrm{PRq}$ \\
\hline 30 & 5,15 & 94,85 & 0,37 & 99,63 \\
60 & 3,41 & 96,59 & 0,13 & 99,65 \\
240 & 1,91 & 98,09 & 0,15 & 99,63 \\
Média & 3,49 & 96,51 & 0,36 & 99,64 \\
\hline
\end{tabular}

Lote 2: Resultados de PUL-TEC obtidos após um mês de fabricação, após a exposição a $40{ }^{\circ} \mathrm{C}$ e $75 \%$ UR por 48 horas e imediatamente após a fabricação.

\begin{tabular}{ccc|cc}
\hline $\begin{array}{c}\text { Tempo } \\
\text { (minutos) }\end{array}$ & $\%{ }^{99 \mathrm{~m}} \mathrm{TcO}_{4}{ }^{-}$ & $\% \mathrm{PRq}$ & $\%{ }^{99 \mathrm{~m}} \mathrm{TcO}_{4}{ }^{-}$ & $\% \mathrm{PRq}$ \\
\hline 30 & 2,55 & 97,45 & 0,22 & 99,78 \\
60 & 2,11 & 97,89 & 0,26 & 99,74 \\
240 & 1,03 & 98,97 & 0,23 & 99,77 \\
Média & 1,90 & 98,10 & 0,24 & 99,74 \\
\hline
\end{tabular}

Lote 3: Resultados de PUL-TEC após dois meses de fabricação, seguido de exposição à $40^{\circ} \mathrm{C}$ e $75 \%$ UR por 48 horas.

\begin{tabular}{ccc|ccc}
\hline $\begin{array}{c}\text { Tempo } \\
\text { (minutos) }\end{array}$ & $\%{ }^{99 \mathrm{~m}} \mathrm{TcO}_{4}{ }^{-}$ & $\% \mathrm{PRq}$ & Órgão & Média \% D.I & Imagem \\
\hline 30 & 4,77 & 95,23 & Fígado & 88,49 & \\
60 & 0,96 & 99,03 & Baço & 4,62 & \\
240 & 1,85 & 98,14 & Pulmão & 1,03 & \\
Média & 2,53 & 97,47 & Carcaça & 4,93 & \\
\hline
\end{tabular}


Lote 4: Resultados do PUL-TEC após sei meses de fabricação, seguido de exposição à $40^{\circ} \mathrm{C}$ e $75 \%$ UR por 48 horas.

\begin{tabular}{ccc|ccc}
\hline $\begin{array}{c}\text { Tempo } \\
\text { (minutos) }\end{array}$ & $\%{ }^{99 \mathrm{~m} \mathrm{TcO}_{4}{ }^{-}}$ & $\% \mathrm{PRq}$ & Órgão & Média \% D.I & Imagem \\
\hline 30 & 11,10 & 88,90 & Fígado & 0,50 & \\
60 & 6,51 & 99,03 & Pulmão & 97,27 & \\
240 & 1,77 & 98,14 & Carcaça & 2,74 & \\
Média & 6,46 & 95,35 & & & \\
\hline
\end{tabular}

Lote 4: Resultados de PUL -TEC após a fabricação, mantido em 2 - $8^{\circ} \mathrm{C}$.

\begin{tabular}{ccc|ccc}
\hline $\begin{array}{c}\text { Tempo } \\
\text { (minutos) }\end{array}$ & $\%{ }^{99 \mathrm{~m}} \mathrm{TcO}_{4}{ }^{-}$ & $\% \mathrm{PRq}$ & Órgão & Média \% DI & Imagem \\
\hline 30 & 0,17 & 99,83 & Fígado & 0,08 & \\
60 & 0,84 & 99,15 & Pulmão & 94,32 & \\
240 & 0,30 & 99,70 & Carcaça & 3,92 & \\
Média & 0,44 & 99,04 & & & \\
\hline
\end{tabular}

Foram avaliados quatro lotes do RL PUL-TEC, e três apresentaram resultados que atenderam ao especificado para pureza radioquímica e biodistribuição, mesmo após serem submetidos a um aumento de temperatura por dois dias. Entretanto, ao se analisar um dos lotes na validade do produto, ou seja, após 6 meses de sua fabricação, apresentou resultado de \% PRq produto marcado abaixo de $90 \%$, mas que aumentou com o tempo de marcação. Desta forma, este fato precisa ser confirmado analisando-se outros lotes após 6 meses de fabricação para avaliar se a temperatura e a umidade estão comprometendo a qualidade do produto.

Tabela 33. Resultados de pureza radioquímica e biodistribuição do TIN-TEC após exposição à temperatura de $40^{\circ} \mathrm{C}$ e $75 \%$ UR, e resultados obtidos imediatamente após a produção de RL mantidos em temperatura de 2 - $8{ }^{\circ} \mathrm{C}$.

Lote 1: Resultados do TIN-TEC após 3 meses de fabricação, seguido de exposição à $40^{\circ} \mathrm{C}$ e $75 \%$ UR por 48 horas.

\begin{tabular}{ccc|cc}
\hline & \multicolumn{2}{c|}{$\begin{array}{c}\text { Acondicionado a } 40{ }^{\circ} \mathrm{C} \text { e } 75 \% \\
\text { UR por } 48 \text { horas. }\end{array}$} & \multicolumn{2}{c}{ Acondicionado em $2-8{ }^{\circ} \mathrm{C}}$. \\
\hline $\begin{array}{c}\text { Tempo } \\
\text { (minutos) }\end{array}$ & $\%{ }^{99 \mathrm{~m}} \mathrm{TcO}_{4}^{-}$ & $\% \mathrm{PRq}$ & $\%{ }^{99 \mathrm{~m}} \mathrm{TcO}_{4}{ }^{-}$ & $\% \mathrm{PRq}$ \\
\hline 30 & 4,11 & 95,89 & 5,75 & 94,25 \\
\hline
\end{tabular}


Lote 1: Resultados do TIN-TEC após 3 meses de fabricação, seguido de exposição à $40^{\circ} \mathrm{C}$ e $75 \%$ UR por 48 horas - continuação.

\begin{tabular}{ccc|cc}
\hline $\begin{array}{c}\text { Tempo } \\
\text { (minutos) }\end{array}$ & $\%{ }^{99 \mathrm{~m}} \mathrm{TcO}_{4}{ }^{-}$ & $\% \mathrm{PRq}$ & $\%{ }^{99 \mathrm{~m}} \mathrm{TcO}_{4}{ }^{-}$ & $\% \mathrm{PRq}$ \\
\hline 60 & 4,48 & 95,52 & 5,74 & 94,26 \\
240 & 3,75 & 96,25 & 6,48 & 93,52 \\
Média & 4,11 & 95,89 & 5,99 & 94,91 \\
\hline
\end{tabular}

Lote 2: Resultados de TIN-TEC após 2 meses de fabricação, seguido de exposição à $40^{\circ} \mathrm{C}$ e $75 \%$ UR por 48 horas.

\begin{tabular}{ccc|ccc}
\hline $\begin{array}{c}\text { Tempo } \\
\text { (minutos) }\end{array}$ & $\%{ }^{99 \mathrm{~m}} \mathrm{TcO}_{4}{ }^{-}$ & $\% \mathrm{PRq}$ & Órgão & Média \% D.I & Imagem \\
\hline 30 & 3,57 & 96,42 & Fígado & 88,49 & \\
60 & 3,17 & 96,83 & Baço & 4,62 & \\
240 & 6,16 & 93,84 & Pulmão & 1,03 & \\
Média & 4,30 & 95,70 & Carcaça & 4,93 & \\
\hline
\end{tabular}

Lote 1: Resultados de TIN-TEC após a fabricação, mantido em 2 - $8{ }^{\circ} \mathrm{C}$

\begin{tabular}{ccc|ccc}
\hline $\begin{array}{c}\text { Tempo } \\
\text { (minutos) }\end{array}$ & $\%{ }^{99 \mathrm{~m}} \mathrm{TcO}_{4}{ }^{-}$ & $\% \mathrm{PRq}$ & Órgão & Média \% D.I & Imagem \\
\hline 30 & 3,57 & 96,42 & Fígado & 82,07 & \\
60 & 3,17 & 96,83 & Baço & 4,49 & \\
240 & 6,16 & 93,84 & Pulmão & 1,57 & \\
Média & 4,30 & 95,70 & Carcaça & 4,72 & \\
\hline
\end{tabular}

Lote 3: Resultados de TIN-TEC após seis meses de fabricação, seguido de exposição à $40^{\circ} \mathrm{C}$ e $75 \%$ UR por 48 horas.

\begin{tabular}{ccc|ccc}
\hline $\begin{array}{c}\text { Tempo } \\
\text { (minutos) }\end{array}$ & $\%{ }^{99 \mathrm{~m}} \mathrm{TcO}_{4}^{-}$ & $\% \mathrm{PRq}$ & Órgão & Média \% D.I & Imagem \\
\hline 30 & 1,48 & 98,52 & Fígado & 85,63 & \\
60 & 8,04 & 91,46 & Baço & 2,32 & \\
240 & 15,92 & 84,06 & Pulmão & 1,12 & \\
Média & 8,48 & 94,68 & Carcaça & 5,31 & \\
\hline
\end{tabular}


Lote 3: Resultados de TIN-TEC após a fabricação, mantido em 2 - $8{ }^{\circ} \mathrm{C}$

\begin{tabular}{ccc|ccc}
\hline $\begin{array}{c}\text { Tempo } \\
\text { (minutos) }\end{array}$ & $\%{ }^{99 m} \mathrm{TcO}_{4}{ }^{-}$ & $\% \mathrm{PRq}$ & Órgão & Média \% D.I & Imagem \\
\hline 30 & 1,25 & 98,74 & Fígado & 81,16 & \\
60 & 1,71 & 98,28 & Baço & 2,45 & Pulmão \\
240 & 7,21 & 92,78 & 1,03 & \\
Média & 1,49 & 98,40 & Carcaça & 14,65 & \\
\hline
\end{tabular}

A \% PRq e biodistribuição de dois dos três lotes que foram expostos por 48 horas $40{ }^{\circ} \mathrm{C}$ e $75 \%$ UR não foram afetadas pela temperatura e umidade, porém em um dos lotes, cuja reanálise ocorreu na validade do $R L$ apresentou resultado de \% PRq abaixo do limite especificado que é de 90\%, em 240 minutos de marcação. A captação hepática está acima de $80 \%$, mas ocorreu aumento da dose injetada na carcaça, indicando que pode ter ocorrido perda de estanho disponível para a manutenção da marcação com ${ }^{99 m}$ Tc ao longo do tempo. A captação pulmonar não foi aumentada. 


\section{CONCLUSÃO}

Apesar de alguns autores acreditarem que a melhor estratégia para realizar o estudo de estabilidade de transporte de fármacos é realizar o estudo em condições mais próximas do real, existem na literatura algumas propostas para se realizar o estudo de estabilidade de transporte. Neste trabalho, optou-se por utilizar uma condição descrita na literatura como uma das mais extremas, ou seja, $40{ }^{\circ} \mathrm{C}$ e $75 \%$ UR, durante o período de tempo médio de transporte do radiofármaco até o cliente final, ou seja, 48 horas, para simular uma condição de transporte e avaliar o efeito desta condição na estabilidade de alguns RL. Foram avaliadas duas situações: após um determinado tempo de armazenamento em temperatura de $2-8{ }^{\circ} \mathrm{C}$, amostras de $\mathrm{RL}$ foram expostas por 48 horas em $40{ }^{\circ} \mathrm{C}$ e $75 \%$ UR e em seguida foram analisadas enquanto outras amostras foram colocadas por 48 horas em $40{ }^{\circ} \mathrm{C}$ e $75 \%$ UR, mantidas em temperatura de 2 - 8 ${ }^{\circ} \mathrm{C}$ até a validade do radiofármaco e analisadas quanto à pureza radioquímica $\mathrm{e}$ biodistribuição.

Foi observado que os $\mathrm{RL}$ submetidos ao aumento de temperatura e umidade propostos por este trabalho, ou seja, $40{ }^{\circ} \mathrm{C}$ a $75 \%$ UR durante 48 horas, não afetaram a qualidade dos radiofármacos produzidos pelo IPEN para DEX-70TEC, DEX-500-TEC, DISI-TEC, DMSA-TEC, DTPA-TEC, PIRO-TEC, MDP-TEC, MIBI-TEC e MDP-TEC, com resultados de \% PRq e biodistribuição que atenderam às especificações, enquanto que CIS-TEC, PUL-TEC e TIN-TEC apresentaram alguns valores de \% PRq menor que o especificado. TIN-TEC apresentou \% PRq de 84\% em um de três lotes, enquanto PUL-TEC apresentou $\%$ PRq de $88 \%$ em um de quatro lotes analisados; CIS-TEC é um RL que ainda precisa melhor analisado, pois os resultados fora do especificado no controle radioquímico e biológico, foram obtidos com um produto fora da validade especificada. Estes resultados indicaram que a pureza radioquímica pode ser afetada pela condição de estudo, o que não foi confirmado pelo controle biológico. 
Os experimentos com algumas embalagens de radiofármacos indicaram que a blindagem utilizada para produtos para uso em PET pode ser utilizada em estudos de estabilidade em câmara climática, pois a temperatura no interior da mesma será igual à externa após cerca de duas horas. O uso da blindagem reduz a exposição da radiação ao analista. Uma embalagem utilizada no transporte de alguns $R L$ composta por uma caixa de isopor e gelo reciclável reduziu o efeito da temperatura externa, porém não foi suficiente para manter a temperatura interna entre $2-8{ }^{\circ} \mathrm{C}$; quando a temperatura externa foi de $40{ }^{\circ} \mathrm{C}$, após cerca de 24 horas a temperatura interna atingiu o valor externo.

\subsection{PERPECTIVAS FUTURAS}

A \% PRq e biodistribuição do CIS-TEC apresentou-se fora do especificado possivelmente por ter sido avaliado fora do período de validade e deverá ser retestado. O lote de PUL-TEC analisado após 6 meses de sua fabricação, apresentou resultado de \% PRq abaixo de $90 \%$, mas que aumentou com o tempo de marcação. O TIN-TEC também apresentou resultados fora do limite especificado e portanto, deverá ser melhor investigado.

O TIN-TEC e PUL-TEC ainda necessitam de outros experimentos para verificar se a temperatura e a umidade afetam a qualidade do produto, pois nem todos os lotes avaliados apresentaram resultados fora do especificado. 


\section{REFERÊNCIAS BIBLIOGRÁFICAS}

Agência Internacional de Energia Atômica. Manual de protocolos de calidad de radiofarmacos.Viena, 1999. Disponível em: <http://www.arcal-lac.org/index.php/en/> Acesso em: 10 fev. 2013.

ALBERTINI, A.; LEE E.; COULIBALY S. O.; SLESHI M.; FAYE .; MATIONG M. L.; OUEDRAOGO K.; TSADIK A. G.; FELEKE S. M.; DIALLO I.; GAYE OUMAR.; LUCHAVEZ J.; BENNETT J.; BELL D.. Malaria rapid diagnostic test transport and storage conditions in Burkina Faso, Senegal, Ethiopia and the Philippines. Malaria Journal, v.11, n. 1, p. 1-9, 2012. Disponível em:

<http://download.springer.com/static/pdf/813/art\%253A10.1186\%252F1475-2875-11406.pdf?originUrl=http\%3A\%2F\%2Fmalariajournal.biomedcentral.com\%2Farticle\%2 F10.1186\%2F1475-2875-11-

406\&token2=exp=1490880646 acl=\%2Fstatic\%2Fpdf\%2F813\%2Fart\%25253A10.11 $86 \% 25252 \mathrm{~F} 1475-2875-11-$

406. $\mathrm{pdf}^{*} \sim \mathrm{hmac}=5 \mathrm{f} 7 \mathrm{ce} 16241 \mathrm{~d} 07190 \mathrm{eb} 8 \mathrm{~b} 13 \mathrm{cbb} 8 \mathrm{da} 486 \mathrm{c} 666505 \mathrm{~b} 0246 \mathrm{~d} 768 \mathrm{fd} 4 \mathrm{fb} 4 \mathrm{~d} 10$ 3e576074> Acesso em : 14 jan. 2015.

ALLEN, L. V. JR.; POPOVICH, N. G.; ANSEL, H. C. Formas farmacêuticas e sistemas de liberação de fármacos. 9. ed. Porto Alegre: Artmed, 2013. 716 p.

\section{ALMEIDA, É. V. DESENVOLVIMENTO E VALIDAÇÃO DE METODOLOGIA PARA RADIOFÁRMACOS DE TECNÉCIO- 99M EMPREGANDO CROMATOGRAFIA LÍQUIDA DE ALTA EFICIÊNCIA (CLAE). 2009.150 p. Dissertação (Mestrado em Tecnologia Nuclear) - Instituto de Pesquisas Energéticas e Nucleares, IPEN- CNEN/SP, São Paulo. Disponível em: $<$ http://www.teses.usp.br/teses/disponiveis/85/85131/tde-24092009-142057/pt- br.php> Acesso em 10 jan. 2014.}

ALMEIDA, É. V. MONTEIRO E. G.; ALVES E. V.; SILVA N G.; FUKUMORI N. T. O.; BARBOZA M. F.; MENGATTI J.; MATSUDA M. M. N.; VASCONCELLOS M. B. A. Controle de Qualidade de EC-99mTc: determinação de pureza radioquímica e investigação da influência de impurezas na biodistribuição. Rev. Bras. Fis. Med., Porto Alegre, v. 1, n. 4, p.71-74, out. 2010. Anual. Disponível em: <http://www.rbfm.org.br/index.php/rbfm/article/view/61/v4n1p71> Acesso em: 12 jul. 2013.

AMMANN, C. Stability Studies Needed to Define the Handling and Transport Conditions. AAPS, v. 12, n. 4, p.1264-1275, 2011. Disponível em: <https://www.ncbi.nlm.nih.gov/pmc/articles/PMC3225534/> Acesso em: 10 jan. 2015

ATKINS, P.; JONES, L. Princípios de química: questionando a vida moderna e o meio ambiente. 5. ed. Porto Alegre: Bookman, 2011. 1048p. 
BAJAJ, S.; SINGLA, D.; NEHA, S. (24 de 03 de 2012). Stability Testing of Pharmaceutical Products. JAPS, v.2, n. 3, p. 129-138, 2012. Disponível em: <http://japsonline.com/admin/php/uploads/409_pdf.pdf> Acesso em: 23 nov. 2015.

BRASIL. Resolução-RE no 560 de 2 de abril de 2002. Guia para realização de estudo de estabilidade. Diário Oficial [da] República Federativa do Brasil, Brasília, DF, 3 ABR. 2003. Disponível em:

<http://www.anvisa.gov.br/hotsite/genericos/legis/resolucoes/2002/560_02re.htm> Acesso em: 20 de jul. 2014.

BRASIL. RESOLUÇÃO-RE № 1, De 29 de julho de 2005. Guia para a realização de estudos de estabilidade. Diário Oficial [da] República Federativa do Brasil, Brasília, DF. 9 nov. 2004. Disponível em:

<http://www.anvisa.gov.br/medicamentos/legis/01_05_re_comentada.pdfl>. Acesso em 04 set. 2015.

BRASIL. Consulta Pública nำ43, de 7 de julho de 2004. Guia para a realização de estudos de estabilidade. Diário Oficial [da] República Federativa do Brasil, Brasília, DF, 9 set. 2004. Disponível em:

<http://www4.anvisa.gov.br/base/visadoc/CP/CP\%5B7760-1-0\%5D.PDF> Acesso em: 10 mai. 2013.

BRASIL. RESOLUÇÃO-RDC Nº 63 de 18 de dezembro de 2009. Dispõe sobre as Boas Práticas de Fabricação de Radiofármacos. Diário Oficial [da] República Federativa do Brasil, Brasília, DF, 23 dez. 2009 Disponível em:

$<$ http://portal.anvisa.gov.br/resultado-de-

busca?p_p_id=101\&p_p_lifecycle $=0 \& p \_p \_s t a t e=$ maximized $\& p \_p \_$mode $=v i e w \& p \_p \_$ col_id=column-

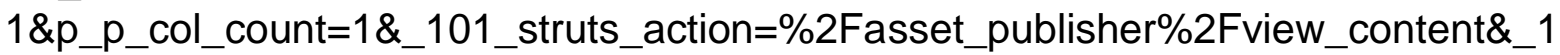
01_assetEntryld=224250\&_101_type=document> Acesso em 28 set. 2013.

BRASIL. RESOLUÇÃO-RDC no 64 de 18 de dezembro de 2009. Dispõe sobre o Registro de Radiofármacos. Diário Oficial [da] República Federativa do Brasil, Brasília, DF, 16 dez. 2009. Disponível em:

<http://portal.anvisa.gov.br/wps/wcm/connect/ccf4de0046b43087bed1fe2e64280806/ Resol-RDC-64-09.pdf?MOD=AJPERES> Acesso em: 15 fev. de 2013.

BRASIL. RESOLUÇÃO- RDC n 50 de 20 de setembro de 2011. Dispõe sobre os procedimentos e condições de realização de estudos de estabilidade para o registro ou alterações pós-registro de produtos biológicos e dá outras providências. Diário Oficial [da] República Federativa do Brasil, Brasília, DF, 21 ago. 2006. Disponível em:

<http://portal.anvisa.gov.br/wps/wcm/connect/90663d804ff7e8d89805fe6d6e8afaaa/ $\mathrm{RDC}+\mathrm{N} \% \mathrm{C} 2 \% \mathrm{BA}+50,+\mathrm{DE}+20+\mathrm{DE}+\mathrm{SETEMBRO}+\mathrm{DE}+2011 . \mathrm{pdf}$ ?MOD=AJPERES > Acesso em: 10 jun. de 2015. 
BREIER, A. R. Fexofenadina: Validação de métodos analíticos e estudo de fotoestabilidade. 2007. 281 p.Tese (Doutorado em Ciências farmacêuticas) Universidade Federal do Rio Grande do Sul, UFRGS, Porto Alegre. Disponível em: <http://www.lume.ufrgs.br/handle/10183/10354?locale=pt_BR> Acesso em: 15 jun. de 2015.

BREITHAUPT, J. Física. 3 ed. Rio de Janeiro: LTC, 2012. 452p.

Congresso de Logística das Faculdades de Tecnologia do Centro Paula Souza. Qualidade no Transporte Rodoviário de Medicamentos. São Paulo, 20011. Disponível em: <http://www.fatecguaratingueta.edu.br/fateclog/artigos/Artigo_117.pdf $\mathrm{f}>$ Acesso em :10 nov. 2015.

CONSELHO REGIONAL DE FARMÁCIA: Transporte e Distribuição. São Paulo. ago. 2016. Disponível em: <http://portal.crfsp.org.br/publicacoes-2/cartilhas-porarea.html?download=4:cartilha-da-comissao-de-distribuicao-e-transporte $>$ Acesso em : 19 set. 2015.

EL MERCADO COMÕN DEL SUR. RES N 53/96: Estabilidad de productos farmacéuticos. 3 ed. Montevideo: Mercosur, 1996. 6 p. Disponível em: <http://www.mercosur.int/msweb/portalintermediario/Normas/normas_web/Resolucio nes/ES/Res_053_096_.PDF> Acesso em: 12 jan. 2013.

\section{ENCINA, G. D. AVALIACÃO DA QUALIDADE NO TRANSPORTE DE} MEDICAMENTOS NO BRASIL. 2012. 28 p. Monografia (Especialista em Tecnologias Industriais Farmacêuticas) - Instituto de Tecnologia em Fármacos, FARMANGUINHOS, Rio de Janeiro. Disponível em: <http://www.arca.fiocruz.br/bitstream/icict/11128/1/18.pdf> Acesso em: 12 nov. 2015.

HOGERZEIL. H. V.; A. BATTERSBY.; V. SRDANOVI.; N. E. STJERNSTROM. Stability of essential drugs during shipment to the tropics. BMJ Journals. v. 304, n. 6821, p. 210-212. Disponível em:

<http://www.bmj.com/content/304/6821/210/related> Acesso em: 10 nov. 2015.

HUYNH-BA, K. Handbook stability testing in pharmaceutical development. 1 ed. New York: Springer, 2009. 389 p.

INMET. INSTITUTO NACIONAL DE METEREOLOGIA, 2014. Apresenta Informações sobre o tempo. Disponível em:

$<$ http://www.inmet.gov.br/html/informacoes/curiosidade/sobre_tempo.html> Acesso em 10 mai. 2015.

INTERNATIONAL CONFERENCE ON HARMONISATION OF TECHNICAL REQUIREMENTS FOR REGISTRATION OF PHARMACEUTICALS FOR HUMAN USE. Q7: GOOD MANUFACTURING PRACTICE GUIDE FOR ACTIVE PHARMACEUTICAL INGREDIENTS. 4 ed. Geneva: ICH, 2000. 49 p. Disponível 
em:

<http://www.ich.org/fileadmin/Public_Web_Site/ICH_Products/Guidelines/Quality/Q7/ Step4/Q7_Guideline.pdf>. Acesso em: 09 dez. 2013.

IPEN. Instituto de Pesquisas Energéticas e Nucleares, 2015. Apresenta texto sobre o Centro de Radiofarmácia. Disponível em:

$<$ https://www.ipen.br/portal_por/portal/interna.php?secao_id=632> Acesso em 20 nov. 2015

\section{LEITE, E. G. ESTABILIDADE : IMPORTANTE PARÂMETRO PARA AVALIAR A QUALIDADE, SEGURANÇA E EFICÁCIA DE FÁRMACOS E MEDICAMENTOS. 2005. 199 p. Dissertação (Mestrado em Ciências Farmacêuticas) - Universidade Federal do Rio Grande do Sul, UFRGS, Porto Alegre. Disponível em: \\ $<$ http://www.lume.ufrgs.br/bitstream/handle/10183/7869/000559401.pdf?sequence $=1$ > Acesso em: 21 mar. 2013.}

\section{LIEBERMAN, H. A.; KANIG, J. L;. LACHMAN, L. TEORIA E PRATICA NA}

INDUSTRIA FARMACEUTICA. Lisboa: fundacao calouste gulbenkian, 2001. $1517 \mathrm{P}$.

MACEDO, S. H. M.; GARCÍA, T. L. Infarma - Ciências Farmacêuticas, Brasília, v. 3, n. 19, p.7-10, 2007. Anual. Disponível em:

<http://www.cff.org.br/sistemas/geral/revista/pdf/9/infarma_v19_1-2.pdf>. Acesso em: 20 out. 2015.

MARQUES, F. N.; OKAMOTO, M. Y.; BUCHPIGUEL, C. Alguns aspectos sobre geradores e radiofármacos de tecnécio-99m e seus controles de qualidade. Radiol. Bras., v. 34, n. 4, p. 233-237, 2001. Disponível em:

<http://www.scielo.br/scielo.php?pid=S010039842001000400011\&script=sci_arttext> Acesso em: 19 mai. 2013.

MARTINS, P. SILVA, J. L. DA.; RAMOS, M. P. S.; OLIVEIRA, I. M.; FELGUEIRAS, C. F.; HERRERIAS R.; JÚNIOR, C. L. Z.; MENGATTI, J.; FUKUMORI, N. T. O.; MATSUDA, M. M. N. RADIOCHEMICAL STABILITY OF

RADIOPHARMACEUTICAL PREPARATIONS. In: INTERNATIONAL NUCLEAR ATLANTIC CONFERENCE, 2 ed., Out. 24-28, 2011, Belo Horizonte. Minas Gerais. Associação Brasileira de Energia Nuclear, 2011. p. 1-6. Disponível em: <http://www.iaea.org/inis/collection/NCLCollectionStore/_Public/43/046/43046455.pdf >Acesso em: 19 ago. 2015.

MONTEIRO, E. G. Estudo comparativo entre metodologias de cromatografia planar para controle radioquímico de radiofármacos de tecnécio-99m. 2012. 99 p. Dissertação (Mestrado em Tecnologia Nuclear) - Instituto de Pesquisas Energéticas e Nucleares, IPEN-CNEN/SP, São Paulo. Disponível em: <http://www.teses.usp.br/teses/disponiveis/85/85131/tde-06032013-134516/ptbr.php> Acesso em: 12 set. 2015. 
NIAZI, S. K. Handbook of Pharmaceutical Manufacturing Formulations. 1 ed. New York: CRC PRESS, 2004. 296 p.

OKUNO, E. Efeitos biológicos das radiações ionizantes. Acidente radiológico de Goiânia. Instituto de Estudos Avançados da Universidade de São Paulo, v.27, n. 77, p. 185- 99, 2013. Disponível em: <http://www.scielo.br/scielo.php?script=sci_arttext\&pid=S0103$40142013000100014>$ Acesso em: 12 jun. 2015.

OLIVEIRA, M. A.; YOSHIDA, M. I.; GOMES, E. C. (2011). Análise térmica aplicada a fármacos e formulações farmacêuticas na indústria farmacêutica. Quím. Nova., v. 34, n. 7, p. 1224-1230, 2011. Disponível em:

<http://www.scielo.br/scielo.php?script=sci_arttext\&pid=S0100$40422011000700022>$ Acesso em: 11 mai. 2013.

OLIVEIRA, R. S.; CARNEIRO, A. L. História da radiofarmácia e as implicações da Emenda Constitucional N. 49. Rev. Bras. Cienc. Farm., v. 44, n. 3, p. 377-382, 2008. Disponível em: <http://www.scielo.br/scielo.php?pid=S151693322008000300006\&script=sci_arttext> Acesso em: 13 jun. 2015.

OLIVEIRA, R.; SANTOS, D.; FERREIRA, D;, COELHO, P.; VEIGA, F. Preparações radiofarmacêuticas e suas aplicações. Rev. Bras. Cienc. Farm.,v.42, n. 2,p. 151165, 2006. Disponível em: <http://www.scielo.br/pdf/rbcf/v42n2/a02v42n2.pdf> Acesso em: 20 fev. de 2013.

SAHA, G. B. Fundamentals of Nuclear Pharmacy. 5 ed. New York: Springer. 2003. $410 \mathrm{p}$.

SILVA, K. R.; SOARES, M. F.; PASSOS, R. S.; FARIA, A. R.; ROLIM NETO, P. I. Modelos de Avaliação da Estabilidade de Fármacos. Rev. Ciênc. Farm. Básica. Apl., v.2, n.30, p. 129-135, 2009. Disponível em: <http://servbib.fcfar.unesp.br/seer/index.php/Cien_Farm/article/viewFile/868/798> Acesso em: 17 abr. 2013

SINDICATO DAS INDÚSTRIAS FARMACÊUTICAS. Apostila curso de cadeia a frio, 2015 São Paulo.

TERESA, L. I.; BISHARA, R. H.; SEEVERS, R. H.. A stability program for the distribution of drug products. AAPS., v. 12, n. 4, p. 68-73, 2004. Disponível em: $<$ http://sensitech.com/assets/articles/lsstabilitydrugdistribution.pdf> Acesso em: 20 ago. 2015.

Universidade Federal do Ceará. Aula 04: Estrutura Eletrônica dos Átomos: Tópico 01: Comportamento dos Átomos, 2000. Fortaleza.

WORLD HEALTH ORGANIZATION. N 86.529: Accelerated stability studies of widely used pharmaceutical substances under simulated tropical conditions. 3 
ed. Geneva: Who, 1986. 118 p. Disponível em:

<http://apps.who.int/iris/bitstream/10665/61480/1/WHO_PHARM_86.529.pdf> Acesso em: 18 out. 2015.

WORLD HEALTH ORGANIZATION. (Org.). Quality assurance of pharmaceuticals: A compendium of guidelines and related materials. 2. ed. Geneva: WHO, 2007. 418 p. Disponível em:

<http://www.who.int/medicines/areas/quality_safety/quality_assurance/QualityAssura ncePharmVol2.pdf> Acesso em: 02 dez. 2013. 